Pontifícia Universidade Católica $_{\text {man }}$

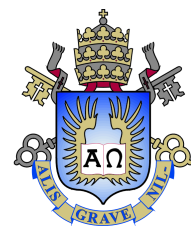

Elisa de Freitas Carneiro

Distinguibilidade Espectral e Visibilidade:

Complementaridade no Interferômetro de

Hong-Ou-Mandel

Dissertação apresentada como requisito parcial para obtenção do grau de Mestre pelo Programa de Pós-graduação em Engenharia Elétrica da PUC-Rio.

Orientador: Prof. Gustavo Castro do Amaral 


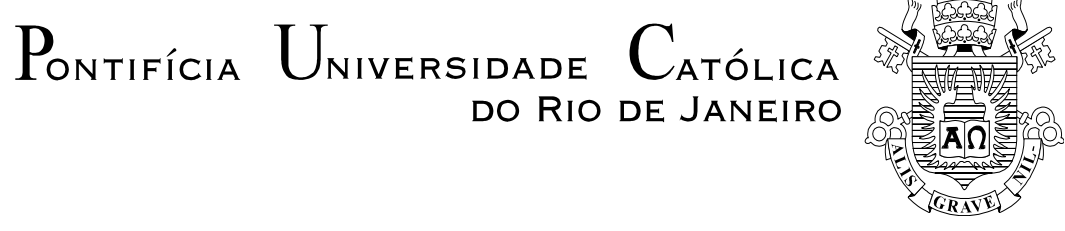

Elisa de Freitas Carneiro

\section{Distinguibilidade Espectral e Visibilidade: Complementaridade no Interferômetro de Hong-Ou-Mandel}

Dissertação apresentada como requisito parcial para obtenção do grau de Mestre pelo Programa de Pós-Graduação em Engenharia Elétrica da PUC-Rio. Aprovada pela Comissão Examinadora abaixo assinada.

Prof. Gustavo Castro do Amaral Orientador Centro de Estudos em Telecomunicações - PUC-Rio

Prof. Guilherme Penello Temporao Centro de Estudos em Telecomunicações - PUC-Rio

Prof. Jean Pierre von der Weid Centro de Estudos em Telecomunicações - PUC-Rio

Prof. Thiago Barbosa dos Santos Guerreiro Departamento de Física - PUC-Rio

Prof. Daniel Schneider Tasca

UFF

Prof. Márcio da Silveira Carvalho Coordenador Setorial do Centro Técnico Científico - PUC-Rio

Rio de Janeiro, 30 de junho de 2017 
Todos os direitos reservados. É proibida a reprodução total ou parcial do trabalho sem autorização da universidade, do autor e do orientador.

\section{Elisa de Freitas Carneiro}

Graduou-se em Engenharia de Telecomunicações pela Universidade Católica de Petrópolis (UCP), RJ, em 2015. Neste mesmo ano, matriculou-se no programa de pós-graduação em Engenharia Elétrica da Pontifícia Universidade Católica do Rio de Janeiro (PUC-Rio). Atualmente é membro ativo do Laboratório de Óptica Quântica e do Grupo de Optoeletrônica e Instrumentação do Centro de Estudos de Telecomunicações da PUC-Rio.

Ficha Catalográfica

Carneiro, Elisa de Freitas

Distinguibilidade Espectral e Visibilidade: Complementaridade no Interferômetro de Hong-Ou-Mandel / Elisa de Freitas Carneiro; orientador: Gustavo Castro do Amaral. - Rio de janeiro: PUC-Rio, Departamento de Engenharia Elétrica, 2017.

v., 99 f: il. color. ; $30 \mathrm{~cm}$

Dissertação (mestrado) - Pontifícia Universidade Católica do Rio de Janeiro, Departamento de Engenharia Elétrica.

Inclui bibliografia

1. Engenharia Elétrica - Teses. 2. Distinguibilidade Espectral;. 3. Visibilidade;. 4. Complementaridade;. 5. Efeito de Coerência Óptica;. 6. Interferômetro de Hong-Ou-Mandel;. I. Amaral, Gustavo Castro do.. II. Pontifícia Universidade Católica do Rio de Janeiro. Departamento de Engenharia Elétrica. III. Título. 


\section{Agradecimentos}

Agradeço muito a Deus e a Nossa Senhora, por essa oportunidade e pela força para superar as dificuldades.

Agradeço ao meu orientador, Prof. Gustavo Castro do Amaral, pela paciência, dedicação e pela contribuição no meu crescimento profissional.

Aos meus pais, Carlos Henrique e Adelaide, que com amor sacrificaram seus dias para que eu pudesse realizar os meus sonhos. Sem vocês com certeza não chegaria até aqui.

Obrigada aos meus irmãos, Henrique e Heloísa pelo incentivo e pelo companheirismo.

Agradeço ao meu marido Israel, só ele sabe o quanto foi difícil me acompanhar nessa conquista. Obrigada pela paciência, pelo apoio e simplesmente por estar ao meu lado.

Aos meus familiares, principalmente aos meus avós, que com certeza intercederam por mim junto a Deus.

A todos os amigos que foram grandes companheiros e compartilharam expectativas, dificuldades e alegrias.

Obrigado aos professores do curso de Pós-Graduação do CETUC, pela atenção e profissionalismo.

Agradeço ao CNPq pelo auxílio financeiro. 


\section{Resumo}

Carneiro, Elisa de Freitas; Amaral, Gustavo Castro do. Distinguibilidade Espectral e Visibilidade: Complementaridade no Interferômetro de Hong-Ou-Mandel . Rio de Janeiro, 2017. 99p. Dissertação de Mestrado - Departamento de Engenharia Elétrica, Pontifícia Universidade Católica do Rio de Janeiro.

Estuda-se a relação de complementaridade entre a visibilidade e a distingubilidade espectral dos pacotes de onda fotônicos deslocados em frequência em um interferômetro de Hong-Ou-Mandel. Uma definição experimental de $K$, o parâmetro de distinguibilidade, é proposta e testada para a desigualdade de complementaridade $K^{2}+V^{2} \leq 1$ quando um parâmetro de visibilidade consistente é definido. Os resultados mostram que a distinguibilidade espectral é, de fato, complementar à visibilidade e que o aspecto quântico do fenômeno de interferência de dois fótons pode ser examinado empregando estados coerentes atenuados.

\section{Palavras-chave}

Distinguibilidade Espectral; Visibilidade; Complementaridade; Efeito de Coerência Óptica; Interferômetro de Hong-Ou-Mandel; 


\section{Abstract}

Carneiro, Elisa de Freitas; Amaral, Gustavo Castro do. (Advisor). Spectral Distinguibility and Visibility: Complementarity in a Hong-Ou-Mandel Interferometer.. Rio de Janeiro, 2017. 99p. Dissertação de Mestrado - Departamento de Engenharia Elétrica, Pontifícia Universidade Católica do Rio de Janeiro.

The complementarity relation between the visibility and the spectral distinguishability of frequencydisplaced photonic wave-packets in a HongOu-Mandel interferometer is studied. An experimental definition of $\mathrm{K}$, the distinguishability parameter, is proposed and tested for the $K^{2}+V^{2}$ $\leq 1$ complementarity inequality when a consistent visibility parameter is defined. The results show that the spectral distinguishability is, indeed, complementary to the visibility and that the quantum aspect of the twophoton interference phenomenon can be examined by employing weakcoherent states.

\section{Keywords}

Spectral Distinguibility; Visibility; Complementarity; Coherent Optical Effects; Hong-Ou-Mandel Interferometer; 


\section{Sumário}

1 Introdução $\quad 16$

2 Revisão Teórica $\quad 20$

2.1 Experimento de Young e Funções de Coerência Clássicas 20

2.2 Princípios Básicos da Mecânica Quântica 23

2.2.1 Espaço de Hilbert 23

2.2.2 Operadores de Criação e Aniquilação 25

$\begin{array}{ll}2.2 .3 & \text { Estados de Fock } \\ 2.2 .4 & 27\end{array}$

2.2.4 Funções de Coerência Quântica 28

2.3 Interferência de Hong-Ou-Mandel 32

2.3.1 Dip de Hong-Ou-Mandel 35

2.3.2 Agrupamento de Fótons 37

2.4 Complementaridade 38

2.5 Fótons Únicos e Estados Coerentes Atenuados 40

2.6 Deslocamento de Frequência no Interferômetro de Hong-Ou-Mandel 43

2.6.1 Modos Espaço-Temporais 44

2.6.2 Coincidências na Saída do Divisor de Feixe 45

2.6.3 Batimento Auto-Heteródino entre Estados Coerentes Atenuados 45

2.6.4 Espectroscopia de Transformada de Fourier de Poucos Fótons 47

2.7 Detectores de Fótons Únicos $\quad 51$

2.7.1 Detectores de Fótons Únicos de Nanofio Supercondutores 52

2.7.1.1 Características dos Detectores de Fótons Único de Nanofio Supercondutores 53

2.7.1.2 Princípio de Operação $\quad 57$

2.7.2 Outros Tipos de Detectores de Fótons Únicos 58

2.7.2.1 Baseados em Tubos Fotomultiplicadores 58

2.7.2.2 Detectores de Fótons Únicos Fotodiodo Avalanche 60

3 Iniciando os Trabalhos com o Detector de Fótons Únicos de Nanofio Supercondutor $\quad 64$

4 Descrição Experimental $\quad 71$

4.1 Formulação Matemática $\quad 71$

4.2 Métodos Experimentais $\quad 75$

4.2.1 Ajuste de Frequência $\quad 76$

4.2.2 Alinhamento de Polarização 77

4.2.3 Intensidade (Número médio de fótons) 79

4.2.4 Sincronismo e Pós-Seleção 80

4.2.5 Caracterização do Alargamento Espectral 82

4.3 Montagem Experimental e Resultados 83

5 Conclusão $\quad 89$

$\begin{array}{lll}5.1 & \text { Submissões } & 90\end{array}$ 
Referências bibliográficas 


\section{Lista de figuras}

Figura 2.1 (a)Configuração padrão para a experiência de interferência de dupla fenda de Young (29).(b)Experimento de Young e a teoria de coerência (30).

Figura 2.2 Montagem baseado na experiência de Hanbury-Brown e Twiss.

Figura 2.3 Contagens de fótons em função do tempo para campos que apresentam (A) antiagrupamento de fótons, (B) aleatoriedade (campo coerente) e (C) agrupamento de fótons (57).

Figura 2.4 Montagem experimental do interferômetro de HOM (13). 33

Figura 2.5 Princípio do efeito de HOM (59). 34

Figura 2.6 Dip de HOM utilizando o processo de SPDC (63). 36

Figura 2.7 Dip de HOM caracterizado pela visibilidade entre WCSs medidos em função do atraso dos pulsos ópticos (20). 37

Figura 2.8 Número de fótons por pulso (67).

Figura 2.9 Probabilidade de um pulso não vazio contendo mais do que um fóton para diferentes valores de número médio de fótons $(67)$.

Figura 2.10 Configuração experimental para WCSs deslocados por frequência criados através de uma configuração baseada em FM auto-heteródino. LD: diodo laser; WG: gerador de forma de onda; VOA: atenuador óptico variável; d: gerador de retardo; OD: atraso óptico; PC: controlador de polarização; AM: modulador de amplitude (69).

Figura 2.11 Chegada dos pulsos de luz modulados em frequência no interferômetro HOM. Dependendo da amplitude da onda triangular moduladora, do seu período e do atraso da fibra, o deslocamento de frequência no interferômetro HOM irá variar. (52)

Figura 2.12 Padrão de interferência de WCS deslocados em frequência (a) $0 \mathrm{MHz}$, (b) $40 \mathrm{MHz}$, (c) $80 \mathrm{MHz}$, (d) $120 \mathrm{MHz}$, (e) 160 $\mathrm{MHz}$, (F) $200 \mathrm{MHz}$ (69).

Figura 2.13 Espectro de batida adquirido com ESA para diferentes delocamentos frequência entre fontes ópticas. As linhas correspondem ao ajuste gaussiano (69).

Figura 2.14 Configuração experimental do método de espectroscopia de poucos fótons. VOA: atenuador óptico variável; PC: controlador de polarização; AWG: gerador de forma de onda arbitrário; $\phi-$ Mod: modulador de fase; PBS: divisor de feixe por polarização; Dn: detector de fóton único(24).

Figura 2.15 Padrão de interferência de HOM entre dois pacotes de onda com estados coerentes atenuados nomeados de referência e teste com deslocamento de frequência de $40 \mathrm{MHz}$ (24). 
Figura 2.16 Resultados da espectroscopia de transformada de Fourier: poucos fótons (linhas tracejadas) e espectograma clássico (linhas contínuas). As FFTs dos interferogramas de poucos fótons são comparados aos espectrogramas de luz brilhante adquiridos no ESA para diferentes valores de deslocamento de frequência (24).

Figura 2.17 (a) Imagem AFM do primeiro nanofio de NbN com 1.3 $\mu \mathrm{m}$ x $225 \mathrm{~nm}$. (b) Imagem SEM do "Meandro SNSPD" de NbN cobrindo uma área grande de $10 \mu \mathrm{m} \times 10 \mu \mathrm{m}$. (c) Um "Meandro SNSPD" de NbN com $3 \mu \mathrm{m}$ x $3 \mu \mathrm{m}$ incorporado à uma cavidade óptica. (d) Múltiplos elementos de nanofio são polarizados em paralelo através de resistências independentes, resultando em um maior resolução número de fótons. (e) Nanofios ultra-finos (30 nm de largura) são conectados em paralelo para melhorar a sensibilidade (eficiência de registro) do SNSPD. (f) Um SNSPD fabricado sobre uma estrutura de guia de ondas ópticas para melhorar a eficiência do acoplamento óptico (79).

Figura 2.18 Contagem de escuro do NbTiN SSPDs (81).

Figura 2.19 Tempo de jitter típico do NbTiN SSPDs (81).

Figura 2.20 Princípio de funcionamento do SNSPD: No estado inicial (à esquerda), o nanofio está no estado supercondutor e polarizado com uma corrente (setas azuis) próxima à corrente crítica. Quando um fóton incide sobre o nanofio (meio), ele pode ser absorvido e causar uma zona local de supercondutividade suprimida. Esta zona cresce em uma região condutora normal através do fio (à direita), que leva a um pulso de tensão mensurável na leitura. Depois, o nanofio relaxa de volta ao seu estado inicial (80).

Figura 2.21 Esquema de um tubo fotomultiplicador (82).

Figura 2.22 Exemplo de circuito usando queching passivo (89).

Figura 2.23 (a): Esquema de um SPDA-Si de junção grossa. (b): Esquema de um SPAD-Si de junção fina (77)

Figura 2.24 Uma comparação entre as eficiências de detecção de SPAD-Si de junção grossa (quadrado) e junção fina (losango) (90)

Figura 2.25 Estrutura do SPAD de InGaAs/InP (77).

Figura 3.1 Montagem experimental para geração prática de bits aleatórios usando SAPD.

Figura 3.2 Resultados do conjunto de testes de aleatoriedade para a sequência de bits aleatória gerada utilizando SPAD.

Figura 3.3 Equivalência entre a montagem experimental SAPD e a montagem alternativa usando um EOAM e um SSPD operando no modo free-running.

Figura 3.4 Resultados do conjunto de testes de aleatoriedade para a sequência de bits aleatória gerada utilizando a configuração alternativa. 
Figura 4.1 Configuração da interferência de HOM resolvida no tempo: quando as frequências centrais ópticas $\omega_{1}$ e $\omega_{1}$ são iguais, o resultado é o dip habitual de HOM; quando $\omega_{1} \neq \omega_{2}$, um padrão de batimento é traduzido no interferograma como franjas de interferência.

Figura 4.2 Interpretação de $K$ e $V$ em relação à separação espectral dos pacotes de onda fotônicos. A) O recobrimento nulo entre as distribuições espectrais, $K=1$ e $V=0$; B) intersecção não nula, podem ser observadas franjas de interferência; C) espectros indistinguíveis permitem visibilidade máxima, $K=0$ e $V=1$.

Figura 4.3 Interpretação de $V$ considerando a contribuição de multifótons dos WCSs.

Figura 4.4 Diagrama de blocos da configuração experimental para ajuste do deslocamento de frequência. Espectros Clássicos medidos com o p-i-n e o ESA.

Figura 4.5 Dependência da visibilidade de interferência na relação de polarização dos estados (24).

Figura 4.6 Desdobramento da montagem experimental considerando que os detectores SSPDs são dependentes de polarização.

Figura 4.7 Dependência da visibilidade de interferência na relação de intensidade dos estados (24).

Figura 4.8 Esquema de sincronismo e pós-seleção dos eventos de detecção para SPADs.

Figura 4.9 Esquema de pós-seleção dos eventos de detecção para SSPDs.

Figura 4.10 Primeira evidência experimental da relação de complementaridade espectral em um interferômetro HOM. A visibilidade do padrão de interferência cai quando a separação entre os pacotes de onda fotônicos é elevada, o que traduz a distinguibilidade espectral. O uso de detectores gatilhados, no entanto, pode ter um impacto direto sobre os resultados, desse modo utilizamos detectores supercondutores de fótons únicos em modo free-running.

Figura 4.11 Diagrama de blocos da configuração experimental. As fontes de luz estabilizadas em frequência e polarização são definidas com estados de polarização idênticos e com frequências de centro óptico separadas de $100 \mathrm{MHz}$. Os VOAs (atenuadores ópticos variáveis) são responsáveis por certificar que a intensidade de ambas as fontes é a mesma e também para definir o número médio de fótons para que os detectores operem linearmente. $\mathrm{O}$ alinhamento do estado de polarização fina é realizado por controladores de polarização mecânica (PC fino). As detecções da SSPD inferior são interpretadas como os eventos de coincidência e formam o interferograma. 
Figura 4.12 A distribuição de intensidade espectral dos pacotes de onda para diferentes valores da largura de pulso. Quando $p_{t}$ é maior que 10 ns (a), a sobreposição espectral é mínima. Quando $p_{t}$ é mais estreito do que 10 ns (b-c-d), no entanto, a sobreposição cresce significativamente. As linhas contínuas representam o ajuste gaussiano.

Figura 4.13 Padrões de interferência adquiridos com diferentes larguras de pulso. É evidente a redução de visibilidade à medida que $p_{t}$ cresce. As linhas contínuas representam o ajuste do modelo quando pulsos de forma gaussiana são considerados.

Figura 4.14 Valores experimentais de $K^{2}+\mathcal{V}^{2}$ rastreados em relação à largura de pulso $p_{t}$. Os resultados seguem a previsão teórica - representada pela linha vermelha pontilhada - dentro da margem de erro experimental. 


\section{Lista de tabelas}

Tabela 2.1 Comparação resumida entre detectores fótons únicos, SNSPDs, PMTs e SPADs . Adaptado de (77).

Tabela 3.1 Resultado do cálculo de entropia

Tabela 4.1 Valores experimentais de $K^{2}$ e $\mathcal{V}^{2}$ medidos em relação à largura de pulso $\mathrm{p}_{t}$. 


\section{Lista de Abreviaturas}

HOM - Hong-Ou-Mandel

MDI-QKD - Measurement-Device-Independent Key Distribution

WCS - Weak Coherent States

$\mathrm{K}$ - Distinguibilidade

$\mathrm{V}$ - Visibilidade

F - Fidelidade

BS - Beam Splitter

$\mathrm{BS}_{H O M}-$ Beam Splitter Hong-Ou-Mandel

SPDC - Spontaneous Parametric Down-Conversion

$\mathrm{BBO}$ - Beta Barium Borate

QKD - Quantum Key Distribution

FWM - Four Wave Mixing

ESA - Electrical Spectrum Analyzer

FM - Frequency Modulation

LD - Laser Diode

WG - Waveform Generator

DDG - Digital Generator Delay

PG - Pulse Generator

VOA - Variable Optical Attenuator

$\mathrm{PC}$ - Polarization Controller

APD - Avalanche Fotodiode

SAPD - Single-Photon Avalanche Photodiodes

SPAD-Si - Silicon Single-Photon Avalanche Photodiodes

SPAD-Ge - Germanium Single-Photon Avalanche Photodiodes

SSPD - Superconducting Single-Photon Detector

SNSPD - Superconducting Nanowire Single-Photon Detector

AFM - Atomic-Force Microscopy

SEM - Scanning Electron Micrograph

DC - Direct Corrent

PMT - Photomultiplier Tubes

FWHM - Full Width At Half Maximum

DCR - Dark Count Rate

G-APD - Geiger-mode Avalanche Photodiode 
OSA - Optical Spectrum Analyser

PID - Proportional integral derivative

PBS - Polarizing Beam Splitter

DFB - Distributed Feedback

CW - Continuous Wave

FPGA - Field Programmable Gate Array

NIST - National Institute of Standards and Technology

EOAM - Electro-Optical Amplitude Modulator

AM - Amplitude Modulator 


\section{Introdução}

A óptica quântica foi uma área vital na investigação científica sobre a natureza da luz. Uma das proposições da teoria quântica sobre seu comportamento é a noção de dualidade onda-partícula que surgiu através das pesquisas de Albert Einsten (1879-1955) (1, 2) e Louis de Broglie (1892-1987) (3). De Broglie apresentou uma visão clara de dualidade ondulatória e corpuscular aos componentes da matéria. Apesar disso, alguns autores $(4,5)$ costumam conceder a concepção desta teoria a Einsten, afirmando que De Broglie teria apenas generalizado a ideia já aceita para a luz.

Em seu experimento seminal de dupla fenda, Thomas Young (1773-1929) mostrou que a luz gera um padrão de interferência, resultado que foi a base do argumento de que a luz se comporta como uma onda (6). Em 1961, Claus Jönsson utilizou esse experimento para analisar o comportamento de elétrons e mostrou que: um feixe de elétrons produz um padrão de interferência e portanto, exibe um comportamento ondulatório (7). Contudo, esse experimento não provou ser um ponto crucial no argumento de que mesmo quando elétrons únicos são disparados na fenda dupla, o padrão de interferência pode ser visualizado. Em 1989, Akira Tonomura (1942-2012) e outros (8) realizaram uma experiência onde analizaram o comportamento de elétrons individuais e mostram que: a acumulação de elétrons únicos sucessivos detectados em uma tela produzem um padrão de interferência. Além disso, Frabboni e outros (9) provaram que o conhecimento do caminho dos elétrons únicos através das fendas destrói o padrão de interferência sendo os elétrons então detectados como partículas. Ou seja, a ideia é que a criação de um padrão de interferência em uma experiência de fenda dupla de elétrons únicos está intimamente ligada a uma preclusão sobre a trajetória dos elétrons, a informação do caminho (do inglês Which-Way Information).

Além da análise do comportamento de elétrons o interferômetro de fenda dupla também foi empregado na investigação do comportamento dos fótons. Sendo assim, com o desenvolvimento da Óptica Quântica (10) e da Teoria Quântica de Coerência (11), a interpretação do desaparecimento do padrão pode ser extendida da perspectiva de informação de caminho para a da distinguibilidade entre os pacotes de onda fotônicos (12). 
Em 1987, Hong, Ou e Mandel desenvolveram um experimento capaz de quantificar o grau de distinguibilidade entre dois estados quânticos fotônicos, o interferômetro de Hong-Ou-Mandel (HOM) (13). O processo físico por trás do experimento remonta ao "agrupamento" (do inglês Bunching) de fótons, um fenômeno observado pela primeira vez por Hanburry-Brown e Twiss três décadas antes (14) e explicado por Fano à luz da mecânica quântica alguns anos depois (15). Como se vê, dois fótons únicos indistinguíveis que entram num divisor de feixe simétrico a partir de diferentes braços de entrada são incapazes de deixar o dispositivo através de diferentes braços de saída. Os pacotes de onda de dois fótons que descrevem o estado de entrada coletiva experimentam interferência destrutiva e os fótons deixam o divisor de feixe "agrupados". Esse fenômeno é intrisicamente quântico e mede o grau de distinção entre os estados de entrada individuais diretamente através da visibilidade do interferograma de HOM: visibilidade unitária que significa indistinguibilidade completa e visibilidade nula, que significa completa distinguibilidade. Com o advento das memórias quânticas, a interferência de HOM ganhou grande atenção: a capacidade de uma memória quântica de preservar a totalidade do pacote de onda fotônico pode ser avaliado através da medição da visibilidade do interferograma de HOM sendo os estados armazenados e recuperados a partir dele (16). Além disso, o fenômeno de interferência de HOM está no cerne de medidas projetivas sobre a base dos estados de Bell (17). Um estado de Bell é definido basicamente como um estado quântico emaranhado de dois sistemas de dois estados (18).

A interferência de HOM e a indistinguibilidade entre os pacotes de onda fotônicos também ganharam grande interesse com o desenvolvimento do protocolo de distribuição quântica de chaves independente do dispositivo de medição (MDI-QKD, do inglês Measurement-Device-Independent Quantum Key Distribution) (19). Nesse protoloco é realizada a medição de estados de Bell sobre fótons indistinguíveis emitidos por fontes independentes de estados coerentes atenuados (WCS, do inglês Weak Coherent States) (20). Devido ao custo reduzido e simplicidade na utilização de WCSs, no contexto prático de criptografia quântica, pulsos de estados coerentes atenuados são empregados como uma aproximação probabilística de um único fóton(21). Entretanto, a interferência de HOM com WCSs não pode alcançar visibilidade unitária mesmo com perfeita indistinguibilidade devido à descrição clássica intrínseca de estados coerentes, com uma visibilidade máxima atingível limitada a 50\% (22). No entanto, e devido ao fato de um pulso WCS probabilisticamente conter um único fóton, a interferência de dois fótons WCSs no interferômetro de HOM foi explicada por uma decomposição estatística da entrada dos pulsos WCS em 
pares de estados de Fock; sendo cada resultado possível ponderado pela sua respectiva probabilidade de ocorrência (23).

Se considerarmos uma configuração de fibra óptica de modo único, onde o modo espacial é pré-determinado, os graus de liberdade que podem distinguir dois pacotes de onda fotônicos são: seu modo de polarização, a intensidade (ou número médio de fótons) e seus modos espectrais. De fato, um resultado recente foi apresentado, quando garantida a indistinguibilidade de todos os graus de liberdade, exceto pelo modo espectral, este último pode ser determinado analisando a interferência de HOM dos pacotes de onda (24). Este resultado, apesar de sua exatidão, coloca uma questão sobre a própria natureza da interferência de HOM: como dois pacotes de onda fotônicos intrinsecamente distinguíveis (o modo espectral distingue cada um) podem produzir efeito de interferência de HOM não nulo quando o fenômeno é, ele próprio, dependente de sua indistinguibilidade?

Aqui, propomos que o fenômeno de interferência é o resultado da impossibilidade dos detectores, ou de qualquer aparelho de medição dentro da configuração experimental, de identificar a distribuição espectral individual dos estados de entrada e, portanto, existe uma impossibilidade de distinguir entre eles. Para isso, apresenta-se uma definição experimental do parâmetro de distinguibilidade espectral entre dois pacotes de onda fotônicos e mostra-se que obedecem uma relação de complementaridade quando WCSs são empregados. O impacto dos resultados apresentados é duplo: em primeiro lugar, mostra que a distinguibilidade espectral é complementar à visibilidade do interferograma HOM; e, em segundo lugar, mostra que o fenômeno de interferência de dois fótons pode ser destilado da interferência WCS em um interferômetro de HOM, uma vez que a complementaridade é uma característica estritamente quântica. Um experimento semelhante foi realizado por (25) com resultados interessantes, mas a análise de complementaridade não foi baseada na interferência de HOM. Dessa forma, se atribuírmos um parâmetro, digamos $V$, à visibilidade do interferograma e um parâmetro, digamos $K$, ao grau em que podemos distinguir espectralmente os pacotes de onda fotônicos, $K$ e $V$ têm mostrado obedecer a relação $K^{2}+V^{2} \leq 1(26)$.

Faz parte da nossa proposta, portanto, contextualizar os parâmetros $K$ e $V$ em termos da nossa configuração experimental e, em última instância, mostrar que eles obedecem a relação $K^{2}+V^{2} \leq 1$. A quantificação do parâmetro $\mathrm{V}$ no contexto da interferência de HOM foi realizada considerando que a visibilidade atingível é de $50 \%$ devido a contribuição multi-fóton dos WCSs (22). Por outro lado, um bom meio de quantificar o parâmetro $K$, foi associá-lo à fidelidade entre dois estados quânticos (27). 
Este trabalho está divido em cinco capítulos. O primeiro capítulo consiste em uma introdução acerca do tema desenvolvido neste trabalho e de uma apresentação do renomado experimento de fenda dupla para inserirmos o conceito de coerência. O segundo capítulo apresenta uma fundamentação teórica sobre alguns conceitos básicos da mêcanica quântica, seguindo com a apresentação da interferência de HOM, a noção de fótons únicos e estados coerentes atenuados, além do conceito de complementariedade, da caracterização do deslocamento de frequência no interferômetro de HOM e o conteúdo sobre detectores de fótons únicos com ênfase nos detectores de fótons únicos supercondutores (SSPD, do inglês Superconducting Single-Photon Detector). No capítulo 3, é apresentado um trabalho experimental que foi base para o início dos trabalhos com o SSPD. Tendo em vista a teoria apresentada nos capítulos anteriores, o quarto capítulo mostra a formulação matemática desenvolvida para o cálculo da distinguibilidade espectral e visibilidade, uma seção intitulada como "Métodos Experimentais" que aponta os passos fundamentais para o ajuste dos principais parâmetros experimentais, além da descrição do experimento e os resultados obtidos. Por fim, o quinto capítulo, apresenta as conclusões sobre o trabalho. 


\section{2}

\section{Revisão Teórica}

\section{1}

\section{Experimento de Young e Funções de Coerência Clássicas}

O experimento de Young, também chamado de experimento de fenda dupla, tem um papel de destaque na física. Em contraste à teoria corpuscular de Issac Newton, que afirmava que a luz era composta de um fluxo de partículas pequenas (28), Young, usou seu conhecimento sobre ondas sonoras sobrepostas para reproduzir um experimento revolucionário. Nos primeiros anos do século XIX, Thomas Young em seu trabalho para Royal Society apresentou a noção da luz se comportando como onda (6). A Fig.2.1 (a) apresenta uma ilustração do interferômetro de Young que é composto por um anteparo que bloqueia, exceto por duas fendas, a passagem da frente de onda.
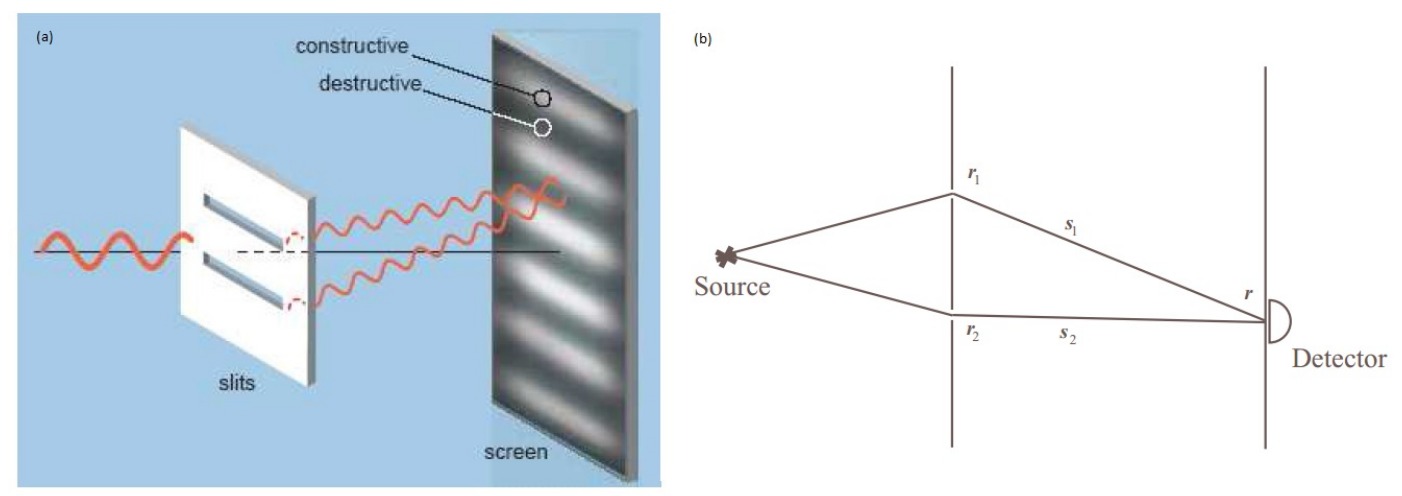

Figura 2.1: (a)Configuração padrão para a experiência de interferência de dupla fenda de Young (29).(b)Experimento de Young e a teoria de coerência (30).

Nesse experimento, Young mostrou que uma onda incidente gera outras duas com características interferométricas. Além disso, variando a posição do detector paralelamente ao anteparo de dupla-fenda, ou seja, observando diferentes pontos da tela, ele observou que: no ponto em que as duas frentes de onda estão perfeitamente em fase temos sua respectiva amplitude máxima e as frentes de onda interferem construtivamente, resultando em uma franja brilhante; no ponto em que as duas ondas estão completamente fora de fase, temos interferência destrutiva, resultando em uma franja escura. 
A configuração padrão do experimento de dupla fenda de Young, apresentada na Fig.2.1 (b), pode ser utilizada para compreensão da teoria clássica de coerência da luz. Como vimos, esse experimento consiste em dividir a luz proveniente de uma única fonte em dois ou mais feixes de ondas secundárias. Nesse caso, como os feixes originam da mesma fonte, eles estão sempre em fase, isto é, as fontes secundárias se comportam como fontes coerentes. Se a fonte tem uma largura espectral $\Delta \nu$ e se $\Delta s=\left|s_{1}-s_{2}\right|$ é a diferença de caminho, a interferência ocorrerá se $\Delta \mathrm{s} \leq \mathrm{c} / \Delta \nu$, onde c é a velocidade da luz no vácuo. Além disso, o comprimento de coerência e o tempo de coerência são respectivamente $\Delta s_{c}=c / \Delta \nu$ e $\tau_{c}=\Delta s_{c} / c=1 / \Delta \nu$ e as franjas de interferência serão visíveis para $\tau_{c} \Delta \nu \approx 1$ (30). No experimento de fenda dupla o campo elétrico no detector, no tempo $t$ pode ser escrito como:

$$
E(r, t)=k_{1} E\left(r_{1}, t_{1}\right)+k_{2} E\left(r_{2}, t_{2}\right),
$$

onde $t_{1}=t-s_{1} / c, t_{2}=t-s_{2} / c . k_{1}, k_{2}$ são fatores geométricos complexos que dependem das distâncias $s_{1}$ e $s_{2}$, respectivamente.

Além disso, a intensidade em um ponto $r$ no anteparo de detecção onde as franjas de interferência são observadas é dada por:

$$
I(r)=\left[I_{1}+I_{2}+2 \sqrt{\left(I_{1}, I_{2}\right)} \operatorname{Re}\left[k_{1} k_{2} \gamma^{(1)}\left(x_{1}, x_{2}\right)\right]\right.
$$

sendo, $x_{1}=r_{1}$, $t_{1}$ e $x_{2}=r_{2}, t_{2}$ e $\gamma^{(1)}\left(x_{1}, x_{2}\right)$ a função de correlação ou função de coerência mútua de primeira ordem, que normalizada pode ser escrita como (30):

$$
\gamma^{(1)}=\frac{\left\langle E^{*}\left(x_{1}\right) E\left(x_{2}\right)\right\rangle}{\sqrt{\left(\left\langle\left[E\left(x_{1}\right)\right]^{2}\right\rangle\left\langle\left[E\left(x_{2}\right)\right]^{2}\right\rangle\right)}} .
$$

Se definirmos $k_{i}=\left|k_{i}\right| e^{i \psi_{i}}$ e escrevermos,

$$
\gamma^{(1)}\left(x_{1}, x_{2}\right)=\left|\gamma^{(1)}\left(x_{1}, x_{2}\right)\right| e^{i \varnothing_{12}}
$$

temos que:

$$
I(r)=I_{1}+I_{2}+2 \sqrt{I_{1} I_{2}}\left|\gamma^{(1)}\left(x_{1}, x_{2}\right)\right| \cos \Delta \phi
$$

sendo $\Delta \phi=\phi_{1}-\phi_{2}$ a diferença de fase que resulta da diferença no comprimento de percurso (30).

De acordo com a Eq. 2-5, a interferência irá ocorrer apenas quando $\gamma^{(1)}$ $\left(x_{1}, x_{2}\right) \neq 0$ e a visibilidade das franjas de interferência pode ser obtida através da equação:

$$
V=\frac{2 \sqrt{I_{1} I_{2}}\left|\gamma^{(1)}\left(x_{1}, x_{2}\right)\right|}{I_{1}+I_{2}} .
$$

O valor da função de coerência mútua $\gamma^{(1)}\left(x_{1}, x_{2}\right)$ vai de 0 , limite de incoerência, até 1 , limite de coerência. Valores entre 0 e 1 são atribuídos à coerência 
parcial (31). A ideia de coerência óptica de primeira ordem está associada à possibilidade de produzir franjas de interferência quando dois campos estão sobrepostos, tal que o maior grau de coerência óptica está associado a um campo que produz franjas com máxima visibilidade. Contudo, experimentos que envolvem coerência de primeira ordem e, portanto, a função de correlação de primeira ordem não são capazes de distinguir estados da luz com distribuições espectrais idênticas, mas com estatísticas de fótons completamente diferentes (30). Nesse caso, é necessário considerarmos coerências de ordem superiores para que possamos distinguir as propriedades estatísticas da luz.

As experiências de correlação de intensidades desenvolvidas por Hanbury Brown e Twiss Hanbury na década de 1950 foram um ponto crucial para o desenvolvimento da ideia de coerência óptica de ordem superiores. A Fig.2.2 apresenta o a montagem básica utilizada atualmente fundamentado nessa experiência. Nesse caso, podemos ver que na saída da fonte um dispositivo conhecido como divisor de feixe (BS, do inglês Beam Splitter) divide o feixe óptico em dois feixes que são encaminhados a dois detectores.

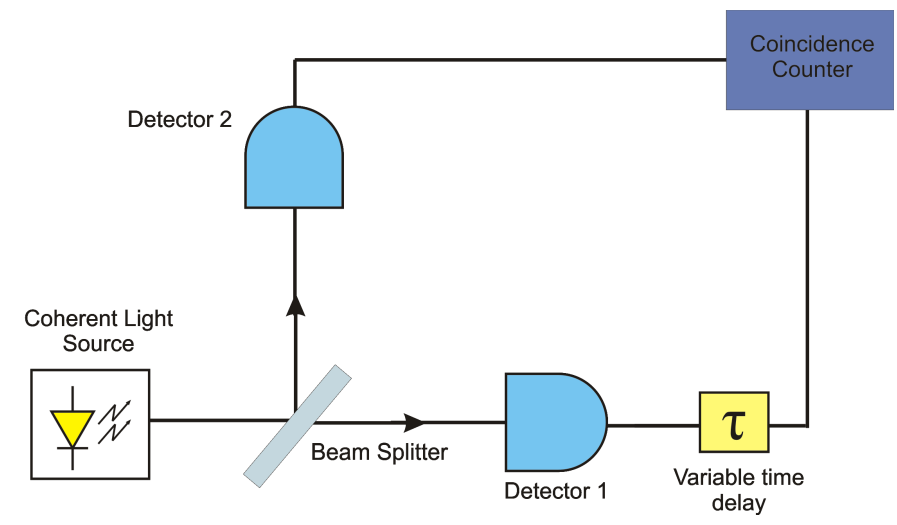

Figura 2.2: Montagem baseado na experiência de Hanbury-Brown e Twiss.

Segundo C.Gerry e P.Knight (30) esta configuração mede a taxa de coincidência em que um dos detectores registra uma contagem no tempo $t$ e o outro uma contagem em $t+\tau$. Se o atraso de tempo $\tau$, é menor que o tempo de coerência $\tau_{c}$, temos as informações sobre a estatística do feixe de luz que atinge o divisor de feixe. Logo, a taxa de contagem coincidente está relacionada com o tempo e $I(t)$ e $I(t+\tau)$ são valores clássicos das intensidades instantâneas nos dois detectores

$$
C(t, t+\tau)=\langle I(t) I(t+\tau)\rangle .
$$

Se a média da intensidade em cada detector é $\langle I(t)\rangle$ e assumindo que $t$ pertence à janela de tempo na qual o campo de radiação já atingiu o estado estacionário, então a probabilidade de se obter uma contagem de coincidência 
com atraso de tempo $\tau$ nos leva à função de coerência clássica de segunda ordem (30)

$$
\gamma^{(2)}(\tau)=\frac{\langle I(t) I(t+\tau)\rangle}{\langle I(t)\rangle^{2}}=\frac{\left\langle E^{*}(t) E^{*}(t+\tau) E(t+\tau) E(t)\right\rangle}{\left\langle E^{*}(t) E^{*}(t+\tau)\right\rangle^{2}} .
$$

Considerando $\tau=0$ a função de autorrelação de segunda ordem pode ser escrita como

$$
\gamma^{(2)}(0)=\frac{\left\langle I(t)^{2}\right\rangle}{\langle I(t)\rangle^{2}}
$$

Ao contrário da função de coerência de primeira ordem que se restringe à unidade ou menos, a função de correlação de segunda ordem nesse caso é restrita ao intervalo $1 \leq \gamma^{(2)}(0)<\infty$, além disso campos clássicos satisfazem à desiqualdade $\gamma^{(2)}(\tau) \leqslant \gamma^{(2)}(0)(32)$.

\section{2}

\section{Princípios Básicos da Mecânica Quântica}

A mecânica quântica surgiu no inicio do século XX, com intuito de desvendar fenômenos que a mecânica clássica não consiguia explicar. As seções seguintes apresentam resumidamente alguns conceitos básicos da mecânica quântica destinados à uma melhor compreensão dos aspectos teóricos desta tese.

\subsection{1}

\section{Espaço de Hilbert}

Na mecânica quântica, o vetor de estados que contém todas as informações sobre o estado físico de um sistema está presente em um espaço vetorial complexo que contém um produto interno. Este espaço é chamado de espaço de Hilbert $(H)$ (45). O espaço de Hilbert pode ser representado por uma formulação matemática que descreve sistemas quânticos e pode ser obtido quando introduzimos uma notação para os vetores, conhecida como notação de Dirac. Essa notação é composta por bras e kets, 〈.| e |.〉, respectivamente (46). Ou seja, no espaço de Hilbert com dimensão finita, um vetor pode ser denotado como um ket $|\psi\rangle \in H$, que representa um vetor coluna com $|N\rangle$ componentes complexas:

$$
|\psi\rangle=\left[\begin{array}{c}
\psi_{0} \\
\psi_{1} \\
\vdots \\
\psi_{N}
\end{array}\right] .
$$


Além disso, existe também um espaço dual $H^{*}$ onde os vetores são chamados de bra e denotados por $\langle\psi| \in H^{*}$. O bra $\langle\psi|$ é o conjugado complexo transposto (adjunto) do ket $|\psi\rangle$ (47), sendo assim, pode ser representado como:

$$
\langle\psi|=\left[\begin{array}{llll}
\psi_{0}^{*} & \psi_{1}^{*} & \cdots & \psi_{N-1}^{*}
\end{array}\right] .
$$

Em um espaço de dimensões infinitas a representação do vetor coluna $|\psi\rangle$ seria uma lista de infinitos números complexos (48). Como o espaço de Hilbert contém um produto interno, na notação de Dirac denotamos o produto entre dois vetores, $|\psi\rangle$ e $|\phi\rangle$ por $\langle\psi \mid \phi\rangle$. As propriedades básicas desse produto são:

$$
\begin{gathered}
\langle\psi \mid \phi\rangle=\langle\phi \mid \psi\rangle^{*} \\
\langle\psi \mid \psi\rangle \geq 0 \\
\left\langle\psi \mid a_{1} \phi+a_{2} v\right\rangle=a_{1}\langle\psi \mid \phi\rangle+a_{2}\langle\psi \mid v\rangle,
\end{gathered}
$$

onde $a_{1}$ e $a_{2} \in \mathbb{C}$ e $|v\rangle$ é também um vetor em $H$.

Sempre que comprimento do vetor $|\psi\rangle$ é $\sqrt{\langle\psi \mid \psi\rangle}=1$, temos a condição de normalização e quando o produto interno dos vetores $\langle\psi \mid \phi\rangle=0$, dizemos que eles são ortogonais um ao outro (48). Além disso, no espaço de Hilbert qualquer vetor pode ser representado por um conjunto de vetores linearmente independentes, que chamamos de base. A dimensão de um espaço vetorial é dada pela cardinalidade comum de suas bases (49). Desta forma, se consideramos uma base $|1\rangle,|2\rangle, \cdots,|N\rangle$ no espaço Hilbert $N$-dimensional os vetores podem ser decompostos conforme a Eq. 2-15 (50)

$$
|\psi\rangle=\sum_{j=1}^{N} \psi_{j}\left|u_{j}\right\rangle .
$$

Os números complexos $\psi_{j}$ que são as componentes do vetor $|\psi\rangle$ podem ser obtidos pelos produtos internos $\left\langle u_{j} \mid \psi\right\rangle$ (51). Inserido esses produtos internos na Eq. 2-15 temos que:

$$
|\psi\rangle=\sum_{j=1}^{N} \psi_{j}\left|u_{j}\right\rangle=\sum_{j=1}^{N}\left|u_{j}\right\rangle\left\langle u_{j} \mid \psi\right\rangle
$$

Os vetores de base formam uma base ortonormal quando satisfazem (51)

$$
\left\langle u_{j} \mid u_{i}\right\rangle=\delta_{j, i} .
$$

Se cada vetor é escrito como uma combinação linear de dois vetores que formam uma base, temos então um espaço Hilbert bidimensional. Exemplos de espaços de Hilbert bidimensionais que representam sistemas quânticos são os estados do spin de um elétron ou o estado de polarização de um fóton (52). Esses espaços podem fornecer uma configuração física de um qubit que nada mais é que a 
superposição de dois ou mais estados quânticos. Por exemplo, a combinação linear dos vetores de base $|0\rangle$ e $|1\rangle$ nos fornece o estado de um único qubit. Logo, um vetor arbitrário $|\psi\rangle$ do espaço de Hilbert pode ser escrito como:

$$
|\psi\rangle=\alpha|0\rangle+\beta|1\rangle
$$

onde $\alpha$ and $\beta$ são números complexos.

Na mecânica quântica os operadores agindo sobre o espaço de Hilbert descrevem as grandezas físicas observáveis que definem completamente um sistema quântico. Basicamente, um operador pode ser definido como uma transformação linear limitada ou contínua de um espaço Hilbert em si mesmo (52). Um operador $A^{\dagger}$ é chamado adjunto do operador $A$. No espaço de Hilbert um operador $A$ é conhecido como um operador normal se obedece à relação de comutação com o seu adjunto, ou seja:

$$
A A^{\dagger}=A^{\dagger} A \text {. }
$$

Esses operadores podem ser diagonalizados usando a base ortonormal

$$
A=\sum_{j} \lambda_{j}\left|\psi_{i}\right\rangle\left\langle\psi_{i}\right|
$$

onde os vetores de base $\left|a_{i}\right\rangle$ são autovetores de $A$ e os números $\alpha_{i}$ são seus autovalores (53). Essa equação é muitas vezes referida como a forma espectral do operador.

Um operador hermitiano $A$ definido pela propriedade $A=A^{\dagger}$ é um exemplo de operador normal. Na mecânica quântica os operadores hermitianos são utilizados para representar variáveis físicas como: energia, momento, momento angular, posição, etc. O operador hermitiano que representa a energia é conhecido como Hamiltoniano (53).

\subsection{2}

\section{Operadores de Criação e Aniquilação}

O operador Hamiltoniano que descreve um modo espectral do campo $(\omega, \vec{k})$ tem a forma de um oscilador harmônico expresso em termos dos operadores observáveis momento $\widehat{p}$ e posição $\widehat{q}$ :

$$
\widehat{H}=\frac{1}{2}\left(\widehat{p}^{2}+\omega^{2} \widehat{q}^{2}\right),
$$

onde $\omega$ é o modo de frequência do campo (30).

O comutador entre dois operadores $A$ e $B$ é dado por

$$
[A, B]=A B-B A,
$$

se $A B=B A$ dizemos que $A$ e $B$ comutam. 
Como os observáveis são sempre reais, os operadores que os representam são os operadores hermitianos que possuem como característica autovalores invariavelmente reais (54). Logo, os operadores observáveis $\widehat{p}$ e $\widehat{q}$ são hermitianos e satizfazem à relação de comutação $[\widehat{p}, \widehat{q}]=i \hbar$, sendo $\hbar=\frac{h}{2 \pi}$ ( $\hbar$ é a constante reduzida de Planck que vale $1,055 \cdot 10^{-34} \mathrm{Js}$ ) (53). A partir do oscilador harmônico podemos introduzir os chamados operadores de criação e aniquilação. Nesse caso, os operadores de criação "criam" um quantum de energia no oscilador harmônico e os operadores de aniquilação "aniquilam" um quantum de energia. No estudo dos fótons, os operadores de criação "criam" fótons e os operadores de aniquilação "aniquilam" os fótons (55).

Um operador de aniquilação pode ser definido por

$$
\widehat{a}=\frac{1}{\sqrt{2 \hbar \omega}}(\omega \widehat{q}+i \widehat{p})
$$

e o adjunto do operador de aniquilação conhecido como operador de criação é dado por

$$
\widehat{a}^{\dagger}=\frac{1}{\sqrt{2 \hbar \omega}}(\omega \widehat{q}-i \widehat{p}),
$$

onde $\omega$ agora é a frequência do fóton e $\hbar \omega$ a energia do fóton. Os operadores $\widehat{a}$ e $\widehat{a}^{\dagger}$ são não-hermitianos e portanto não observáveis. Além disso, como não são escalares, não podemos esperar que a propriedade de identidade seja válida para $\widehat{a}$ e $\widehat{a}^{\dagger}$ uma vez que $\left[\widehat{a}, \widehat{a}^{\dagger}\right]=\widehat{a} \widehat{a}^{\dagger}-\widehat{a}^{\dagger} \widehat{a}$ não desaparece . De fato, esses operadores obedecem a relação de comuntação (51):

$$
\left[\widehat{a}, \widehat{a}^{\dagger}\right]=1 \text {. }
$$

Escrevendo os operadores $\widehat{p}$ e $\widehat{q}$ em função de $\widehat{a}$ e $\widehat{a}^{\dagger}$ :

$$
\begin{aligned}
& \widehat{p}=\frac{1}{2 i}\left(\widehat{a}-\widehat{a}^{\dagger}\right) \sqrt{2 \hbar \omega} \\
& \widehat{q}=\frac{1}{2 \omega}\left(\widehat{a}+\widehat{a}^{\dagger}\right) \sqrt{2 \hbar \omega}
\end{aligned}
$$

Podemos reescrever o operador Hamiltoniano através da expressão:

$$
\widehat{H}=\hbar \omega\left(\widehat{a}^{\dagger} \widehat{a}+\frac{1}{2}\right)
$$

Um fato interessante dos operadores de criação e aniquilação é seu comportamento em relação ao hamiltoniano que possui um número de fótons bem definido, ou seja, se aplicarmos $\widehat{H}$ a um estado com $n$ fótons bem definidos representado por $|n\rangle$ podemos obter sua energia:

$$
\widehat{H}|n\rangle=\hbar \omega\left(\widehat{a}^{\dagger} \widehat{a}+\frac{1}{2}\right)|n\rangle=E_{n}|n\rangle .
$$

Logo, ao observarmos em termos de energia a ação desses operadores no estado $n$, podemos verificar que o operador $\widehat{a}$ reduz a energia do sistema em 
uma unidade de $\hbar \omega$ e o operador $\widehat{a}^{\dagger}$, eleva a energia do sistema em uma unidade de $\hbar \omega(30)$

$$
\begin{aligned}
\widehat{H}(\widehat{a}|n\rangle) & =\left(E_{n}-\hbar \omega\right)(\widehat{a}|n\rangle) \\
\widehat{H}\left(\widehat{a}^{\dagger}|n\rangle\right) & =\left(E_{n}+\hbar \omega\right)\left(\widehat{a}^{\dagger}|n\rangle\right) .
\end{aligned}
$$

Repetindo-se indefinidamente a aplicação do operador de aniquilação no estado $|n\rangle$, eventualmente extinguímos a energia do sistema. Por outro lado, a operação de criação no estado $|0\rangle$ nos indica a energia associada ao estado de vácuo. A aplicação do operador hamiltoniano num estado de vácuo $|0\rangle$ nos fornece uma energia não zero:

$$
\widehat{H}|0\rangle=\hbar \omega\left(\widehat{a}^{\dagger} \widehat{a}+\frac{1}{2}\right)|0\rangle=\frac{\hbar \omega}{2}|0\rangle .
$$

Nesse caso, a energia do vácuo é $\frac{\hbar \omega}{2}$. O operador $\widehat{a}^{\dagger} \widehat{a}$ é chamado operador número de fótons. Estados com número bem definido de fótons são autoestados desse operador:

$$
\widehat{a}^{\dagger} \widehat{a}|n\rangle=\widehat{n}|n\rangle=n|n\rangle .
$$

Os estados com número bem definidos de fótons são também conhecidos estados de Fock, ou também estados de números e são normalmente representados por $|n\rangle$.

\section{2 .3}

\section{Estados de Fock}

É possível avaliarmos o estado de Fock (estado com número bem definido de fótons) através da operação de $\widehat{a}$ e $\widehat{a}^{\dagger}$ :

$$
\begin{aligned}
\widehat{a}|n\rangle & =D_{n}|n-1\rangle \\
\widehat{a}^{\dagger}|n\rangle & =C_{n}|n+1\rangle .
\end{aligned}
$$

A constante $D_{n}$ pode ser determinada fazendo o produto interno de $\widehat{a}|n\rangle$ consigo mesmo

$$
\left\langle n\left|\widehat{a}^{\dagger} \widehat{a}\right| n\right\rangle=\langle n|\widehat{n}| n\rangle=n .
$$

Além disso, substituindo $\widehat{a}|n\rangle=D_{n}|n-1\rangle$ temos que:

$$
\left(\langle n| \widehat{a}^{\dagger}\right)(\widehat{a}|n\rangle)=\left\langle n-1\left|D_{n}^{*} D_{n}\right| n-1\right\rangle=\left|D_{n}\right|^{2}
$$

$\log \mathrm{o}, D_{n}=\sqrt{n}$.

Analogamente, podemos determinar $C_{n}$ fazendo o produto interno de $\widehat{a}^{\dagger}|n\rangle$ consigo mesmo: 


$$
\left\langle n\left|\widehat{a} \widehat{a}^{\dagger}\right| n\right\rangle=\left\langle n\left|\widehat{a}^{\dagger} \widehat{a}+1\right| n\right\rangle=\langle n|\widehat{n}+1| n\rangle=n+1
$$

$\log \mathrm{O}, C_{n}=\sqrt{n+1}$.

Podemos então reescrever as Eq. 2-34 e 2-35 na forma:

$$
\begin{gathered}
\widehat{a}|n\rangle=\sqrt{n}|n-1\rangle \\
\widehat{a}^{\dagger}|n\rangle=\sqrt{n+1}|n+1\rangle .
\end{gathered}
$$

Um estado de Fock $|n\rangle$ pode ser obtido através da operação consecutiva do operador de criação sobre o vácuo

$$
|n\rangle=\frac{\left(\widehat{a}^{\dagger}\right)^{n}}{\sqrt{n !}}|0\rangle
$$

Esses estados apresentam duas importantes propriedade:

- Estados com diferentes números de fótons são ortogonais

$$
\langle m \mid n\rangle=\delta_{m, n} .
$$

- Estados formam um espaço completo:

$$
\sum_{n=0}^{\infty}|n\rangle\langle n|=I
$$

onde I é o operador de identidade no espaço de Hilbert do sistema monomodo. Quando se deseja uma descrição simplificada de um experimento os estados de Fock são extremamente úteis (52).

\subsection{4}

\section{Funções de Coerência Quântica}

$\mathrm{Na}$ década de 60, pesquisas desenvolvidas por R.Glauber e outros, mostraram que certos estados do campo exibiam características não clássicas que não poderiam ser descritas por uma teoria estatística clássica (56). Segundo C.Gerry e P.Knight (30), a absorção de um fóton incidente no detector resulta na ionização dos átomos que constituem esse dispositivo e isso faz com que tenhamos um fotoelétron. Esse fotoelétron é obtido a partir de uma transição eletrônica no detector. Logo, se faz necessário pensarmos na probabilidade de transição de um estado inicial $|i\rangle$ para um estado final $|f\rangle$ para a partir da contagem dos fotoelétrons, podermos determinar as propriedades estatísticas do campo (31).

Na teoria quântica o operador campo elétrico pode ser escrito considerando o somatório sobre o cojunto de inteiros que especificam um modo normal do campo $(k)$ e o somatório sobre as duas polarizações possíveis $(s)$ :

$$
\hat{E}(r, t)=i \sum_{k, s} \sqrt{\frac{\hbar \omega_{k}}{2 \varepsilon_{0} V}} e_{k s}\left[\hat{a}_{k s}(t) e^{i k \cdot r}-\hat{a}_{k s}^{\dagger}(t) e^{-i k \cdot r}\right]
$$


sendo,

$\hbar$ - a constante reduzida de Planck.

$\omega_{k}$ - a frequência do modo.

$\varepsilon_{0}$ - a constante de permissividade do vácuo.

$V$ - o volume efetivo da cavidade.

$e_{k s}$ - a real polarização do vetor.

$\widehat{a}_{k s}$ - o operador de criação.

$\widehat{a}_{k s}^{\dagger}$ - o operador de aniquilação.

$k$ - número da onda $\left(k=\omega_{k} / c\right)$.

Como o comprimento de onda da luz é longo quando comparado com as dimensões do átomo, ou seja, $|k \cdot r| \ll 1$ (30), podemos escrever a equação do campo no detector, como sendo:

$$
\hat{E}(r, t)=i \sum_{k, s} \sqrt{\frac{\hbar \omega_{k}}{2 \varepsilon_{0} V}} e_{k s}\left[\hat{a}_{k s}(t)-\hat{a}_{k s}^{\dagger}(t)\right] .
$$

Somando os termos proporcionais ao operador de aniquilação e proporcionais ao operador de criação, temos que:

$$
\hat{E}(r, t)=\hat{E}^{(+)}(r, t)+\hat{E}^{(-)}(r, t)
$$

onde,

$$
\begin{gathered}
\hat{E}^{(+)}(r, t)=i \sum_{k, s} \sqrt{\frac{\hbar \omega_{k}}{2 \varepsilon_{0} V}} e_{k s} \hat{a}_{k s}(t) \\
\hat{E}^{(-)}(r, t)=\left[\hat{E}^{(+)}(r, t)\right]^{\dagger} .
\end{gathered}
$$

A probabilidade de transição por unidade de tempo que um fóton tem de ser absorvido por um detector ideal no ponto $r$ no tempo $t$ é dada por:

$$
p(r, t) \propto\left|\left\langle f\left|\hat{E}^{(+)}(r, t)\right| i\right\rangle\right|^{2}
$$

Além disso, a soma de todas as possíveis transições que dão origem a probabilidade total de um fóton incidente gerar um fotoelétron pode ser escrita como:

$$
\begin{gathered}
p(r, t)=\sum_{f}\left|\left\langle f\left|\hat{E}^{(+)}(r, t)\right| i\right\rangle\right|^{2}= \\
\sum_{f}\left\langle i \mid \hat{E}^{(-)}(r, t) f\right\rangle\left\langle f\left|\hat{E}^{(+)}(r, t)\right| i\right\rangle=\left\langle i\left|\hat{E}^{(-)}(r, t) \hat{E}^{(+)}(r, t)\right| i\right\rangle
\end{gathered}
$$

Devido ao desconhecimento preciso do estado inicial do campo é nenessário realizar a média sobre todos os estados iniciais possíveis 


$$
p \propto \sum_{i} P_{i}\left\langle i\left|\hat{E}^{(-)}(r, t) \hat{E}^{(+)}(r, t)\right| i\right\rangle
$$

onde $P_{i}$ é a probabilidade do estado inicial $|i\rangle(31)$.

De acordo com C. Gerry e P. Knight(30), no experimento de dupla fenda de Young, como representado na Fig.2.1, a intensidade da luz no fotodetector é dada por:

$$
\begin{gathered}
I(r, t)=\sum_{i} P_{i}\left\langle i\left|\hat{E}^{(-)}(r, t) \hat{E}^{(+)}(r, t)\right| i\right\rangle= \\
\left|K_{2}\right|^{2} G^{(1)}\left(x_{1}, x_{1}\right)+\left|K_{1}\right|^{2} G^{(1)}\left(x_{2}, x_{2}\right)+2 \operatorname{Re}\left[K_{1}^{*} K_{2} G^{(1)}\left(x_{1}, x_{2}\right)\right]
\end{gathered}
$$

para $x_{1}=r_{1}, t_{1}$ e $x_{2}=r_{2}, t_{2}$. Os termos $k_{1}, k_{2}$ são fatores geométricos complexos que dependem das distâncias $s_{1}$ e $s_{2}$. $G^{(1)}\left(x_{1}, x_{1}\right)$ e $G^{(1)}\left(x_{2}, x_{2}\right)$ são as intensidades de luz no detector que chegam a partir $x_{1}$ e $x_{2}$, respectivamente. Já o termo $G^{(1)}\left(x_{1}, x_{2}\right)$ se refere a função de correlação de primeira ordem, que nos apresenta a medida da correlação da luz que chega a partir de $x_{1}$ e $x_{2}$. Ou seja, uma medida de interferência. A função de coerência quântica de primeira ordem normalizada, analogamente à função de coerência clássica $\gamma^{(1)}\left(x_{1}, x_{2}\right)$ apresentada na Seção I. Eq.2-2 pode ser escrita como

$$
g^{(1)}\left(x_{1}, x_{2}\right)=\frac{G^{(1)}\left(x_{1}, x_{2}\right)}{\left[G^{(1)}\left(x_{1}, x_{1}\right) G^{(1)}\left(x_{2}, x_{2}\right)\right]^{\frac{1}{2}}} .
$$

Como vimos, é necessário considerarmos coerências de ordem superiores para que possamos distinguir as propriedades estatísticas da luz. Para chegarmos à função de autocorrelação quântica de segunda ordem, podemos considerar a probabilidade de dois detectores, posicionados em $r_{1}$ e $r_{2}$, detectarem um fóton cada, um no instante $t_{1}$ e outro no instante $t_{2}(31)$

$$
\begin{gathered}
p \propto \sum_{i} P_{i} \sum_{f}\left|\left\langle f\left|\hat{E}^{(+)}\left(r_{2}, t_{2}\right) \hat{E}^{(+)}\left(r_{1}, t_{1}\right)\right| i\right\rangle\right|^{2}= \\
\sum_{i} P_{i}\left\langle i\left|\hat{E}^{(-)}\left(r_{1}, t_{1}\right) \hat{E}^{(-)}\left(r_{2}, t_{2}\right) \hat{E}^{(+)}\left(r_{1}, t_{1}\right) \hat{E}^{(+)}\left(r_{2}, t_{2}\right)\right| i\right\rangle .
\end{gathered}
$$

A função de autocorrelação de segunda ordem governa a probabilidade conjunta de detecção (31)

$$
\begin{gathered}
G^{(2)}\left(r_{1}, t_{1} r_{2}, t_{2}\right)=\operatorname{Tr}\left[\rho \hat{E}^{(-)}\left(r_{1}, t_{1}\right) \hat{E}^{(-)}\left(r_{2}, t_{2}\right) \hat{E}^{(+)}\left(r_{2}, t_{2}\right) \hat{E}^{(+)}\left(r_{1}, t_{1}\right)\right. \\
=\left\langle\hat{E}^{(-)}\left(r_{1}, t_{1}\right) \hat{E}^{(-)}\left(r_{2}, t_{2}\right) \hat{E}^{(+)}\left(r_{2}, t_{2}\right) \hat{E}^{(+)}\left(r_{1}, t_{1}\right)\right\rangle .
\end{gathered}
$$

Então, considerando que a probabilidade para um campo estacionário só depende de $r_{1}, r_{2}$ e $\tau=t_{2}-t_{1}$ podemos escrever a função de autocorrelação de segunda ordem normalizada segundo a probabilidade de detectarmos um fóton em um tempo $t$ e outro fóton em um tempo $t+\tau$ 


$$
g^{(2)}(\tau)=\frac{\left\langle\hat{E}^{(-)}(t) \hat{E}^{(-)}(t+\tau) \hat{E}^{(+)}(t+\tau) \hat{E}^{(+)}(t)\right\rangle}{\left\langle\hat{E}^{(-)}(t) \hat{E}^{(+)}(t)\right\rangle\left\langle\hat{E}^{(-)}(t+\tau) \hat{E}^{(+)}(t+\tau)\right\rangle} .
$$

Para um campo monomodo, a Eq.2-56 pode ser reduzida para a equação abaixo que utiliza operadores de criação e aniquilação

$$
g^{(2)}(\tau)=\frac{\left\langle\hat{a}^{\dagger} \hat{a}^{\dagger} \hat{a} \hat{a}\right\rangle}{\left\langle\hat{a}^{\dagger} \hat{a}\right\rangle^{2}} .
$$

Considerando $g^{(2)}(\tau)$ no tempo de atraso zero $(\tau=0)$, temos que

$$
g^{(2)}(0)=1+\frac{\left\langle\Delta \hat{n}^{2}\right\rangle-\langle\hat{n}\rangle}{\langle\hat{n}\rangle^{2}},
$$

onde $\hat{n}=\hat{a}^{\dagger} \hat{a}$ é o operador número de fótons, $\langle\hat{n}\rangle$ é o número médio de fótons e $\langle\Delta \hat{n}\rangle^{2}=\left\langle\hat{n}^{2}\right\rangle-\langle\hat{n}\rangle^{2}$ é a variância do número médio de fótons. A partir de $g^{(2)}(\tau)$ e $g^{(2)}(0)$ é possível definir a estatística do campo e definir limites nos quais o campo se comporta quanticamente. Como vimos, a função de correlação de segunda ordem clássica para o tempo de atraso zero $(\tau=0)$ é restrita ao intervalo $1 \leq \gamma^{(2)}(0)<\infty$. Por outro lado, quanticamente, o intervalo é definido por $0 \leq g^{(2)}(0)<\infty(32)$. Assim podemos observar que para $g^{(2)}(0) \geq 1$ não podemos distinguir entre um campo clássico e um campo quântico uma vez que tanto a teoria clássica quanto a quântica admitem este resultado. Por outro lado, se $g^{(2)}(0)<1$ temos evidenciado um comportamento quântico, isto é, não há como descrever campos que satisfazem essa desigualdade através de uma teoria estatística clássica.

A função de autocorrelação quântica de segunda ordem nos fornece a estatística de fótons da seguinte forma:

- Estatística super-Poissoniana: $g^{(2)}(0)>1 \Longleftrightarrow\left\langle\Delta \hat{n}^{2}\right\rangle>\langle\hat{n}\rangle$

- Estatística Poissoniana: $g^{(2)}(0)=1 \Longleftrightarrow\left\langle\Delta \hat{n}^{2}\right\rangle=\langle\hat{n}\rangle$

- Estatística sub-Poissoniana: $g^{(2)}(0)<1 \Longleftrightarrow\left\langle\Delta \hat{n}^{2}\right\rangle<\langle\hat{n}\rangle$.

Além disso, tendo em vista a teoria quântica podemos identificar o fenômeno de agrupamento de fótons (bunching) quando $g^{(2)}(\tau)<g^{(2)}(0)$ e o fenômeno de antiagrupamento (antibunching) quando $g^{(2)}(\tau)>g^{(2)}(0)$. A Fig.2.3 mostra o perfil de contagens de fótons utilizando o experimento de HanburyBrown e Twiss. Na Fig.2.3 (A) podemos ver que quando o campo apresenta antiagrupamento de fótons, estes têm uma maior probabilidade de chegarem aos detectores mais espaçados temporalmente. Na Fig.2.3 (B) temos o caso de um campo coerente, aonde os fótons chegam aleatoriamente, mostrando ausência de correlações de fótons. Por outro lado, quando o campo apresenta agrupamento de fótons Fig.2.3 (C), este tem uma maior probabilidade de che- 
garem em intervalos de tempos menos espaçados.

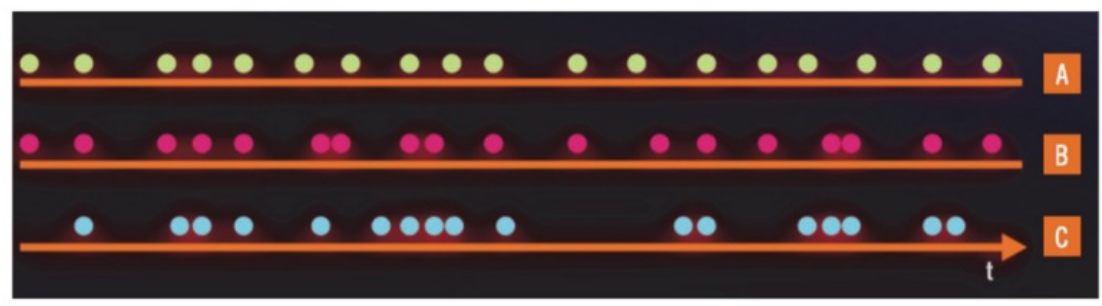

Figura 2.3: Contagens de fótons em função do tempo para campos que apresentam (A) antiagrupamento de fótons, (B) aleatoriedade (campo coerente) e (C) agrupamento de fótons (57).

Uma vez que o valor de $g^{2}(\tau)$ se encontra no intervalo $0<g^{2}(\tau)<\infty$, se uma fonte apresenta $g^{2}(0)$ igual a zero haverá antiagrupamento de fótons. De acordo com (57), se há antibunching, o feixe, obrigatoriamente, apresenta comportamento sub-Poisson. Vê-se, portanto, que antibunching e sub-Poisson são comportamentos diferentes de um feixe de luz em que um implica no outro, mas não o contrário. Ao avaliar experimentalmente o valor de $g^{2}(0)$, através do experimento de Hanburry-Brown e Twiss, por exemplo, podemos acessar o comportamento estatístico da emissão de fótons e determinar se há uma maior probabilidade de emissão de estados de fótons únicos dentro do comprimento de coerência da fonte.

\section{3}

\section{Interferência de Hong-Ou-Mandel}

O efeito de interferência representa a superposição de duas ou mais ondas num mesmo ponto e foi utilizado para compreessão da luz desde o seu estabelicimento com a teoria de ondas clássicas sobrepostas, chegando a coompreensão conceitual da física quântica. Nesta tese, utilizaremos a interferência de Hongou Mandel (HOM) associado ao conceito de complementaridade para obtermos a relação entra a distinguibilidade espectral entre os pacotes de onda fotônicos e a visibilidade do padrão de interferência. A interferência de Hong-ou-Mandel é um dos fenômenos mais relevantes quando falamos de interferência de dois fótons e tem sido amplamente utilizado em muitos campos da óptica quântica. Sua primeira observação ocorreu em 1987 quando C. K. Hong, Z. Y. Ou e L. Mandel analisaram o que ocorreria quando dois bósons idênticos entravam em um divisor de feixe (13). A Fig.2.4 apresenta a configuração original do interferômetro de HOM.

Nesse experimento foi considerado a luz gerada pelo processo de conversão paramétrica descendente espontânea (SPDC, do inglês Spontaneous Pa- 


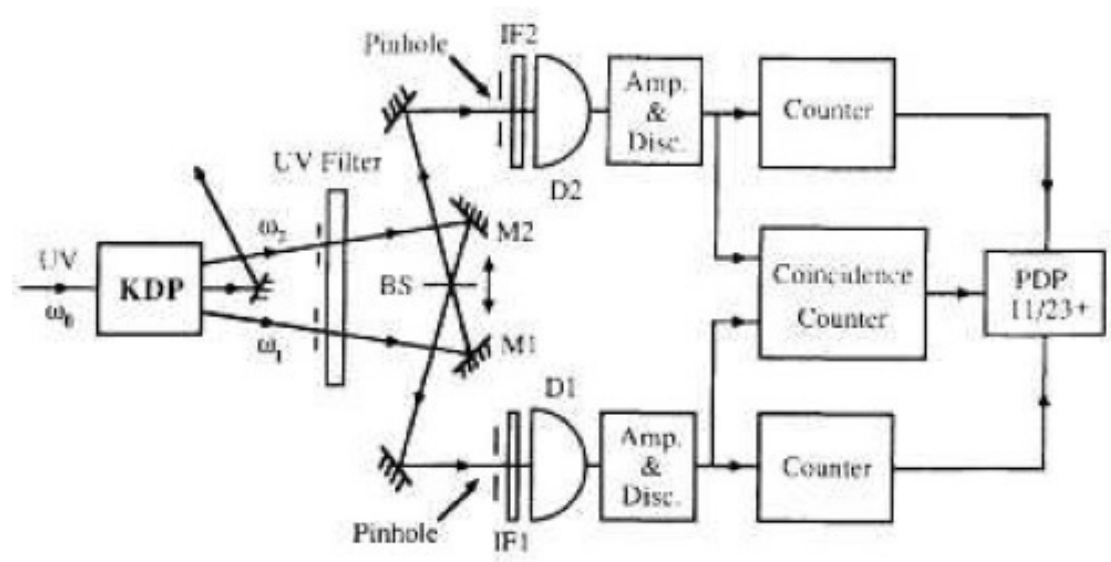

Figura 2.4: Montagem experimental do interferômetro de HOM (13).

rametric Down-Conversion) que consiste em utilizar um material com propriedades ópticas não-lineares, tal como o cristal do tipo BBO (do inglês, Beta Barium Borate), para tranformar um fóton de bombeio em dois fótons de energia menor chamados de signal e idler. Devido à conservação de energia nesse sistema, de modo que os fótons, signal e idler, apresentam forte correlação temporal, espectral e de polarização entre si, a soma das frequências desses fótons deve igualar-se à frequência do fóton de bombeio $\omega_{0}$

$$
\omega_{0}=\omega_{1}+\omega_{2}
$$

Conforme apresenta a Fig.2.4, Hong e outros (13) incidiram um feixe de bombeio de argônio com frequência $\omega_{0}$ em $351.1 \mathrm{~nm}$ em um cristal não linear que dividiu os fótons incidentes em dois fótons com frequências menores $\omega_{1}$ e $\omega_{2}$. Antes de serem medidos esses dois fótons gerados passaram através de um divisor de feixe e eles determinaram o número relativo de medições coincidentes, ou seja, aquelas em que o fóton 1 é detectado no detector $D_{1}$ e o fóton 2 em $D_{2}(58)$.

Um interferômetro de Hong-Ou-Mandel constitui-se então, de um divisor de feixe 50:50 e dois fótons que entram nesse dividor por lados opostos. Se, no entanto, fótons distinguíveis forem enviados através das duas portas de entrada desse divisor, haverá, conforme apresenta a Fig.2.5, quatro possibilidades diferentes para a reflexão ou a transmissão dos fótons nesse dispositivo.

$\mathrm{Na}$ 2.5(a) ambos os fótons são transmitidos e na 2.5(b) ambos são refletidos. Por outro lado, em ambos os casos, nas Fig.2.5 (c) e 2.5 (d), um dos fótons é transmitido e o outro é refletido, resultando em saídas para portas separadas. Este efeito pode ser observado usando dois detectores, um em cada 


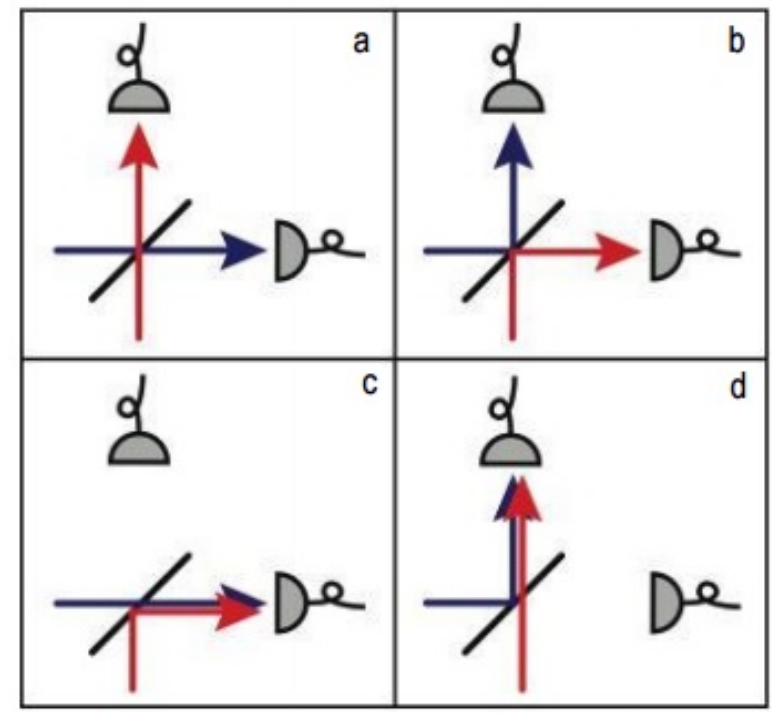

Figura 2.5: Princípio do efeito de HOM (59).

saída do divisor de feixe. Para os dois últimos casos, como em um divisor de feixe 50:50 as amplitudes são as mesmas, ocorre uma interferência destrutiva (60). Matematicamente, este efeito pode ser explicado considerando modos espaciais de entrada diferentes $a$ e $b$ com operadores correspondentes de criação e aniquilação $\widehat{a}, \widehat{a}^{\dagger}$ e $\widehat{b}, \widehat{b}^{\dagger}$. No divisor de feixe esses operadores de criação e aniquilação seguem as seguintes transformações:

$$
\begin{array}{ll}
\widehat{a}^{\dagger}=\frac{i \widehat{c}^{\dagger}+\widehat{d}^{\dagger}}{\sqrt{2}} & \widehat{c}^{\dagger}=\frac{-i \widehat{a}^{\dagger}+\widehat{b}^{\dagger}}{\sqrt{2}} \\
\widehat{b}^{\dagger}=\frac{\widehat{c}^{\dagger}+i \widehat{d}^{\dagger}}{\sqrt{2}} & \widehat{d}^{\dagger}=\frac{\widehat{a}^{\dagger}-i \hat{b}^{\dagger}}{\sqrt{2}}
\end{array}
$$

onde c e d são estados de saída do divisor de feixes, que realiza uma transformação unitária. Uma reflexão de uma das superfícies do divisor de feixe induz um deslocamento de fase relativo na função de onda do fóton, enquanto uma transmissão não induz qualquer deslocamento de fase (30).

Considerando que fótons únicos indistinguivéis são injetados simultaneamente nas duas portas de um divisor de feixe 50:50, o estado de entrada desses fótons descritos pelos estados Fock pode ser dado por

$$
\left|\phi_{i n}\right\rangle=\widehat{a}^{\dagger} \widehat{b}^{\dagger}|0,0\rangle_{a, b}=|1,1\rangle_{a, b}
$$

onde $|0\rangle$ é vácuo e $|1\rangle$ é um estado de um único fóton. Nesse caso, considerando as diferentes transformações da Eq. 2-60 o estado incidente no divisor de feixe $|1,1\rangle_{a, b}$ pode ser escrito como 


$$
\begin{gathered}
\left|\phi_{i n}\right\rangle=|1,1\rangle_{a b}=\widehat{a^{\dagger}} \widehat{b}^{\dagger}|0,0\rangle_{a b}=\left(\frac{i \widehat{c}^{\dagger}+\widehat{d^{\dagger}}}{\sqrt{2}}\right)\left(\frac{\widehat{c}^{\dagger}+i \widehat{d}^{\dagger}}{\sqrt{2}}\right)|0,0\rangle_{a b}= \\
\frac{1}{2}\left(i \widehat{c}^{\dagger 2}-\widehat{c}^{\dagger} \widehat{d}^{\dagger}+\widehat{c}^{\dagger} \widehat{d}^{\dagger}+i \widehat{d}^{\dagger 2}\right)|0,0\rangle_{a b}= \\
\frac{i}{2}\left(\widehat{c}^{\dagger 2}+\widehat{d}^{\dagger 2}\right)|0,0\rangle_{a b} .
\end{gathered}
$$

O fator dois no expoente dos operadores de criação indica que eles operaram duas vezes sobre o estado de vácuo, gerando um estado de dois fótons. Podemos notar, que quando os fótons são indistinguíveis temos uma diferença entre os casos em que eles são transmitidos e refletidos, uma vez que os termos com sinais opostos se anulam. Assim, observamos a criação de um fenômeno de interferência onde os fótons saem sempre juntos do dispositivo. A ausência de informação sobre o caminho do conjunto de fótons interagindo com o divisor é o que chamamos de ausência de informação do caminho (52). Logo, a saída do divisor de feixe são dois fótons no modo espacial de saída c e nenhum em d ou dois fótons no modo espacial da saída d e nenhum de c

$$
\left|\phi_{\text {out }}\right\rangle=\frac{i\left(|2,0\rangle_{c d}+|0,2\rangle_{c d}\right.}{\sqrt{2}}
$$

Este estado na saída do divisor de feixe indica então, a probabilidade de dois fótons idênticos serem detectados em portas de saída diferentes, como podemos ver na equação acima o estado $|1,1\rangle$ desaparece, portanto a probabilidade $P(1,1)=0$.

\subsection{1 \\ Dip de Hong-Ou-Mandel}

Na prática, ao contrário da análise acima onde consideramos o caso de um único modo, os campos estão em vários modos, ou seja, sob esta circuntância, os fótons são descritos como pacotes de onda. Para que ocorra o efeito de interferência os pacotes de onda dos fótons devem coincidir exatamente no divisor de feixe. Por outro lado, quando os pacotes de onda chegam ao divisor separados a interferência não ocorre e temos uma probabilidade que não será zero para dois fótons chegando em lados opostos (60).

A coerência mútua dos fótons interferentes $g_{a b}(\tau)$ é um aspecto importante nas experiências interferométricas que caracteriza o tempo de coerência mútua dos fótons $\tau_{c}$. Nos detectores, quando o atraso relativo entre eles coincide com o tempo de coerência mútua dos fótons teremos eventos de fótons indistinguivéis no divisor de feixe gerando estados de saída como na Eq.2-63. O fenômeno conhecido como dip de HOM ocorre quando varremos o atraso relativo entre os dois pacotes de onda de fótons. A Fig.2.6 mostra o resultado experimental do dip observado por Mandel e outros (13). 


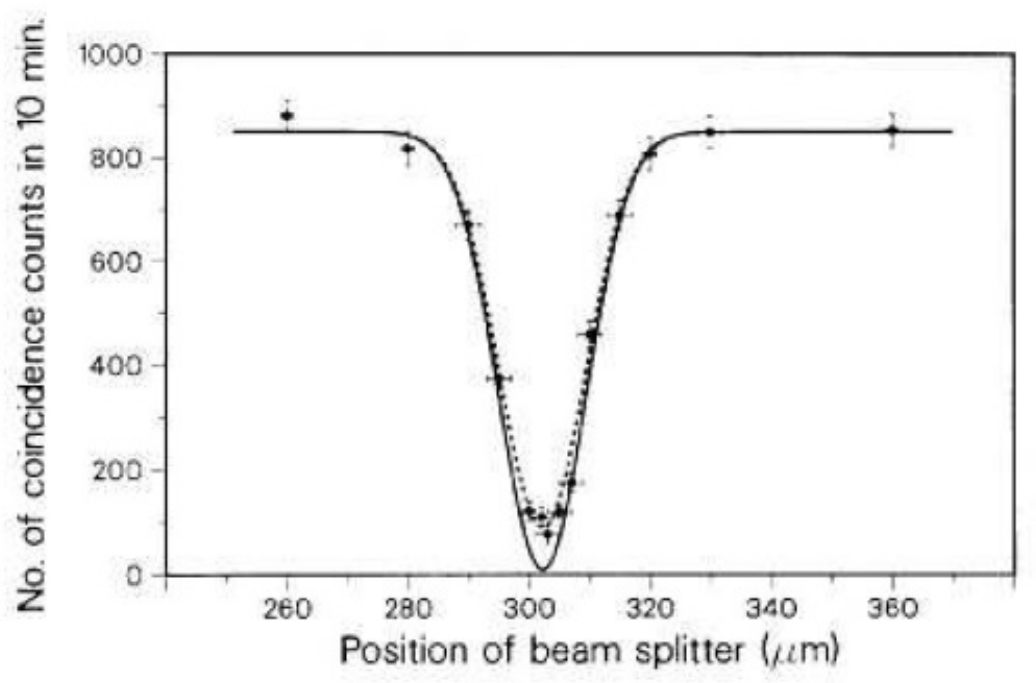

Figura 2.6: Dip de HOM utilizando o processo de SPDC (63).

Como podemos ver a probabilidade $P(1,1)$ exibirá uma queda até atingir zero quando o atraso for zero. No entanto, quando os fótons não coincidem, os eventos pós-selecionados correspondem a fótons totalmente distintos que não interferem, então o trajecto óptico tomado pelos fótons é igualmente provável e os eventos coincidentes correpondem a linha plana da Fig.2.6 que é exatamente o número de fótons por intervalo de tempo que entra no divisor de feixe.

A visibilidade do dip de HOM que é dada por

$$
V=\frac{R_{\max }-R_{\min }}{R_{\max }+R_{\min }}
$$

onde $R_{\max }$ e $R_{\min }$ são respectivamente o máximo e o mínimo de coincidências observadas nos indica a medida do grau de interferência dos fótons. Na prática, é impotante notarmos que a visibilidade pode nunca ser exatamente 100\%, pois qualquer desalinhamente da configuração ou desajuste na função espectral fazem com que os efeitos de interferência diminuam. Além disso, temos perdas na maioria dos dividores de feixes e eles podem não dividir a luz perfeitamente (61).

Na próxima seção falaremos mais detalhadamente sobre WCSs, onde a luz é altamente atenuada a partir de uma fonte laser. O dip de HOM de interferência de dois fótons únicos pode ser observado também para estes estados, no entanto, nesse caso devido à emissão de multi-fótons a visibilidade de interferência é limitada a aproximadamente 50\%. A Fig.2.7 apresenta o resultado da interferência entre estados coerentes apresentada em (20).

O tempo de coerência mútua dos fótons interferentes, ou seja, o intervalo de tempo em que eles interagem definem a largura do dip de HOM. Logo, apesar de os fótons gerados a partir do processo de SPDC serem uma boa 


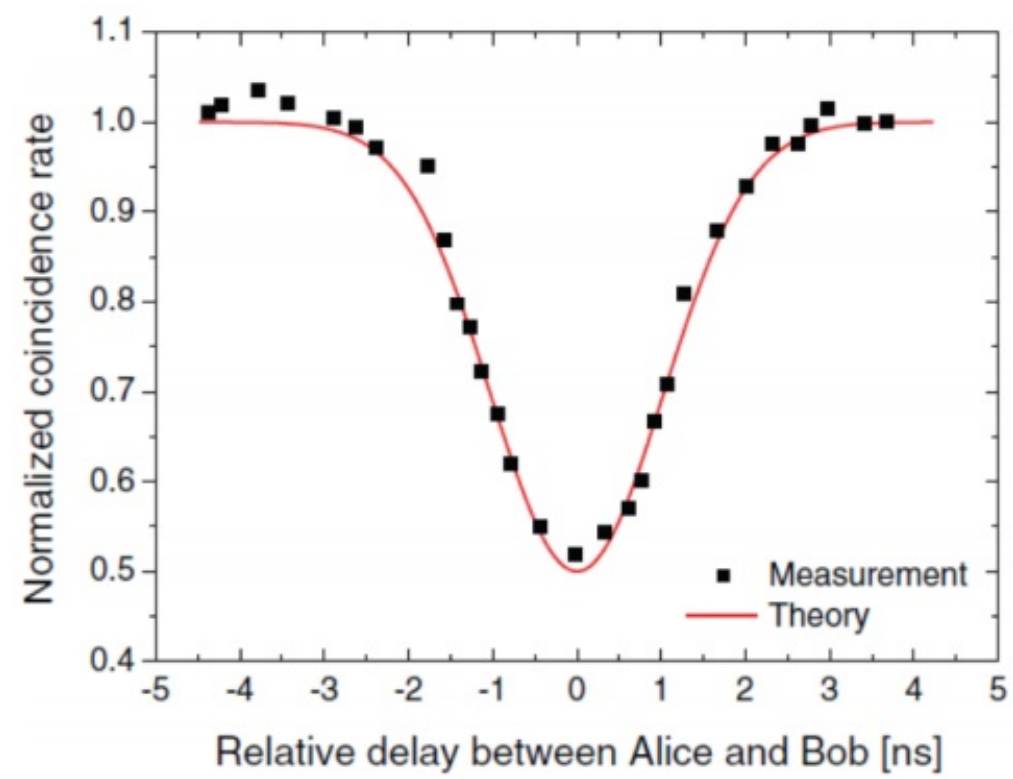

Figura 2.7: Dip de HOM caracterizado pela visibilidade entre WCSs medidos em função do atraso dos pulsos ópticos (20).

aproximação para o estado de um único fóton, e portanto, exibirem uma visibilidade perto de $100 \%$, a largura do dip de HOM é muito estreita devido a largura dos fótons que é geralmente ampla. Quando os fótons tem frequências diferentes é esperado, um padrão de batimento quântico modulando o dip de HOM, mas este efeito só pode ser observado se o tempo de coerência dos fótons for alto o suficiente (62). No caso de WCSs, apesar da visibilidade ser limitada a $50 \%$ é necessário uma a largura de linha muito mais estreita para que o padrão de interferência possa ser visualizado (16).

\subsection{2}

\section{Agrupamento de Fótons}

Como vimos na Seção I.1 o efeito de agrupamento de fótons, foi inicialmente discutido através de experiências realizados por Hanbury-Brown e Twiss na década de 50 (14). Contudo, apenas na década de 60 no monumental trabalho de Glauber sobre a coerência ótica, tivemos uma discussão clara sobre a conexão entre o efeito de agrupamente de fótons e a interferência de amplitudes dos pacotes de onda de dois fótons (11). O interferômeto de HOM pode ser utilizado para entendermos mais precisamente em termos interferência de dois fótons o efeito de agrupamento. Para isto, ao invés de estarmos interessados em $P(1,1)$ voltamos nosso olhar aos termos $|2,0\rangle,|0,2\rangle$ da Eq.2-63 a partir dos quais encontramos a probabilidade de ambos os fótons seguirem por um dos caminhos (63). Os fótons comportam-se como partículas clássicas se 
entram bem separados no divisor. Logo, as probabilidades das possibilidades de seguirem um caminho ou o outro são somadas (60)

$$
P_{2}^{c l}=|A|^{2}+|A|^{2} .
$$

Por outro lado, se há uma sobreposição no divisor de feixe as duas possibilidades não podem ser distintas e a probabilidade total é a soma das amplitudes antes de tomar o valor absoluto (60)

$$
P_{2}^{q u}=|A+A|^{2}=4|A|^{2}=2 P_{2}^{c l}(2,0)=2 P_{2}^{c l}(0,2) .
$$

Basicamente o que acontece é que quando as funções de onda, ou os pacotes de onda que descrevem os fótons que entram em um divisor de feixe simétrico são indistinguíveis, ou seja, não é possível distingui-los, esses pacotes que descrevem o estado de entrada coletiva experimenam uma interferência destrutiva e exite um cancelamento das funções de onda que descrevem os dois fótons e eles são incapazes de deixar o dispositivo através de diferentes braços de saída deixando o divisor de feixe agrupados, daí o fenômeno de bunching. Então, o interferômetro de HOM mede o grau de distinção entre os estados de entrada individuais diretamente através da visibilidade do interferograma.

\section{4}

\section{Complementaridade}

O princípio da complementaridade foi enunciado por Niels Borh em 1928 (33). Este conceito em sua totalidade geral é resumido na afirmação de que um sistema quântico pode as vezes ter comportamento de onda, as vezes de partícula (34). Um paradigma bem conhecido deste conceito é a dualidade onda-partícula em um interferômetro de fenda-dupla (35). As famosas discussões entre Einsten e Bohr (36) giravam em torno desta questão que está no cerne da mecânica quântica desde a sua criação e foi ponto de partida para diversas experiências nas últimas décadas. Na famosa experiência de dupla fenda de Young, por exemplo, um único elétron pode aparentemente passar através de ambas as fendas simultaneamente, formando um padrão de interferência (conceito típico de ondas). Contudo, se um detector for empregado para determinar por qual fenda a partícula passou, ou seja, qual o caminho do elétron (conceito típico de partícula), o padrão de interferência é destruído (37). Para muitos pesquisadores $(38,39,40)$ o príncipio da complementaridade se baseia nas relações de incerteza de Heisenberg, ou seja, para inferir por qual fenda a partícula teria passado, é fundamental conhecer as condições de posição e momento não só da partícula como do anteparo (41). Mas, a aquisição de informação espacial da partícula aumenta a incerteza no momento, destruindo a interferência (37). A ideia de que as relações de incerteza seriam a causa da 
complementaridade foi disseminada por Feynman (42) quando tentou usar a luz para determinar por qual das fendas o elétron passaria (41).

Em 1996, Englert(26) apresentou um importante trabalho que vislumbrava os passos para quantificação do príncipio da complementaridade sem fazer uso de qualquer relação de incerteza de Heisenberg. Esse método consite em realizar uma medida real do caminho da partícula obtendo um resultado aleatório caracterizado pela diferença entre as probabilidades $\omega_{+}$e $\omega_{-}$ de uma partícula tomar um caminho ou outro. A magnitute dessa diferença $\mathcal{P}=\left|\omega_{+}-\omega_{-}\right|$é chamada de previsibilidade (43). Segundo Englert (26), $\mathcal{P}$ e $V$ satisfazem a seguinte desigualdade:

$$
\mathcal{P}^{2}+V^{2} \leq 1
$$

onde $\mathrm{V}$ é a visibilidade do padrão de interferência que é determinada a partir da intensidade máxima e mínima da franja de interferência como

$$
V=\frac{I_{\max }-I_{\min }}{I_{\max }+I_{\min }}
$$

Além disso, uma outra maneira utilizada por (26) para quantificar esse princípio foi adicionar um detector de informação de caminho na sua configuração estendendo a formulação para uma usando a visibilidade, $V$, dos padrões de interferência para quantificar a natureza ondulatória e a distinguibilidade, $D$, entre os estados do detector dependendo do caminho da partícula, para quantificar sua natureza de partícula (44). A incompatibilidade entre essas duas medidas dão origem à desigualdade de complementaridade

$$
D^{2}+V^{2} \leq 1
$$

A igualdade nesses dois casos é garantida considerando a utilização de estados puros. Desta forma, os caminhos não podem ser distinguidos em absoluto se $D=0$, e eles podem ser mantidos completamente separados se $D=1$ (43). Os dois casos extremos $(V=1, D=0)$ e $(V=0, D=1)$ têm sido claramente confirmados por experimentos realizados com uma ampla gama de objetos quânticos, bem como na configuração de apagamento quântico (44).

Como vimos na seção anterior, o interferômetro de HOM mede o grau de ditinção entre os estados de entrada individuais diretamente através da visibilidade do interferograma. Esse conceito associado à desigualdade de complementaridade apresentada por Englert são utlizados para apresentação de uma medida experimental da distinguibilidade com base na distruibuição espectral dos pacotes de onda que descrevem os fótons em relação a visibilidade do padrão de interferência no interferômetro de HOM. 


\section{5}

\section{Fótons Únicos e Estados Coerentes Atenuados}

O interesse por métodos de geração de pulsos de luz contendo fótons únicos tem aumentado à medida que novos campos científicos de pesquisa se desenvolvem. Esses métodos encontram diversas aplicações no processamento óptico da informação quântica como, por exemplo, a criptografia quântica. Nesse contexto, a informação é codificada em propriedades fundamentais da luz e é necessário, portanto, que as fontes sejam capazes de manipular esses estados.

A criptografia quântica, ou mais precisamente a distribuição quântica de chaves (QKD, do ingês quantum key distribution), também utiliza métodos de geração de fótons únicos e já possuem relevância no mercado mundial, oferecendo um meio de compartilhamento seguro de chaves criptográficas para comunicação segura. A segurança da informação, nesse caso, é garantida no caso de pulsos de luz contendo fótons únicos serem transmitidos ou pelo menos pulsos com distribuições estatísticas que apresentem uma menor probabilidade de multi-fótons (pulsos com mais de um fóton).

Dentre os métodos utilizados para geração de fótons únicos, podemos destacar: pontos quânticos; vacâncias de nitrogênio no diamante; fontes gatilhadas baseadas no processo de SPDC; mistura de quatro ondas, (FWM, do inglês Four Wave Mixing); e processos ópticos lineares. A atenuação de lasers utilizada nesta tese é empregada como uma aproximação probabilística da emissão de fótons únicos. O estado que descreve os lasers podem ser caracterizados como tendo um número indefinido de fótons (64). Este estado é conhecido como estado coerente e pode ser definido como uma superposição de estados de Fock de $n$-fótons. A forma de onda do estado coerente é descrito pelo estado $|\alpha\rangle$ que pode ser obtido ao utilizarmos a relação de completeza do estado de Fock (64)

$$
|\alpha\rangle=\sum_{n}|n\rangle\langle n \mid \alpha\rangle
$$

Para calcularmos $\langle n \mid \alpha\rangle$ utilizamos a definição de que $\widehat{a}|\alpha\rangle=\alpha|\alpha\rangle$ e multiplicamos $\langle n|$ a esquerda, logo temos:

$$
\langle n|a| \alpha\rangle=\langle n|\alpha| \alpha\rangle
$$

Sabendo que,

$$
\widehat{a}^{\dagger}|n\rangle=\sqrt{n+1} \Rightarrow\langle n| \widehat{a}=\sqrt{n+1}\langle n+1|,
$$

podemos reescrever a relação da Eq.2-71 como:

$$
\sqrt{n+1}\langle n+1 \mid \alpha\rangle=\alpha\langle n \mid \alpha\rangle .
$$


Substituindo o número $n$ por $n-1$ :

$$
\langle n \mid \alpha\rangle=\frac{\alpha}{\sqrt{n}}\langle n-1 \mid \alpha\rangle .
$$

Pela iteração do último passo, isto é, substituindo novamente $n$ por $n-1$ na equação acima (64):

$$
\langle n \mid \alpha\rangle=\frac{\alpha^{2}}{\sqrt{n(n-1)}}\langle n-2 \mid \alpha\rangle=\ldots=\frac{\alpha^{n}}{\sqrt{n !}}\langle 0 \mid \alpha\rangle .
$$

Essa expanção pode então ser substuida na Equação para obtermos:

$$
|\alpha\rangle=\langle 0 \mid \alpha\rangle \sum_{n=0}^{\infty} \frac{\alpha^{n}}{\sqrt{n !}}|\alpha\rangle .
$$

Sendo $\langle 0 \mid \alpha\rangle$ dada por

$$
\langle 0 \mid \alpha\rangle=e^{-\frac{|\alpha|^{2}}{2}}
$$

, podemos escrever o estado coerente em termos de uma expansão exata no espaço Fock (64)

$$
|\alpha\rangle=e^{-\frac{|\alpha|^{2}}{2}} \sum_{n=0}^{\infty} \frac{\alpha^{n}}{\sqrt{n !}}|n\rangle,
$$

onde $|n\rangle$ é um estado característico da energia do $n$-fóton e $\left|\alpha^{2}\right|=\mu$ é o número médio de fótons em um intervalo de tempo. Em fontes de lasers atenuados o número de fótons em cada pulso segue uma distribuição estatística Poissoniana (65), ou seja, a probabilidade de se encontrar $n$ fótons em um pulso em um determinado intervalo de tempo contendo um número médio de $\mu$ fótons, é dada por:

$$
P(n \mid \mu)=\left\langle n\left|\alpha^{*} \alpha\right| n\right\rangle=\frac{\mu^{n} e^{(-\mu)}}{n !} .
$$

Estados coerentes atenuados são utilizados para geração de fótons únicos com uma probabilidade considerável (66). Nesse tipo fonte podemos apenas controlar o número médio de fótons por pulso $\mu$, já que o número de fótons $n$ é aleatório. Isto leva a pulsos com $n=0$ (pulsos vazios), $n=1$ (pulsos com apenas um fóton) e $n>1$ (pulsos com multi-fótons) (65). Ou seja, a decisão sobre o valor ideal de $\mu$ dependente da aplicação e é um compromisso entre pulsos com multi-fótons e pulsos vazios. Em criptografia quântica, por exemplo, pulsos vazios não são desejados, pois, têm o efeito de diminuir a taxa de transmissão, por outro lado, pulsos com dois ou mais fótons são uma ameaça à segurança da QKD, porque um intruso pode remover um dos fótons do pulso e obter informações da chave que está sendo transmitida sem ser detectado. Para que seja possível maximixar a segurança na QKD o valor de $\mu$ deve ser 
estabelecido de forma que a probabilidade de haver apenas um fóton por pulso seja muito maior que a probabilidade de haver mais de um fóton por pulso:

$$
P(n=1) \gg P(n>1) .
$$

Sendo, $P(n>1)=1-P(n=0)-P(n=1)$ e substituindo na Eq.2-80, temos que:

$$
P(n=1) \gg 1-P(n=0)-P(n=1) .
$$

Aplicando $n=0$ e $n=1$ na Eq.2-79, temos respectivamente as seguintes equações de probabilidade de pulsos vazios e pulsos contendo um único fóton:

$$
\begin{gathered}
p(n=0)=e^{(-\mu)} \\
p(n=1)=\mu e^{(-\mu)} .
\end{gathered}
$$

Considerando que é fundamental que a probabilidade de haver pulsos de luz com um único fóton seja muito maior do que a probabilidade de haver pulsos de luz com mais que um fóton e utilizando uma relação de $10 \%$ entre essas duas probabilidades, podemos escrever:

$$
\mu e^{(-\mu)}>10\left(1-e^{(-\mu)}-\mu e^{(-\mu)}\right) .
$$

Como podemos ver na Fig.2.8, os valores que satisfazem essa desigualdade estão na faixa de $0<\mu<0.1875$, esta faixa descreve a região de operação ideal em termos do número médio de fótons por pulso.

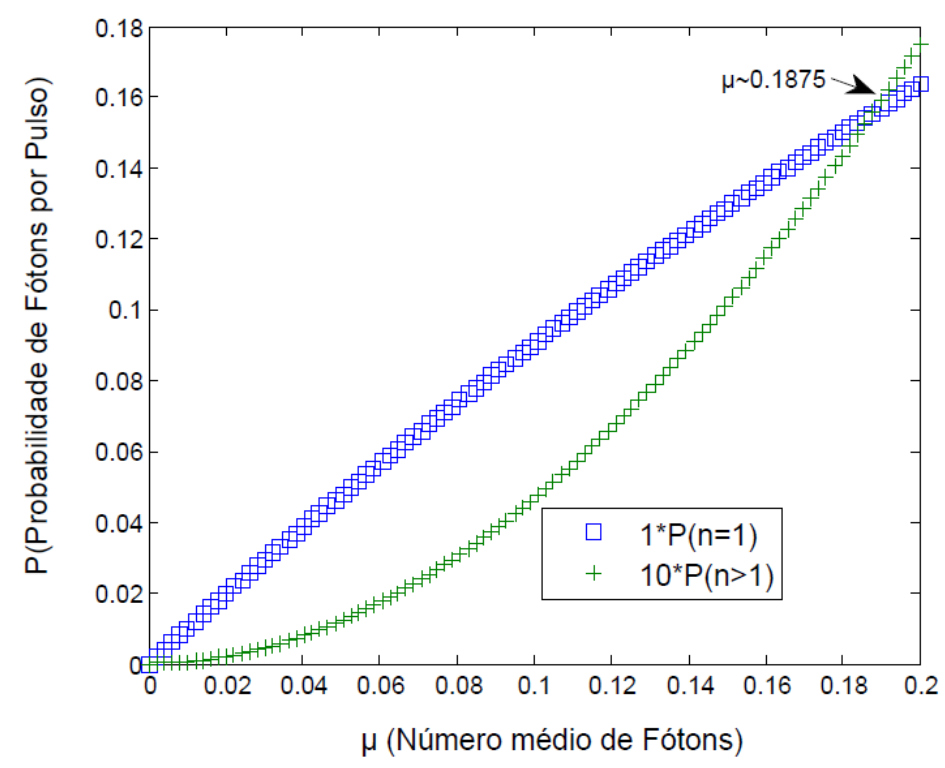

Figura 2.8: Número de fótons por pulso (67).

Para $\mu \approx 0.1$, temos a região que melhor descreve a desigualdade 
$P(n=1) \gg P(n>1)$. Ou seja, um valor típico para o número médio de fótons gerados em um pulso de luz de uma fonte atenuada para aplicações QKD é da ordem de 0.1 (20). A partir da Fig.2.9 podemos ver que se $\mu=0.1$, apenas aproximadamente $5 \%$ dos pulsos não vazios irão conter mais do que um fóton.

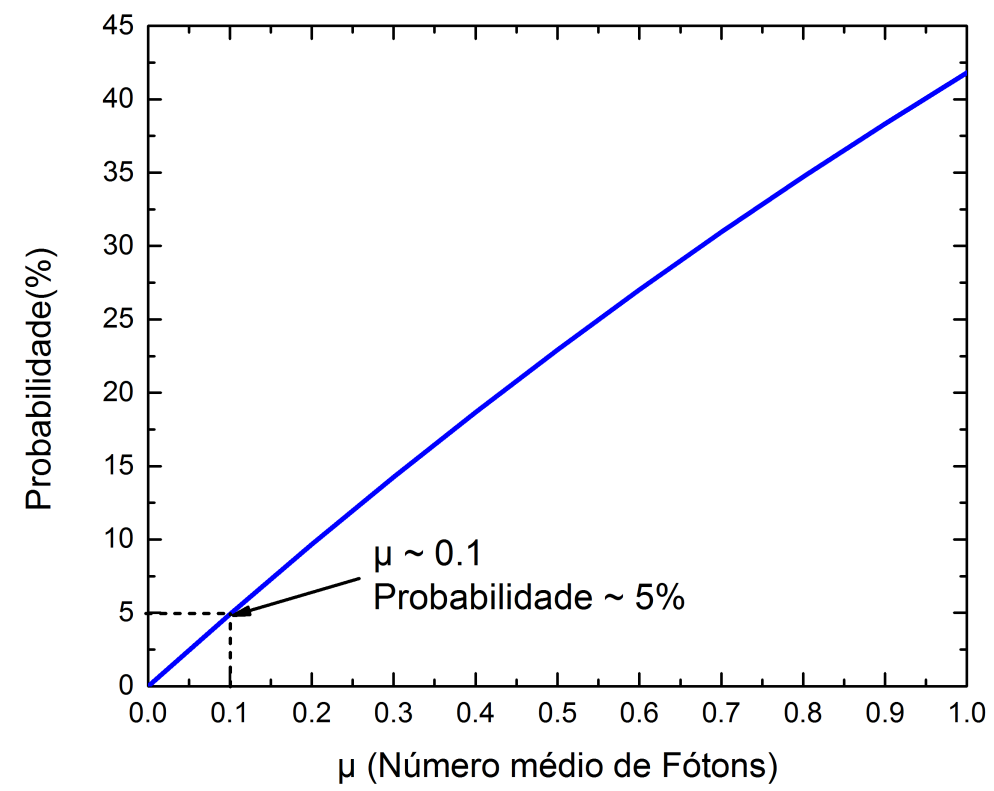

Figura 2.9: Probabilidade de um pulso não vazio contendo mais do que um fóton para diferentes valores de número médio de fótons $(67)$.

Se alimentamos um divisor de feixe com duas fontes WCSs com valores semelhantes de $\mu$, a probabilidade de encontrar um par de estados de Fock nos modos de entrada é dada por

$$
P(m, n \mid \mu)=\mu^{m+n} e^{\frac{(-2 \mu)}{(m ! n !)}} .
$$

A probabilidade de ambas as fontes emitirem um único fóton simultaneamente $P(1,1 \mid \mu)$, é igual à probabilidade de qualquer fonte emitir dois fótons enquanto a outra emite vácuo, $P(2,0 \mid \mu)+P(0,2 \mid \mu)$.

\section{6}

\section{Deslocamento de Frequência no Interferômetro de Hong-Ou-Mandel}

Como vimos, a experiência de interferência de dois fótons feita por Hong, Ou e Mandel mostra que quando dois fótons indistinguíveis passam por um divisor simétrico de feixe, cada fóton em um modo de entrada, eles tendem a se juntar. Além disso, como mencionado anteriormente, quando varremos o 
tempo relativo entre os pacotes de onda que descrevem os dois fótons à medida que são igualados no interferômetro HOM, veremos um efeito de interferência destrutiva na forma de um dip na taxa de contagem de coincidência. T.Legero e outros (68), demonstraram que fótons indistinguíveis deslocados em frequência geram um padrão de batimento que modula o padrão de interferência, e $(69,24)$ demonstraram a sua caracterização espectral no regime de poucos fótons. Para analisarmos o deslocamento de frequência no interferômeto de HOM, podemos utilizar um divisor de feixe simétrico com dois modos espaciais de entrada $\mathrm{A}$ e B e dois modos espaciais de saída C e D.

\subsection{1}

\section{Modos Espaço-Temporais}

De acordo com T.Legero e outros (62), os pacotes de onda de um único fóton no domínio espaço-tempo não podem ser descritos pelos operadores de criação. Desta forma, podemos considerar uma nova descrição para pacotes de onda de um único fóton que chegam ao BS. Nessa aborgagem, os operadores de campo são definidos por funções unidimensionais em modos espaço-temporais rotulados pelo índice $\mathrm{k}$

$$
\xi_{k}(z, t)=\varepsilon\left(t-\frac{z}{c}\right) e^{-i \varphi_{k}\left(t-\frac{z}{c}\right)} .
$$

A coordenada espacial z pode ser omitida colocando o divisor de feixe em $\mathrm{z}=0(62)$

$$
\xi_{k}(t)=\varepsilon_{k}(t) e^{-i \varphi_{k}(t)},
$$

onde $\varepsilon_{k}(t)$ e $\varphi_{k}(t)$ são a amplitude e a fase, respectivamente. Essa descrição da função de onda de cada fóton pode ser combinada aos operadores de criação, para obtermos os operadores campo elétrico

$$
\widehat{E}_{k}^{+}(t)=\xi_{k}(t) \widehat{a}_{k} \therefore \widehat{E}_{k}^{-}(t)=\xi_{k}^{*}(t) \widehat{a}_{k}^{\dagger} .
$$

Nós podemos relacionar os operadores campo elétrico às portas de entrada do BS

$$
\begin{aligned}
& \widehat{E}_{A}^{+}(t)=\xi_{A}(t) \widehat{a}_{A} \therefore \widehat{E}_{A}^{-}(t)=\xi_{A}^{*}(t) \widehat{a}_{A}^{\dagger} \\
& \widehat{E}_{B}^{+}(t)=\xi_{B}(t) \widehat{a}_{B} \therefore \widehat{E}_{B}^{-}(t)=\xi_{B}^{*}(t) \widehat{a}_{B}^{\dagger} .
\end{aligned}
$$

Além disso, os operadores de campo elétrico podem ser definidos relacionando as portas de entrada e saída do divisor de feixe $(62,30)$. Logo, os modos de entrada podem ser escritos como: 


$$
\begin{aligned}
\widehat{E}_{A}^{+}(t) & =\frac{i \widehat{E}_{C}^{+}+\widehat{E}_{D}^{+}}{\sqrt{2}}=\frac{i \xi_{C}(t) \widehat{a}_{C}+\xi_{D}(t) \widehat{a}_{D}}{\sqrt{2}} \\
\widehat{E}_{B}^{+}(t) & =\frac{\widehat{E}_{C}^{+}+i \widehat{E}_{D}^{+}}{\sqrt{2}}=\frac{\xi_{C}(t) \widehat{a}_{C}+i \xi_{D}(t) \widehat{a}_{D}}{\sqrt{2}} .
\end{aligned}
$$

E os modos espaciais-temporais da saída do divisor do feixe:

$$
\begin{gathered}
\widehat{E}_{C}^{+}(t)=\frac{-i \widehat{E}_{A}^{+}+\widehat{E}_{B}^{+}}{\sqrt{2}}=\frac{-i \xi_{A}(t) \widehat{a}_{A}+\xi_{B}(t) \widehat{a}_{B}}{\sqrt{2}} \\
\widehat{E}_{D}^{+}(t)=\frac{\widehat{E}_{A}^{+}-i \widehat{E}_{B}^{+}}{\sqrt{2}}=\frac{\xi_{A}(t) \widehat{a}_{A}-i \xi_{B}(t) \widehat{a}_{B}}{\sqrt{2}} .
\end{gathered}
$$

\subsection{2}

\section{Coincidências na Saída do Divisor de Feixe}

Ao restringirmos a análise em até dois fótons, os possívies estados de entrada são: $|1,1\rangle_{A, B},|2,0\rangle_{A, B}$ e $|0,2\rangle_{A, B}$. No primeiro caso, dois fótons únicos entram no divisor de feixe, sendo que cada um vem de uma fonte WCS (69). O estado de entrada desses fótons pode ser escrito como $\left|\psi_{i n}\right\rangle=|1,1\rangle_{A, B}=$ $\widehat{a}_{A}^{\dagger} \widehat{a}_{B}^{\dagger}|0,0\rangle$. Para obtermos a probabilidade de detecção coincidente de um fóton no modo espacial de saída $\mathrm{C}$ em $t=\tau_{0}$ e outro no modo $\mathrm{D}$ em $t=\tau_{0}+\tau$, precisamos usar os operadores campo elétrico $\widehat{E}_{C}^{ \pm}\left(\tau_{0}\right)$ e $\widehat{E}_{D}^{ \pm}\left(\tau_{0}+\tau\right)(62)$. Logo,

$$
P_{C, D}^{1,1}\left(\tau_{0}, \tau\right)=\left\langle\psi_{i n}\left|\widehat{E}_{C}^{-}\left(\tau_{0}\right) \widehat{E}_{D}^{-}\left(\tau_{0}+\tau\right) \widehat{E}_{D}^{+}\left(\tau_{0}+\tau\right) \widehat{E}_{C}^{+}\left(\tau_{0}\right)\right| \psi_{\text {in }}\right\rangle
$$

Usando a definição da Eq. 2-93 e 2-94, somos levados a

$$
P_{C, D}^{1,1}\left(\tau_{0}, \tau\right)=\frac{1}{4}\left[\xi_{A}\left(\tau_{0}+\tau\right) \xi_{B}\left(\tau_{0}\right)-\xi_{A}\left(\tau_{0}\right) \xi_{B}\left(\tau_{0}+\tau\right)\right]^{2}
$$

A equação acima pode ser expandida para os envelopes e fases dos modos espaço-temporais (69):

$$
\begin{gathered}
P_{C, D}^{1,1}\left(\tau_{0}, \tau\right)=\frac{1}{4} \varepsilon_{A}^{2}\left(\tau_{0}+\tau\right) \varepsilon_{B}^{2}\left(\tau_{0}\right)+\frac{1}{4} \varepsilon_{A}^{2}\left(\tau_{0}\right) \varepsilon_{B}^{2}\left(\tau_{0}+\tau\right) \\
-\frac{1}{2} \varepsilon_{A}\left(\tau_{0}\right) \varepsilon_{B}^{2}\left(\tau_{0}\right) \varepsilon_{A}\left(\tau_{0}+\tau\right) \varepsilon_{B}^{2}\left(\tau_{0}+\tau\right) \cos \left[\varphi_{A}\left(\tau_{0}\right)-\varphi_{A}\left(\tau_{0}+\tau\right) \varphi_{B}\left(\tau_{0}+\tau\right)\right] .
\end{gathered}
$$

Quando temos dois fótons vindo do mesmo modo de entrada do BS os estados de entrada desses respectivos fótons são dados por $\left|\psi_{i n}\right\rangle=|2,0\rangle_{A, B}=$ $\widehat{a}_{A}^{\dagger} \widehat{a}_{A}^{\dagger}|0,0\rangle$ e $\left|\psi_{\text {in }}\right\rangle=|0,2\rangle_{A, B}=\widehat{a}_{B}^{\dagger} \widehat{a}_{B}^{\dagger}|0,0\rangle$. Logo, podemos fazer uma avaliação semelhante para $P_{C, D}^{2,0}\left(\tau_{0}, \tau\right)$ e $P_{C, D}^{0,2}\left(\tau_{0}, \tau\right)(69)$.

\subsection{3}

\section{Batimento Auto-Heteródino entre Estados Coerentes Atenuados}

Para ilustrarmos o sinal de batimento quântico oriundo de fontes WCS que emitem dois fótons com frequência ligeiramente diferentes, podemos con- 
siderar o caso de dois fótons polarizados em paralelo com pacotes de onda gaussianos incidindo sobre um divisor de feixe 50:50 com um tempo de atraso relativo $\delta_{\tau}$ e com uma diferença de frequência $\Delta=\omega_{B}-\omega_{A}$ (62). Os pacotes de onda com dois modos de frequências bem definidos $\omega_{A}$ e $\omega_{B}$ são descritos pelas funções do modo espaço-temporal:

$$
\begin{aligned}
& \xi_{A}(t)=\frac{1}{\sqrt[4]{\pi \sigma^{2}}} e^{-\left(t-\frac{\delta_{\tau}}{2}\right)^{2} /\left(2 \sigma^{2}\right)} e^{-i\left(\omega-\frac{\Delta}{2}\right) t} \\
& \xi_{B}(t)=\frac{1}{\sqrt[4]{\pi \sigma^{2}}} e^{-\left(t-\frac{\delta_{\tau}}{2}\right)^{2} /\left(2 \sigma^{2}\right)} e^{-i\left(\omega+\frac{\Delta}{2}\right) t}
\end{aligned}
$$

onde $\omega=\left(\omega_{A}+\omega_{B}\right) / 2$ e $\sigma$ é a meia largura em $\frac{1}{e}$ do pacote de onda. O modelo de probabilidade de coincidência de batimento quântico entre WCS, após normalização, é dado por

$$
P_{\text {coinc }}(\tau)=\frac{1}{2}-\frac{1}{4} e^{\frac{-\tau^{2}}{2 \sigma^{2}}} \cos (\tau \Delta)
$$

onde $\tau$ é a diferença de tempo entre os modos de saída do divisor de feixe (69). A Fig.2.10 apresentada por T.F. da Silva e outros em (69) exibe uma montagem experimental que é composto por duas WCSs com potência óptica idêntica e estado de polarização iguais. A técnica auto-heteródina utilizada neste experimento combina modulação de frequência e amplitude para variar a diferença de frequências ópticas entre o $\mathrm{WCS}_{1}$ e $\mathrm{WCS}_{2}$ por uma quantidade controlável. Nesta configuração, a diferença de frequência $\Delta$ entre os fótons que

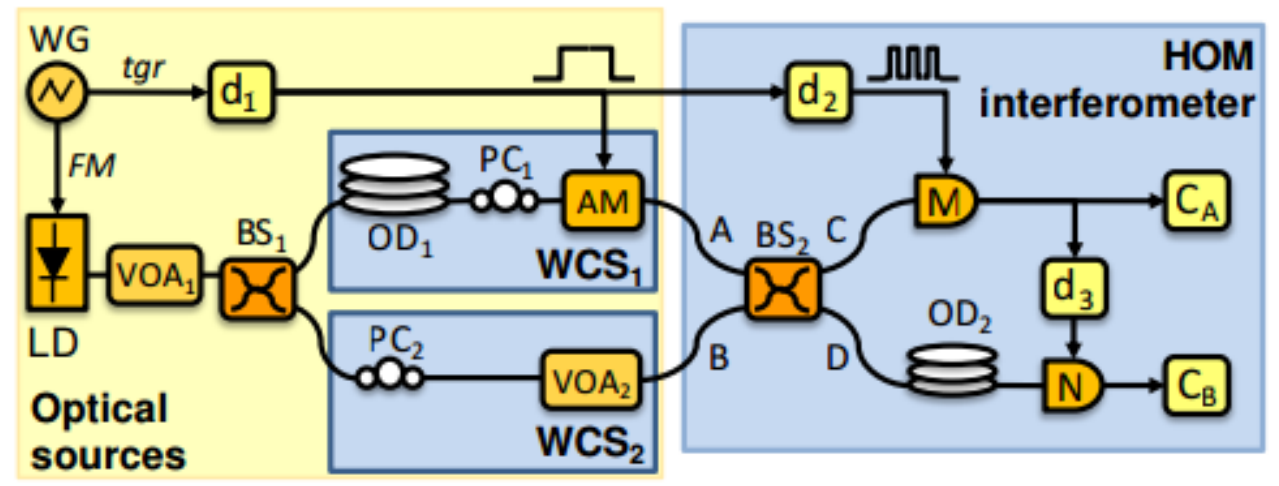

Figura 2.10: Configuração experimental para WCSs deslocados por frequência criados através de uma configuração baseada em FM auto-heteródino. LD: diodo laser; WG: gerador de forma de onda; VOA: atenuador óptico variável; d: gerador de retardo; OD: atraso óptico; PC: controlador de polarização; AM: modulador de amplitude (69).

emergem dos dois braços do $\mathrm{BS}_{2}$ foi controlada através da escolha apropriada da profundidade de modulação $\mathrm{A}$ e do período $\mathrm{T}$ do diodo laser modulado 
em frequência (FM, do inglês Frequency Modulation) com uma forma de onda triangular simétrica, assim como ilusta a Fig.2.11 (52).

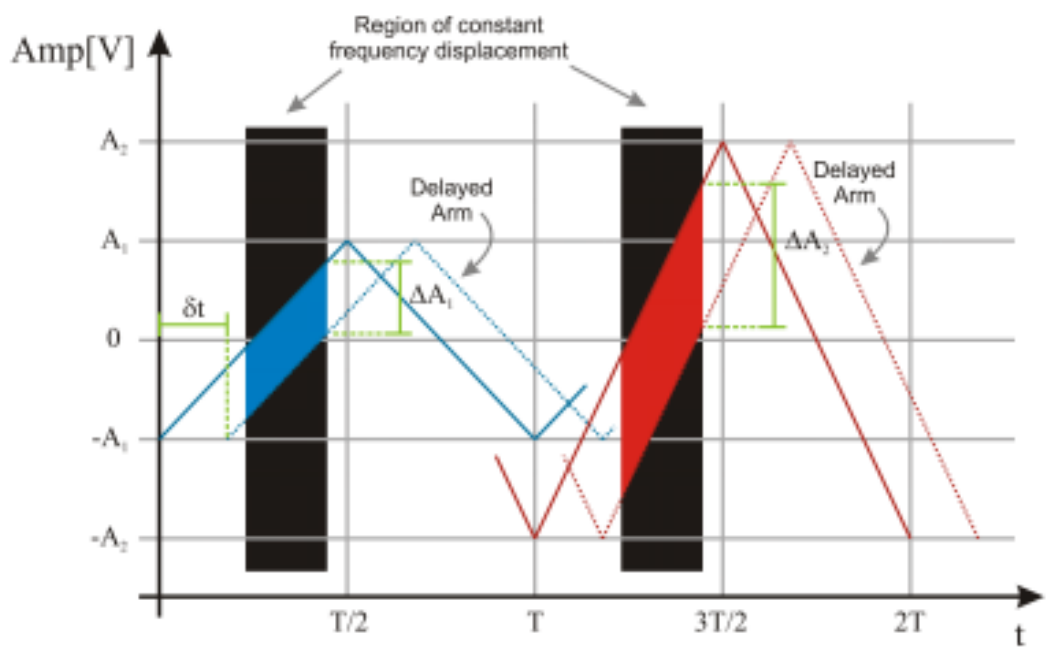

Figura 2.11: Chegada dos pulsos de luz modulados em frequência no interferômetro HOM. Dependendo da amplitude da onda triangular moduladora, do seu período e do atraso da fibra, o deslocamento de frequência no interferômetro HOM irá variar. (52)

Os resultados presentes em (69) Fig.2.12, mostram o padrão de interferência medido para diferentes deslocamentos de frequência entre os WCSs, variando de zero a $200 \mathrm{MHz}$, com passos de $40 \mathrm{MHz}$.

Além disso, para cada uma dessas configurações o espectro de batimento clássico entre as fontes ópticas deslocadas em frequência foi verificado através de um analisador de espectro elétrico (ESA, do inglês Electrical Spectrum Analyzer) colocado em um modo de saída de $\mathrm{BS}_{2}$. Através do ajuste dos dados obtidos na Fig.2.12 ao modelo apresentado na Eq. 2-100, os parâmetros $\Delta$ (frequência central) e $\sigma$ foram extraídos e utilizados para o a criação de curvas gaussianas que se aproximam da batida clássica. Os resultado apresentados na Fig. 2.13 mostram que há uma alta correspondência entre o interferograma do padrão de interferência obtido através da contagens de coincidência no interferômetro de HOM e o espectrograma obtido a partir do batimento das fontes ópticas observado no ESA.

\subsection{4}

\section{Espectroscopia de Transformada de Fourier de Poucos Fótons}

Uma técnica distinta para caracterização espectral de WCSs desenvolvida por (24) utiliza um processo conhecido como espectroscopia de transformada de Fourier (do inglês Fourier-Tranform Spectroscopy) (70). A Fig.2.14 apresenta 


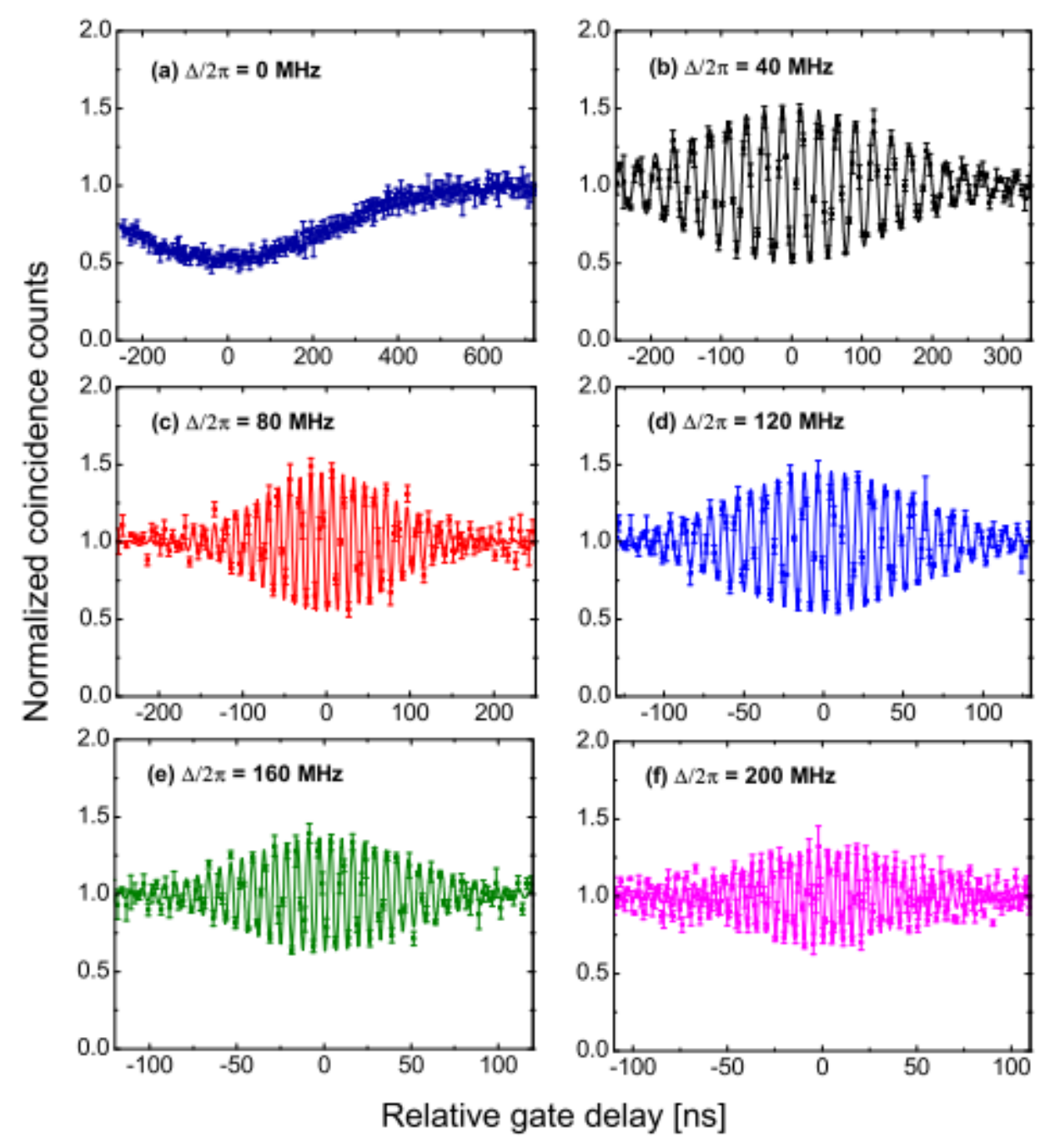

Figura 2.12: Padrão de interferência de WCS deslocados em frequência (a) 0 MHz, (b) $40 \mathrm{MHz}$, (c) $80 \mathrm{MHz}$, (d) $120 \mathrm{MHz}$, (e) $160 \mathrm{MHz}$, (F) $200 \mathrm{MHz}$ (69).

a configuração experimental auto-heteródina utilizada neste trabalho para caracterização espectral de WCSs deslocados em frequência. Esta configuração exibe uma ligeira diferença à apontada por (69), Fig.2.10 que está relacionada principalmente ao fato de que os lasers não estão sendo modulados em frequência.

A partir desta configuração, G.C. do Amaral e outros (24) obtiveram o padrão de interferência de HOM dos pacotes de onda de dois fótons com WCSs. Um dos estados de entrada foi nomeado como estado de referência e outro estado como teste, Fig.2.15. A fonte de geração do estado de referência utilizada foi um díodo laser de cavidade externa estabilizado em frequência através de uma célula de gás em $1547.32 \mathrm{~nm}$ e a fonte de teste um laser de comprimento de onda sintonizável. Os WCSs foram deslocados por uma frequência de $40 \mathrm{MHz}$ e o interferograma foi adquirido varrendo o atraso relativo entre os detectores 


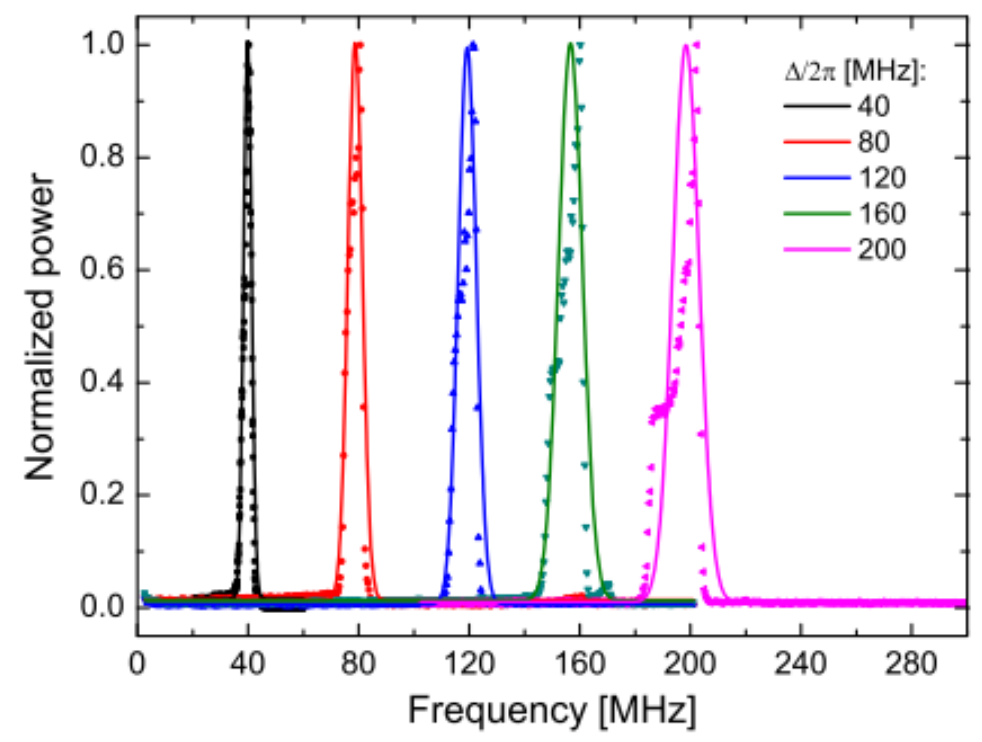

Figura 2.13: Espectro de batida adquirido com ESA para diferentes delocamentos frequência entre fontes ópticas. As linhas correspondem ao ajuste gaussiano (69).

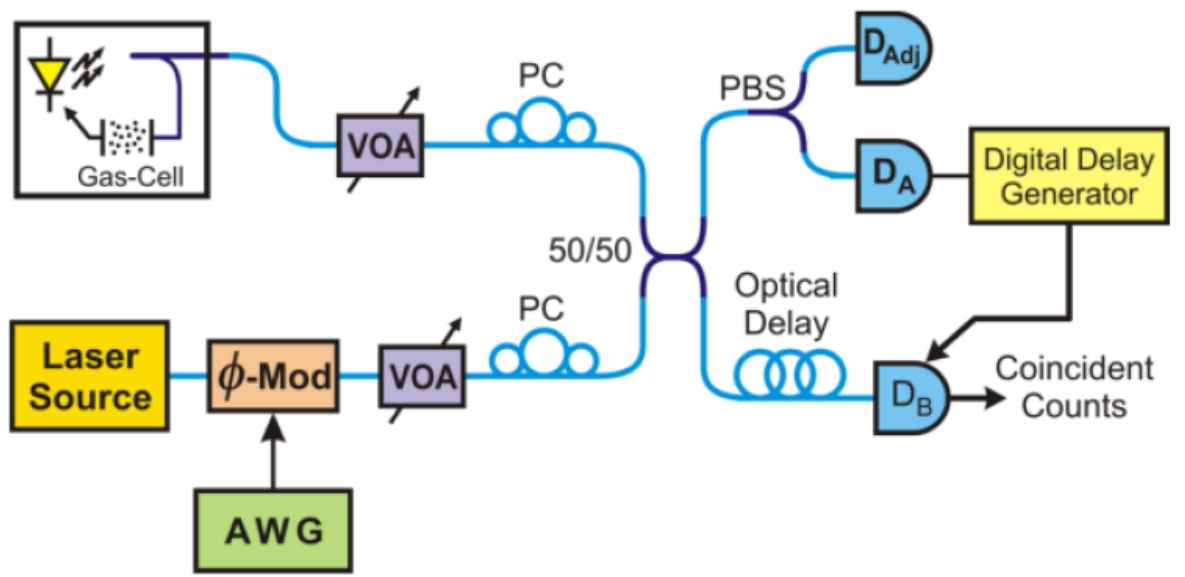

Figura 2.14: Configuração experimental do método de espectroscopia de poucos fótons. VOA: atenuador óptico variável; PC: controlador de polarização; AWG: gerador de forma de onda arbitrário; $\phi-M o d$ : modulador de fase; PBS: divisor de feixe por polarização; Dn: detector de fóton único(24).

no interferômetro de HOM.

$\mathrm{Na}$ seção I.1 apresentamos a equação de interferência de duas ondas parcialmente coerentes. Esta equação pode ser escrita em termos da densidade espectral de potência, $S(\nu)$, para $I_{1}=I_{2}(70)$, temos que:

$$
I(\tau)=2 \int_{0}^{\infty} S(\nu)[1+\cos (2 \pi \nu \tau)] d \nu
$$

onde $\tau$ é o atraso temporal relativo entre os dois pacotes de onda ópticos. 


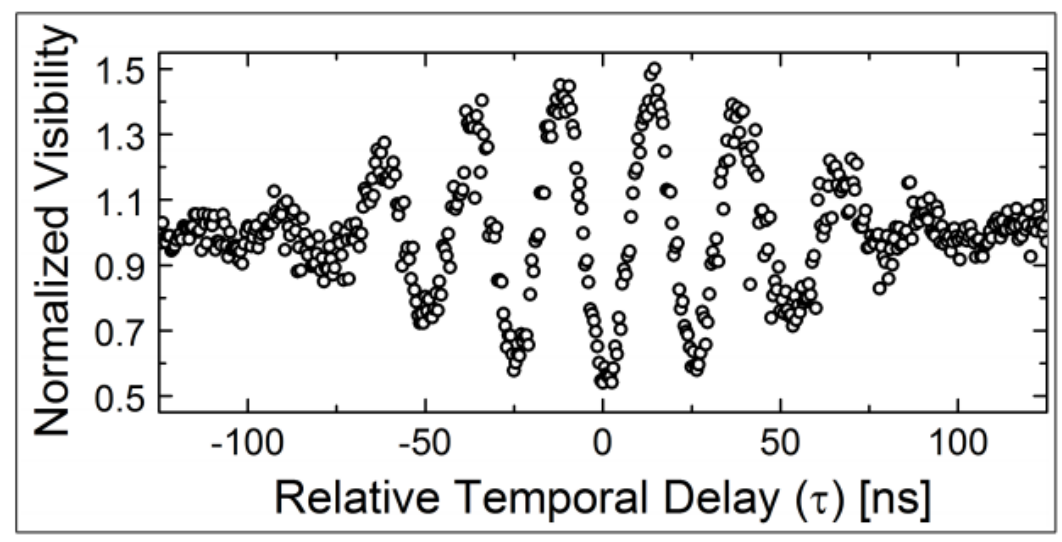

Figura 2.15: Padrão de interferência de HOM entre dois pacotes de onda com estados coerentes atenuados nomeados de referência e teste com deslocamento de frequência de $40 \mathrm{MHz}(24)$.

Segundo G.C. do Amaral e outros (24), a partir desse resultado, podemos através do processo de espectroscopia de transformada de Fourier determinar o espectrograma do batimento de duas fontes de luz, tomando a transformada rápida de Fourier (FFT, do inglês Fast Fourier Transform) inversa do respectivo interferograma. A sobreposicão entre os espectros obtidos através da técnica de espectroscopia da transformada de Fourier de poucos fótons e o espectograma clássico para diferentes valores de deslocamentos de frequencias entre WCSs estão presentes na Fig.2.16 (24).

Os pacotes de onda temporais que descrevem cada um dos dois pulsos de poucos fótons, denominados de $f_{1}(t)$ e $f_{2}(t)$ são determinados por:

$$
\begin{aligned}
& f_{1}(t)=\frac{1}{\sqrt{2 \pi}} \int \phi_{1}(\omega) e^{-i \omega t} d \omega \\
& f_{2}(t)=\frac{1}{\sqrt{2 \pi}} \int \phi_{2}(\omega) e^{-i \omega t} d \omega .
\end{aligned}
$$

No contexto de mecânica quântica, a probabilidade de detecção conjunta entre os detectores é definido pela coerência mútua dos pacotes de onda $g_{A, B}$ onde a expressão matemática dependente dos pacotes de onda temporais $f_{1}(\mathrm{t})$ e $f_{2}(\mathrm{t})(24)$ :

$$
g_{A, B}\left(t_{0}, \tau\right)=\frac{1}{4}\left|f_{1}\left(t_{0}+\tau\right) f_{2}(t)-f_{1}(t) f_{2}\left(t_{0}+\tau\right)\right|^{2} .
$$

A caracterização espectral de fontes ópticas no regime de poucos fótons pode ser realizada pela transformada de Fourier do interferograma de dois fótons. A Eq. 2-105 define a espectroscopia da transformada de fourier de poucos fótons (Few-Photon FTS, do inglês Few-Photon Fourier Transform Spectroscopy) (24) : 


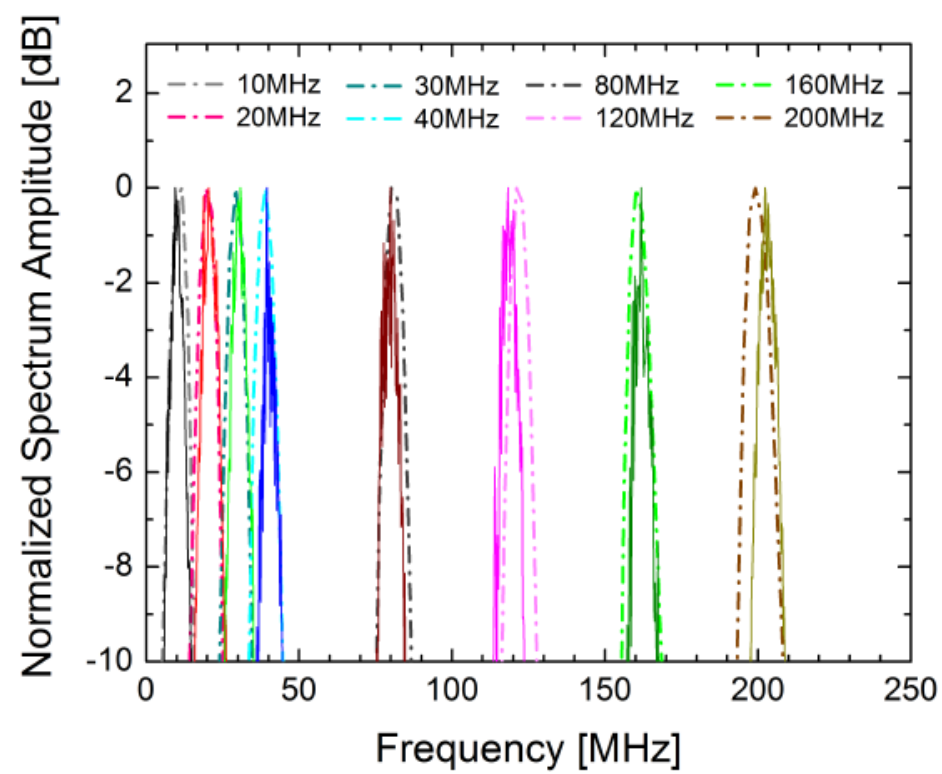

Figura 2.16: Resultados da espectroscopia de transformada de Fourier: poucos fótons (linhas tracejadas) e espectograma clássico (linhas contínuas). As FFTs dos interferogramas de poucos fótons são comparados aos espectrogramas de luz brilhante adquiridos no ESA para diferentes valores de deslocamento de frequência (24).

$$
\left|\phi_{1}(\omega) * \phi_{2}(\omega)\right|^{2} \simeq \Im \int_{-\infty}^{\infty} g_{A, B}\left(t_{0}, \tau\right) d t_{0} .
$$

Os resulados apresentados por G.C do Amaral (24) mostraram que a transformada de Fourier do interferograma da interferência de dois fótons em um interferômetro de Hong-OuMandel pode ser associada a forma espectral dos pacotes de onda interferentes.

\section{7}

\section{Detectores de Fótons Únicos}

Nas últimas décadas observamos um aumento considerável no interesse em tecnologias de geração de fótons únicos. Uma das principais causas desta tendência foi o crescimento de aplicações de informação quântica, tais como a distribuição quântica de chave. Contudo, o estudo e o desenvolvimento de técnicas de geração de fótons únicos, não seriam relevantes se não fossemos capazes de detectar eficientemente esses fótons. Para tal, temos mais comumente a utilização de detectores de fótons únicos com tecnologia baseada em fotodiodo avalanche (SPADs, do inglês Single-Photon Avalanche Photodiodes) que é mais amplamente difundido, devido a sua praticidade na utilização. No entanto, além desta tecnologia existem outros dispositivos capazes de detectar fótons únicos, como por exemplo, os detectores de tubos fotomultiplicadores 
(PMT, do inglês Photomultiplier Tubes) e os detectores de fótons únicos supercondutores (SSPD, do inglês Superconducting Single-Photon Detector). Para o desenvolvimento experimental desta tese utilizamos os SSPDs que não possuem uma tecnologia profundamente difundida e que foram a partir desse trabalho pela primeira vez utilizados em nossos laboratórios, mas que apresentam vantagens que serão discutidas nas próximas seções.

A seguir apresentaremos maneiras de quantificar o desempenho dos detectores de fóton único com foco em SSPDs, além dos progressos realizados na melhoria das principais tecnologias de detecção desses fótons.

\subsection{1}

\section{Detectores de Fótons Únicos de Nanofio Supercondutores}

Os detectores de fótons únicos supercondutores, surgiram através do desenvolvimento do bolômetro que pode ser considerado um tipo de detector. Este dispositivo foi originalmente utilizado em 1878, por Samuel Pierpont Langley, com o objetivo de medir a energia incidente dos fótons através de efeitos térmicos (71). Em 1957, pesquisadores da Universidade Johns Hopkins desenvolveram um bolômetro baseado no supercondutor de Nitreto de Nióbio (NbN) (72). Nos anos seguintes, Bertin e Rose criaram um bolômetro de NbN de filme fino (73), basedo no trabalho de Andrews e Strandberg (74) e Von Gutfeld e outros (75) com supercondutores de película fina. Contudo, o salto de bolômetro como detector de fóton único foi dado apenas em 1991 por Gol'tsman e outros (76). Este dispositivo ficou conhecido como detector supercondutor de fóton único (SSPD) ou detector de fóton único de nanofios supercondutores (SNSPD, do inglês Superconducting Nanowire Single-Photon Detector) (77). Já em 2001, Gol'tsman e outros demonstraram a sensibilidade de fótons únicos em $\lambda=790 \mathrm{~nm}$ no nanofio supercondutor de $\mathrm{NbN}$ com corrente polarizada mantido a uma temperatura de $4.2 \mathrm{~K}$. Este dispositivo possuia carateristicamente $200 \mathrm{~nm}$ de largura, $5 \mathrm{~nm}$ de espessura, $1 \mu \mathrm{m}$ de comprimento (78).

Nas últimas décadas grupos de pesquisa em todo o mundo assumiram o desafio de melhorar o desempenho do SNSPD. Essas investigações intensivas tiveram como objetivo o desenvolvimento de uma estrutura de detector pronta para aplicação. A Fig.2.17, apresenta alguns avanços importantes na evolução dos designs do SNSPD (79). A primeira demonstração de um SNSPD está representada na Fig.2.17 (a), onde temos uma imagem de microscopia de força atômica (AFM, do inglês Atomic-Force Microscopy) do primeiro nanofio de NbN que possuia $1.3 \mu \mathrm{m}$ x $225 \mathrm{~nm} \mathrm{NbN}$ (79). Para melhorar a eficiência de acoplamento óptico e, consequentemente, a eficiência de detecção, pesquisado- 
res criaram uma estrutura chamada "Meandro SNSPD". Com essa estrutura drobrou-se o nanofio para cobrir áreas maiores do detector. Uma imagem de micrografia eletrônica de varredura (SEM, do inglês Scanning Electron Micrograph) dessa estrutura está presente na Fig.2.17 (b) (79). A eficiência de detecção pode ainda ser limitada pela baixa probabilidade de absorção dos supercondutor estreitos (80). A incorporação do nanofio em uma cavidade óptica têm sido utilizada para aumentar essa eficiência Fig.2.17 (c). Além disso, para obter uma melhor resolução no número de fótons, estão sendo desenvolvidos projetos de dispositivos multi-pixel assim como apresenta a Fig.2.17 (d)(79). Outra evolução dos SSPDs está sendo na utilização de nanofios ultra-finos (30 nm de largura) conectados em paralelo para melhorar a sensibilidade (eficiência de registro) do SNSPD Fig.2.17 (e) (79). A Fig.2.17 (f) apresenta um forma modificada de incidir luz no detector, através de um guia de onda ao longo do nanofio na parte superior. O campo evanescente do modo no guia de onda estende-se para o NbN e provoca uma probabilidade de absorção finita (80). Portanto, também são utilizados para melhora da eficiência de absorção.

\subsubsection{1 \\ Características dos Detectores de Fótons Único de Nanofio Supercondu- tores}

Os detector de fótons únicos podem ser avaliados através de parâmetros tais como: taxa de contagem de escuro (DCR, do inglês Dark Count Rate), tempo morto, eficiência de detecção, faixa espectral e tempo de jitter. A seguir serão apresentados resumidamente os principais conceitos dos parâmetros que definem esses dispositivos, com ênfase nos SSPDs:

- Taxa de Contagem de Escuro: Grande parte das tecnologias tem a probabilidade de registrar contagens falsas, que são oriundas das propriedades dos materiais do detector, das condições de polarização ou da susceptibilidade ao ruído externo (77). Essa taxa indica a média de contagens registradas sem qualquer luz incidente e determina a taxa de contagem mínima na qual o sinal é causado predominantemente por fótons reais.

Nos detectores SSPDs a taxa de contagem de escuro depende da corrente de polarização e da temperatura, a Fig.2.18 apresenta essa relação. Apesar disso, em relação a outros detectores de fóton únicos as contagens escuras nos SSPDs geralmente são baixas em comparação à sua eficiência (81).

- Tempo Morto: Define-se como o intervalo de tempo após o detector absorver um fóton. Nesse intervalo este dispositivo torna-se incapaz de registar um segundo fóton com confiabilidade. Os fatores que influenciam o tempo morto dependem fortemente do tipo de detector (77). No detector de fótons 


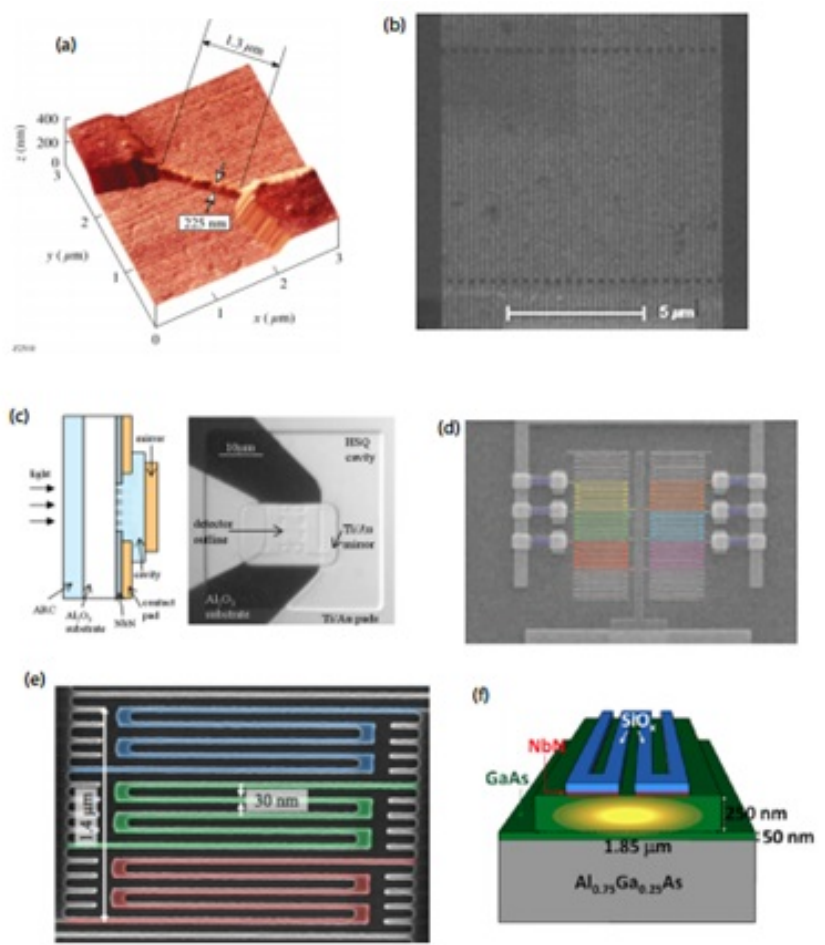

Figura 2.17: (a) Imagem AFM do primeiro nanofio de NbN com $1.3 \mu \mathrm{m} \mathrm{x}$ $225 \mathrm{~nm}$. (b) Imagem SEM do "Meandro SNSPD" de NbN cobrindo uma área grande de $10 \mu \mathrm{m}$ x $10 \mu \mathrm{m}$. (c) Um "Meandro SNSPD" de NbN com $3 \mu \mathrm{m}$ x $3 \mu \mathrm{m}$ incorporado à uma cavidade óptica. (d) Múltiplos elementos de nanofio são polarizados em paralelo através de resistências independentes, resultando em um maior resolução número de fótons. (e) Nanofios ultra-finos (30 nm de largura) são conectados em paralelo para melhorar a sensibilidade (eficiência de registro) do SNSPD. (f) Um SNSPD fabricado sobre uma estrutura de guia de ondas ópticas para melhorar a eficiência do acoplamento óptico (79).

ideal não haveria este tempo morto, e a duração do intervalo entre duas janelas de detecção dependeria da rapidez de pulsação do laser. Em sistemas reais, em muitos casos o tempo morto é consequência do circuito de bias ou da eletrônica utilizada e não apenas do próprio elemento do detector.

Nos SSPDs o tempo de detecção é definido pelas suas propriedades elétricas e térmicas e o equilíbrio entre essas propriedades determina se o SSPD estará pronto para receber uma nova detecção. Para isto, o tempo de resfriamento após um evento de detecção deve ser suficientemente rápido em comparação com o tempo que leva para a corrente diminuir e retornar no SSPD. Sendo assim, a constante de tempo elétrica não pode baixar indefinidamente. Em um fio $\mathrm{NbTiN}$ de $500 \mu \mathrm{m}$ de comprimento, por exemplo, o tempo morto é determinado pelo indutância cinética do nanofio que é proporcional ao comprimento do nanofio dividido pela área da seção transversal do nanofio e pela impedância da carga à qual está conectado, isso devido ao 


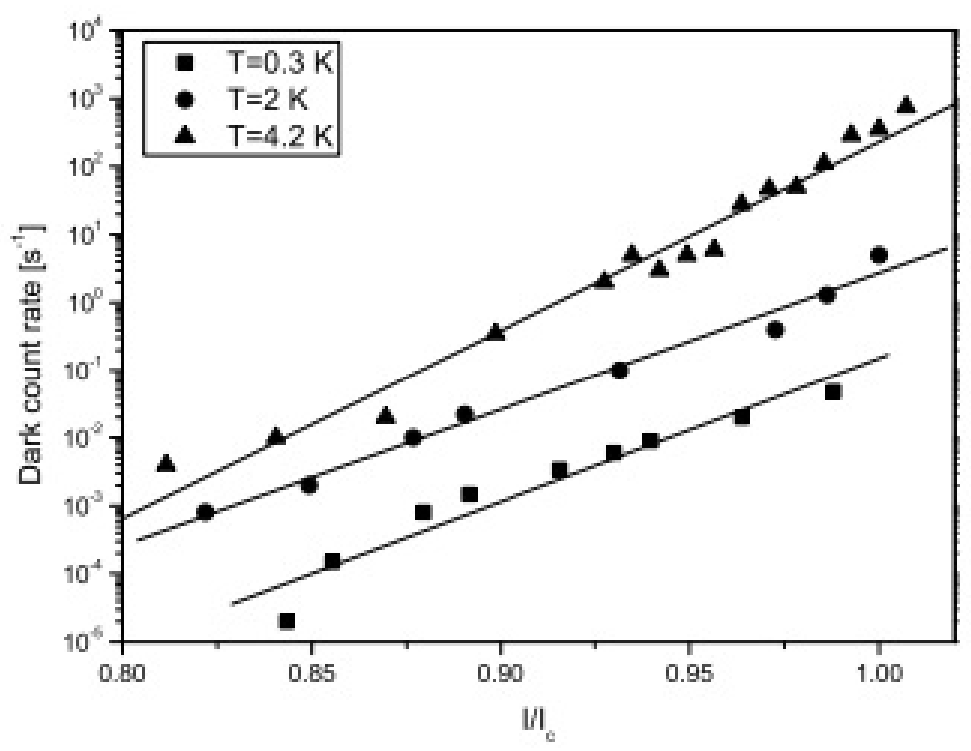

Figura 2.18: Contagem de escuro do NbTiN SSPDs (81).

resfriamento que é muito mais rápido do que a constante de tempo elétrica (81). Nesses dispositivos, é possível reduzir as constantes elétricas de tempo, por exemplo, aumentando a impedância vista pelos detectores, no entanto, devido às propriedades do material que limitam as constantes térmicas, temos um limitante inferior no tempo de reposição. Diferentes materiais e substratos estão sendo investigados para a produção de SSPDs com constantes térmicas reduzidas (81).

- Eficiência de Detecção $(\eta)$ : É a fração de fótons incidentes que são registrados como uma contagem quando o mesmo chega ao detector (77). Tanto a taxa de contagem máxima no detector como o número médio de fótons nesse dispositivo governam a taxa máxima na qual um fóton pode ser registrado.

Na prática, a eficiência de detecção deve considerar tanto o produto de perdas de acoplamento $\eta_{\text {loss }}$ através de óptica de espaço livre ou fibras ópticas, como a eficiência quântica intrínseca do detector $\eta_{\text {det }}$, tal que

$$
\eta=\eta_{\text {loss }} \cdot \eta_{\text {det }}
$$

Para que $\eta$ seja medido com precisão, deve-se considerar a taxa de contagem de escuro do detector, o tempo morto, além da eletrônica de contagem (77).

Nos SSPDs para o cálculo da eficiência, podemos visualizar uma mudança quando comparada a outros detectores. Nesse caso,

$$
\eta=\eta_{\text {loss }} \cdot \eta_{A} \cdot \eta_{\text {det }}
$$


onde $\eta_{A}$ é a eficiência de absorção de fótons do nanofio supercondutor. Esse fator depende das propriedades de absorção do nanofio, que depende das camadas circundantes, isto é, do substrato e das camadas de revestimento (81).

\section{- Faixa Espectral}

Um detector de fótons únicos só é sensível ao longo de uma determinada faixa espectral, já que cada material que o constitui possui um tipo de dependência distinta, sendo alguns mais sensíveis para certas regiões do espectro do que outros (77). Valores muitos comuns de tecnologias disponíveis já existentes são $780 \mathrm{~nm}, 850 \mathrm{~nm}, 1300 \mathrm{~nm}$ e $1550 \mathrm{~nm}$. O detectores SSPD operam em uma ampla faixa de comprimento de onda, com excelentes propriedades temporais. Apesar das aplicações de telecomunicações utilizarem o comprimento de onda de $1550 \mathrm{~nm}$ devido as pequenas perdas nessa faixa, um grande número fontes de fótons únicos não emitem fótons necessariamente neste comprimento de onda, logo é conveniente que um detector cubra um amplo espectro (81).

\section{- Tempo de Jitter}

Esse parâmetro representa a variação do intervalo de tempo entre a absorção de um fóton e a geração de um impulso elétrico de saída (77). O tempo de jitter do detector é um parâmetro determinante para muitas aplicações e é crucial que ele seja suficientemente inferior à duração do pulso, de forma que seu efeito seja possivelmente desprezível. Nos detectores SSPD o tempo de jitter não é um fator limitante, pois ele é muito menor que o tempo de reset. A Fig.2.19 apresenta o jitter típico dos detectores utilizados nesta tese que é de $\approx 60$ ps em (FWHM, do inglês Full Width at Half Maximum) (81).

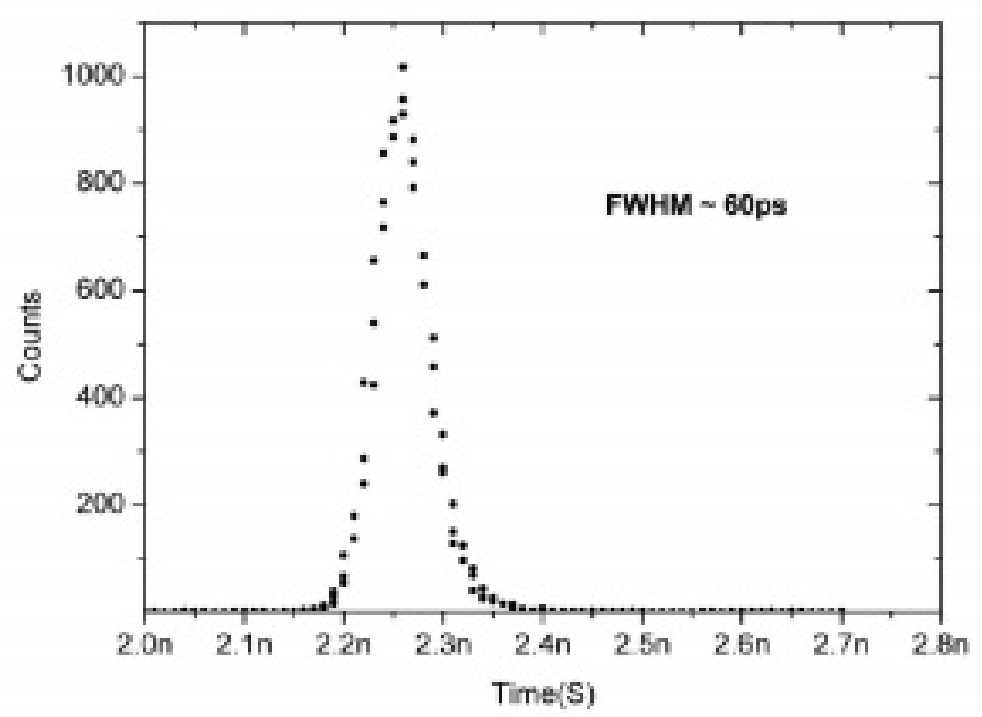

Figura 2.19: Tempo de jitter típico do NbTiN SSPDs (81). 


\subsubsection{2}

\section{Princípio de Operação}

A Fig. 2.20 apresenta o esquema do princípio de funcionamento básico dos detectores de fóton único de nanofio supercondutor que operam em modo livre (do inglês Free-Running). Todo processo do princípio de operação descrito abaixo foi baseado nos trabalhos de Henrich e Natarajan $(80,79)$.
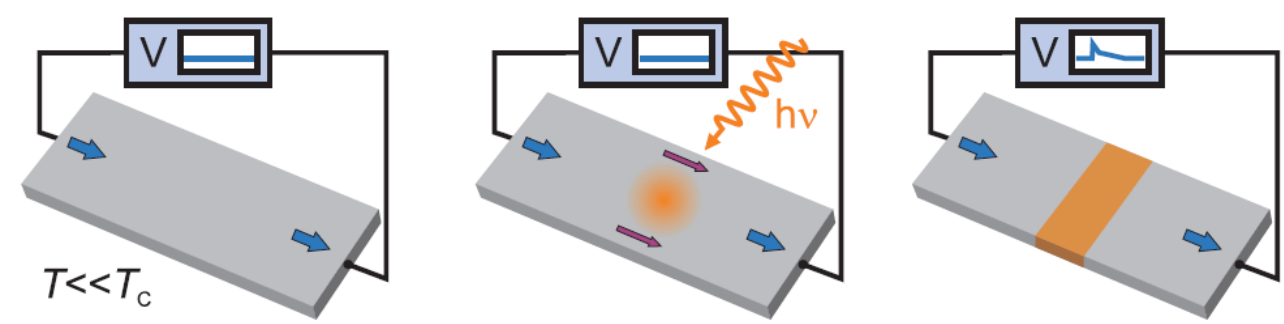

Figura 2.20: Princípio de funcionamento do SNSPD: No estado inicial (à esquerda), o nanofio está no estado supercondutor e polarizado com uma corrente (setas azuis) próxima à corrente crítica. Quando um fóton incide sobre o nanofio (meio), ele pode ser absorvido e causar uma zona local de supercondutividade suprimida. Esta zona cresce em uma região condutora normal através do fio (à direita), que leva a um pulso de tensão mensurável na leitura. Depois, o nanofio relaxa de volta ao seu estado inicial (80).

Inicialmente, o nanofio supercondutor que é representado pela placa cinza é resfriado para temperaturas bem abaixo da sua temperatura crítica $\left(T \ll T_{c}\right)$. As setas azuis indicam a corrente $I_{b}$ que polariza o fio. Está corrente está abaixo da corrente crítica $I_{c}$ que é definida como a energia cinética máxima dos pares de elétrons, que são também chamados, nesse caso, de pares Cooper. O gráfico à esquerda apresenta este estado inicial onde a tensão medida através do dispositivo é zero. Ao incidirmos um fóton único no fio supercondutor assim como mostra o gráfico central, há uma chance de que ele seja absorvido por um dos pares Cooper. Como a energia de um fóton óptico $\left(E_{p h} \approx 1 \mathrm{eV}\right)$ é geralmente muito maior que a distância típica de energia supercondutora $\Delta \approx$ $1 \mathrm{meV}$, os fótons únicos têm energia suficiente para perturbar pares de Cooper, isto significa que o par quebrará em quase-partículas de energia elevada que começam uma cascata de geração adicional de quase-partículas formando assim um hot-spot. A região hotspot representada por um círculo de cor laranja força a corrente a fluir em torno da região de absorção. O número de quase-partículas geradas nesse processo de avalanche torna-se maior a medida que aumentamos a energia fotônica inicial $E_{p h}$. Por outro lado, quanto menor o intervalo de energia em um supercondutor, menos energia é necessária para criar uma quantidade suficiente de quase-partículas. A supercorrente através da secção 
transversal do local de absorção tem agora de ser mantida por uma quantidade reduzida de pares de Cooper. Isso efetivamente provoca uma diminuição de $I_{c}$, também nas regiões que não foram diretamente afetadas (setas roxas). Sendo asim, a densidade de corrente local aumenta para além da densidade de corrente crítica e forma uma barreira resistiva em toda a largura do nanofio. $\mathrm{O}$ aumento repentino na resistência de zero para um valor finito gera um impulso de tensão de saída mensurável entre os nanofios. O aquecimento Joule (através da polarização DC) auxilia o crescimento da região resistiva ao longo do eixo do nanofio até que o fluxo de corrente é bloqueado e a corrente de polarização é desviado por um circuito externo. Isso permite que a região resistiva diminua e o nanofio irá eventualmente voltar ao seu estado superconductor inicial. A constante de tempo para este processo depende principalmente da indutância do dispositivo e do circuito elétrico. Para o SNSPD típico, o tempo efetivo do dispositivo está na faixa de nanossegundos, mas pode ser melhorado muito abaixo desse valor se necessário.

Os SNSPDs são alternativas altamente promissoras para a contagem de fóton únicos em comprimentos de onda infravermelhos e no comprimento de onda de telecomunicações e oferecem alta sensibilidade combinada com baixa DCR e um curto tempo de recuperação (82).

\subsection{2}

\section{Outros Tipos de Detectores de Fótons Únicos}

\subsubsection{1}

\section{Baseados em Tubos Fotomultiplicadores}

Em 1913, Elster and Geiter, construíram um aparelho conhecido como tubo fotoelétrico (83). Esse dispositivo é capaz de detectar luz com intensidade muito baixa e foi determinante para desenvolvimentos subsequentes que deram origem ao notável tubo fotomultiplicador (PMT). Inventado a mais de 80 anos atrás, o PMT foi o primeiro dispositivo utilizado para detectar fótons únicos e atualmente são utilizados especialmente em aplicações biológicas e médicas (84). Esse dispositivo é formado a partir de um tubo de vácuo com um fotocatodo na entrada seguido de uma série de dinodos e um anodo na extremidade. A Fig.2.21 apresenta o esquema de um tubo fotomultiplicador.

Segundo G.Buller e R.Collins (82), nesses dispositivos o fotocatodo absorve o fóton incidente e emite um elétron e dependendo da composição do material do fotocatodo, eles podem ser eficazes para a detecção de luz em diferentes comprimentos de onda. Uma vez que um elétron é emitido a partir do fotocatodo, ele colide com o primeiro dinodo carregado positivamente. Esta 


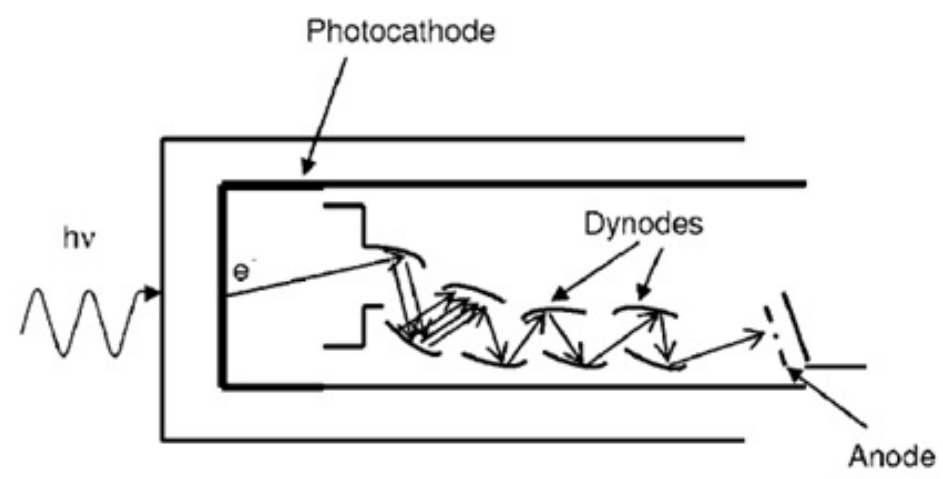

Figura 2.21: Esquema de um tubo fotomultiplicador (82).

colisão libera mais elétrons que são então acelerados para o segundo dinodo. Cada dinodo sucessivo na PMT está carregado com um potencial positivo mais elevado que o precedente resultando em uma amplificação, ou seja, há um aumento do número de elétrons que colidem com os dinodos posteriores. $\mathrm{O}$ fator de multiplicação $M$ dos tubos fotomultiplicadores, dependem diretamente da quantidade $N$ de dinodos utilizados e do coefiente de elétrons segundários $\alpha$ de cada um

$$
M=\alpha^{N} .
$$

Apesar dos detectores de PMTs apresetarem a vantagem de não serem normalmente dependentes do comprimento de onda dos fótons incidentes, eles geralmente apresentam desvantagens como baixa eficiência de detecção e alto jitter, ou seja em aplicações em que são necessárias maiores eficiências de detecção e jitter inferior, os PMDs são menos susceptíveis de serem utilizados (82). Levando em conta o alto jitter, de acordo com Kume e outros (85), uma configuração alternativa ao PMT básico seria o tubo fotomultiplicador de placa de microcanais, onde os capilares de vidro são fundidos em paralelo e revestidos com um material de emissão de eletrões secundários para se obter um único dinodo contínuo sob uma tensão de bias. Esses PMTs tem a vantagem de oferecem um jitter melhorado de até $\approx 20$ ps em FWHM.

Outro desenvolvimento importante desta tecnologia foi o fotodetector híbrido, este dispositivo combina um fotocatodo com um fotodiodo avalanche de baixa capacitância e funcionam com tensões de polarização baixas de cerca de $400 \mathrm{~V}$ oferecendo uma eficiência quântica de $46 \%$ no comprimento de onda de $500 \mathrm{~nm}$, nesse caso, o jitter de tempo é cerca 61 ps em FWHM e a taxa de contagem escuro é aproximadamente $\approx 1 \mathrm{KHz}(77)$.

\subsubsection{2}




\section{Detectores de Fótons Únicos Fotodiodo Avalanche}

O fotodiodo é um dispositivo de junção p-n que quando polarizado com uma tensão reversa aumenta a sua corrente assim que acontece a absorção de fótons. A avalanche é uma corrente elétrica de magnitude crescente que atravessa o fotodiodo e uma vez iniciada deve ser extinta para não danificar o componente. Nos fotodiodos avalanche (APD, do inglês Avalanche Photodiode) portadores de carga transitando em uma região interna chamada de multiplicação são capazes de arrancar outros portadores através do processo de ionização por impacto, este efeito proporciona alto ganho ao dispostitivo (86). Quando o APD opera no modo Geiger, ou seja reversamente polarizado ligeiramente acima da região de ruptura um único fóton pode ser capaz de desencadear uma avalanche e temos possibilidade de detectar esses fótons, este dispositivo é denominado detector de fótons únicos baseados em fotodiodo avalanche (SPAD) (também conhecido como Geiger-mode APD ou G-APD). A fim de interromper a avalanche, é necessário redefinir o detector de modo que ele esteja pronto para receber mais fótons, esse processo chama-se queching. Existem três principais formas de queching aplicadas aos detectores o passivo, o ativo (87). A Fig.2.22, mostar o exemplo de um circuito usando queching passivo.

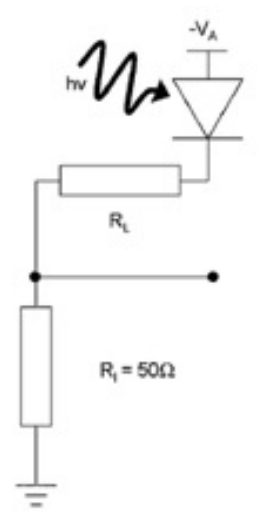

Figura 2.22: Exemplo de circuito usando queching passivo (89).

Se o APD estiver acima da tensão de ruptura um par elétron-buraco pode gerar uma avalanche. A avalanche é descarrega através da resistência $R_{L}$ e a tensão de $V_{A}$ diminui. Isto é sentido por um comparador que produz um sinal de contagem de fótons e de temporização. Quando o fluxo de corrente cessa, a capacitância do fotodiodo recarrega-se e sua polarização retorna a condição inicial, acima do limiar de ruptura, tornando-se o dispositivo apto a detectar um novo fóton. Este tipo de circuito pode ter uma taxa máxima de contagem 
reduzida devido ao alto tempo morto, onde não há episódios de detecção de fótons.

O tempo morto entre a avalanche e o restabelecimento da condição de polarizacão próxima à ruptura pode ser minimizado através da técnica de queching ativo. Esta técnica utiliza uma eletrônica mais sofisticada para fazer uma detecção ativa da presença de avalanche, sendo capaz de reduzir o tempo morto para alguns nanosegundos (88).

Além disso, de acordo com G.Buller e R.Collins (82) se conhecermos o tempo de chegada dos fótons é possível operar o SPAD em um modo no qual a tensão é aumentada além do limiar de ruptura apenas para os instantes de tempo nos quais é esperada a chegada de um pulso. Esse método é conhecido como modo gatilhado (do inglês gated) e permite tempos mortos da mesma ordem de grandeza que os obtidos por quenching ativo com uma eletrônica mais simples, porém à custa de um sistema de sincronismo.

Como vimos, os SPADs apresentam uma região interna chamada de multiplicação. Em princípio, qualquer material semicondutor pode ser utilizado como uma região de multiplicação, mas teoricamente os principais materiais utilizados são o silício, o germânio e o In-GaAs/InP. Detectores de fótons únicos baseados em fotodiodo avalanche de silício (SPAD-Si, do inglês Silicon Single-Photon Avalanche Diode detectors) são amplamente utilizados na região espectral de 400-1000 nm. Assim como apresentado na Fig.2.23, existem dois principais tipos de arquitetura SPAD-Si disponíveis atualmente no mercado, com junção grossa e fina. A principal diferença entre as duas arquiteturas é a espessura da região de depleção em que ocorre a absorção de fótons (77).

a

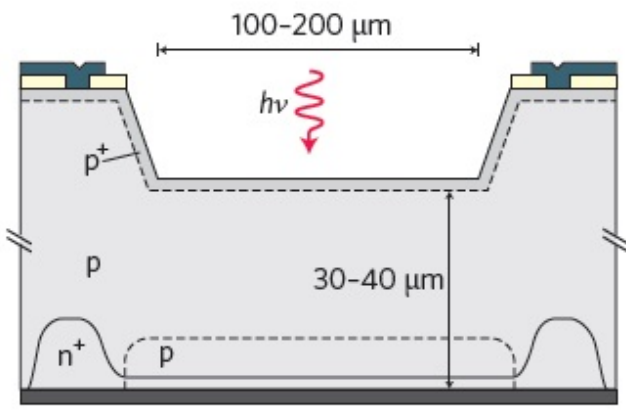

b

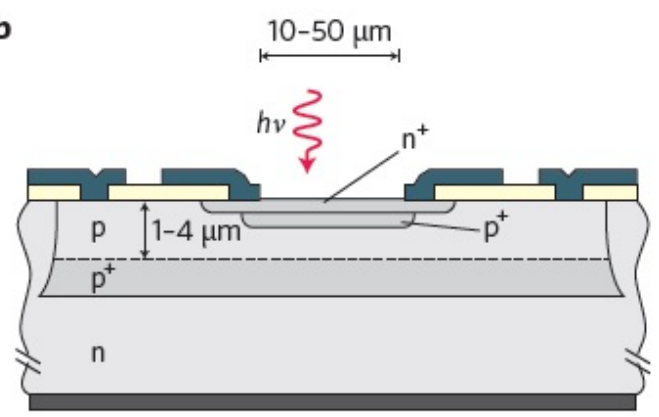

Figura 2.23: (a): Esquema de um SPDA-Si de junção grossa. (b): Esquema de um SPAD-Si de junção fina (77)

Os dipostitivos de junção fina, geralmente possuem uma eficiência de detecção inferior aos de junção grossa. A partir da Fig.2.24, podemos ver uma 
comparação entre as eficiências de detecção do SPAD-Si de junção fina e grossa (90).

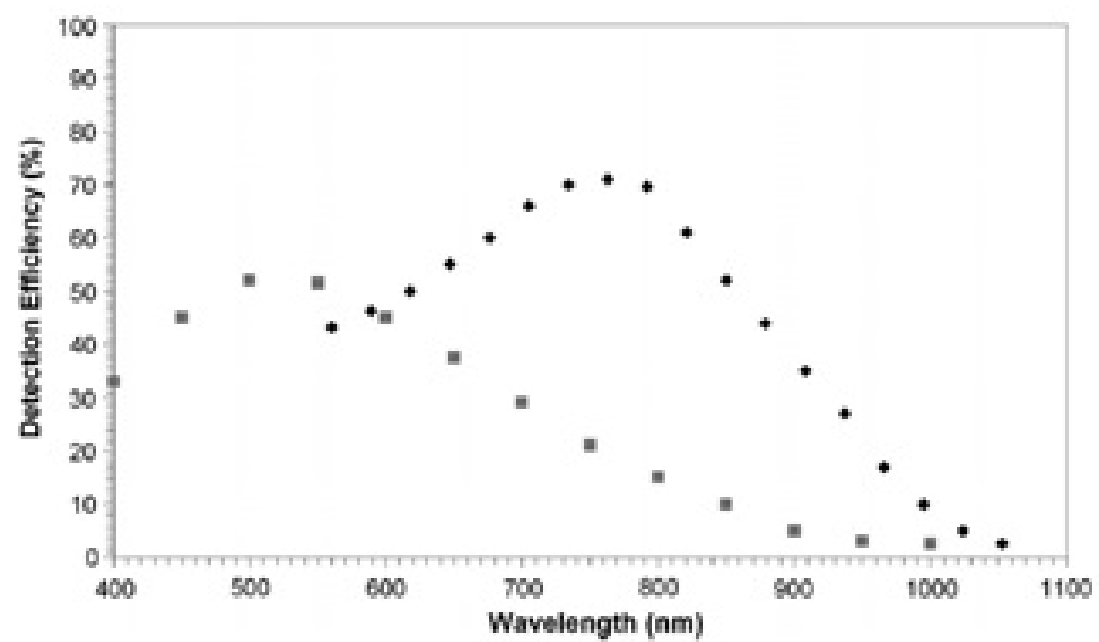

Figura 2.24: Uma comparação entre as eficiências de detecção de SPAD-Si de junção grossa (quadrado) e junção fina (losango) (90)

A fim de aumentar a eficiência de detectores SPAD-Si de junção fina, Ghioni e outros (91) utilizaram cavidades ressonantes aumentando a eficiência de detecção de $10 \%$ para $34 \%$ no comprimento de onda de $850 \mathrm{~nm}$. Apesar disso, para estendermos o desempenho dos SPADs aos comprimentos de onda de telecomunicações de $1310 \mathrm{~nm}$ e $1550 \mathrm{~nm}$ é necessário a utilização de materiais semicondutores como o germânio e o InGaAs (77).

Os detectores de fótons únicos baseados em fotodiodo avalanche de germânio (SPAD-Ge, do inglês Germanium Single-Photon Avalanche Diode Detectors, estiveram disponíveis comercialmente como detectores de fótons únicos no comprimento de onda infravermelho a partir da década de 90. Uma restrição prática desses detectores é que eles precisam ser resfriados a temperaturas tão baixas quanto $77 \mathrm{~K}$ para que tenham bom desempenho. Contudo, em temperaturas baixas a eficiência de detecção a 1550 nm é significativamente reduzida (82).

Os dispositivos de InGaAs /InP são os candidatos mais propícios para a detecção de fóton único no comprimento de onda de $1550 \mathrm{~nm}$, adequandose bem a sistemas de transmissão de fótons sobre fibra óptica. Os SPADs baseados em InGaAs representam uma tecnologia madura e são facilmente encontrados para comercialização. A Fig.2.25 apresenta a estrutura do SPAD de InGaAs/InP, onde o uso de um semicondutor de bandgap menor estende a sensibilidade da detecção de fótons únicos para comprimentos de onda de telecomunicações. 


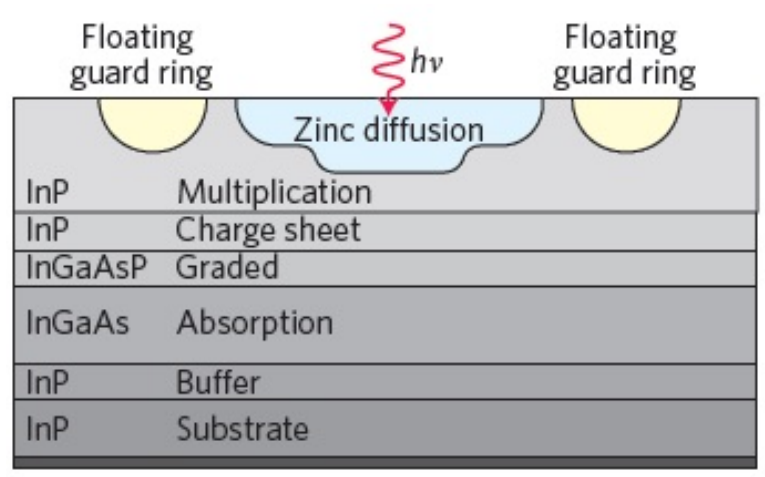

Figura 2.25: Estrutura do SPAD de InGaAs/InP (77).

Esta estrutura de funcionamento, proporcionou sensibilidades de detecção de fótons únicos na faixa de comprimento de onda de 1000-1600 nm (77). Entretanto, esse dispositivos apresentam alta DCR devido a defeitos nos materiais que o compõem. Em vista disso, os SPADs de InGaAs operam tipicamente no modo Geiger/Gatilhado. Segundo Hadfield (77), a DCR do SPAD de InGaAs também pode ser reduzida para $\approx 10 \mathrm{KHz}$ incluindo uma resfriamento de $\approx 200 \mathrm{~K}$, mas esta diminuição da temperatura exacerbada provoca uma alta taxa de tempo morto cerca de $10 \mu \mathrm{s}$. A Tab.2.1 apresenta resumidamente uma comparação entre os detectores apresentados: SSPDs, PMTs e SPADs.

Tabela 2.1: Comparação resumida entre detectores fótons únicos, SNSPDs, PMTs e SPADs . Adaptado de (77).

\begin{tabular}{|c|c|c|c|c|c|c|}
\hline $\begin{array}{c}\text { Tipo } \\
\text { de } \\
\text { Detector }\end{array}$ & $\begin{array}{l}\text { Temp. } \\
\text { de } \\
\text { Oper. }\end{array}$ & $\begin{array}{l}\text { Eficiência } \\
\text { de } \\
\text { Detecção }\end{array}$ & $\begin{array}{l}\text { Tempo } \\
\text { de } \\
\text { Jitter }\end{array}$ & DCR & $\begin{array}{l}\text { Figura } \\
\text { de } \\
\text { Mérito }\end{array}$ & $\begin{array}{c}\text { Máx. } \\
\text { Taxa de } \\
\text { Contagem }\end{array}$ \\
\hline $\begin{array}{l}\text { PMT(visible- } \\
\text { near-infrared) }\end{array}$ & 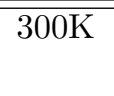 & $40 \% @ 500 \mathrm{~nm}$ & 300ps & $100 \mathrm{~Hz}$ & $1.33 \times 10^{7}$ & $10 \mathrm{MHz}$ \\
\hline PMT(Infrared) & $200 \mathrm{~K}$ & 2\%@1550nm & $300 \mathrm{ps}$ & $200 \mathrm{KHz}$ & $3.33 \times 10^{2}$ & $10 \mathrm{MHz}$ \\
\hline $\begin{array}{l}\text { SPAD-Si(thick } \\
\text { junction) }\end{array}$ & $250 \mathrm{~K}$ & 65\%@650nm & $400 p s$ & $25 \mathrm{~Hz}$ & $6.5 \times 10^{7}$ & $10 \mathrm{MHz}$ \\
\hline $\begin{array}{l}\text { SPAD-Si } \\
\text { (shallow } \\
\text { juntion) }\end{array}$ & $250 \mathrm{~K}$ & 49\%@550nm & $35 \mathrm{ps}$ & $25 \mathrm{~Hz}$ & $5.6 \times 10^{8}$ & $10 \mathrm{MHz}$ \\
\hline $\begin{array}{c}\text { InGasAs } \\
\text { (gated) }\end{array}$ & $200 \mathrm{~K}$ & 10\%@1550nm & $370 \mathrm{ps}$ & $91 \mathrm{KHz}$ & $2.97 \times 10^{5}$ & $10 \mathrm{MHz}$ \\
\hline $\begin{array}{l}\text { SNSPD } \\
\text { (meander) }\end{array}$ & $3 \mathrm{~K}$ & 0.7\%@1550nm & $60 \mathrm{ps}$ & $10 \mathrm{~Hz}$ & $1.16^{7}$ & $100 \mathrm{MHz}$ \\
\hline SNSPD(new) & $1.5 \mathrm{~K}$ & $57 \% @ 1550 \mathrm{~nm}$ & $30 \mathrm{ps}$ & - & - & $1 \mathrm{GHz}$ \\
\hline
\end{tabular}




\section{Iniciando os Trabalhos com o Detector de Fótons Únicos de Nanofio Supercondutor}

O funcionamento do SSPD foi inicialmente compreendido através da realização de um experimento preliminar no qual propusemos e validamos um método prático de geração de número aleatório (RNG, do inglês Random Number Generators) usando estados coerentes e o limiar (do inglês threshold) dos detectores. Além disso, este trabalho, prova a teoria de equivalência entre uma montagem utilizando um modulador de amplitude eletro-óptico (EOAM, do inglês Electro-Optical Amplitude Modulator também conhecido como AM) para "cortar" (do inglês Chopping) a luz simulando o gate do detector e a configuração experimental usando SAPD operando no modo Geiger. Esta similaridade, por exemplo, foi utilizada para o desenvolvimento experimental desta tese.

A idéia básica do protocolo utilizado para RNG consiste em um estado coerente $|\alpha\rangle$ medido diretamente no Espaço de Hilbert usando os seguintes operadores de projeção:

$$
\begin{gathered}
P_{0}=|0\rangle\langle 0| \\
P_{1}=1-P_{0}
\end{gathered}
$$

onde $|0\rangle$ é o estado de vácuo e 1 é o operador de identidade. Estes operadores correspondem à noção de "limiar do detector", isto é, um dispositivo que indica a presença de qualquer número de fótons maior ou igual a um, ou a ausência completa de fótons (vácuo). A maioria dos detectores de fótons únicos comercialmente disponíveis tem este comportamento exato. A idéia é que a probabilidade de projeção do estado $|\alpha\rangle$ em cada um desses operadores seja igual a $1 / 2$, ou seja, a probabilidade de ter ou não um "clique" de detecção é $1 / 2$. Escrevendo $|\alpha\rangle$ como uma superposição linear dos estados de Fock temos, então:

Sendo assim,

$$
|\alpha\rangle=e^{-|\alpha|^{2} / 2} \sum_{n=0}^{\infty} \frac{\alpha^{n}}{\sqrt{n !}}|n\rangle .
$$

$$
\left\langle\alpha\left|P_{0}\right| \alpha\right\rangle=\operatorname{Prob}(0)=1-e^{-\mu}
$$


onde $\mu=|\alpha|^{2}$. De acordo com a Eq. 3-4, a probabilidade de $50 \%$ requer que $\mu$ seja $\approx 0.7$. Até este ponto, considera-se um detector de fóton único sem ruído com eficiência quântica de 100\%. Como mostrado em trabalhos anteriores $(23,69)$, a eficiência de detecção $\eta$ pode ser incluída no número médio de fótons, de modo que possamos considerar o produto $\mu \eta$ como um número médio efetivo de fótons que invadem um detector ideal sem perdas (92). Nesta abordagem, assumi-se que o procedimento de pós-seleção introduzido pela eficiência de detecção é imparcial, como provado recentemente nas experiências que fecharam a lacuna de detecção (93, 94). A aleatoriedade gerada do nosso protocolo depende não apenas da aleatoriedade quântica intrínseca dos números de fótons em um estado coerente, mas também no processo de macroscópico de fotodetecção.

Conforme ilustrado na Fig.3.1, o método proposto para a geração prática de bits aleatórios faz uso de uma configuração experimental simples. A saída de um diodo laser momomodo de feedback distribuído (DFB, do inglês Distributed Feedback Laser) (Mitsubishi Model FU-68PDF-5 (95)) de onda contínua (CW, do inglês Continuous Wave) foi dirigida para um atenuador óptico variável (VOA, do inglês Variable Optical Attenuator), para controle de intensidade e, então, para um SAPD de InGas (idQuantique 201 (96)) operando em modo Geiger. O atenuador, bem como a configuração inteira, são fibrados. Portanto, o alinhamento do modo espacial é garantido pelo único modo espacial de uma fibra padrão. A taxa da matriz de porta programável no campo (FPGA, do inglês Field Programmable Gate Array) é constante e retirada de uma amostra do "clock", isto é, a taxa de trigger (gatilho) direcionada ao detector é periódica com uma taxa igual a 1MHz. Em outras palavras, o sinal de trigger enviado ao detector poderia ter sido um sinal de pulso constante de $1 \mathrm{MHz}$, mas, para simplificar o sistema usando um único dispositivo, o "clock"é enviado pela FPGA.

A fim de obter o melhor compromisso entre eficiência e DCR (120cps), os parâmetros do detector são ajustados para: $15 \%$ eficiência de detecção; largura de gate 4 ns ; e $10 \mu$ s de tempo morto (24). Uma FPGA (model Spartan-3E (97)) gera os pulsos de trigger do detector e faz a aquisição dos respectivos pulsos. A FPGA foi conectada a um computador pessoal para comunicação de dados.

De acordo com (98), o número médio de fótons por gate incidindo sobre o detector é dada por

$$
\mu=-\frac{\ln \left(1-\frac{C}{T_{e f f}}\right)}{\eta},
$$

onde $T_{\text {eff }}$ é a taxa de trigger efetivo, $C$ é a taxa de contagem no detector e 


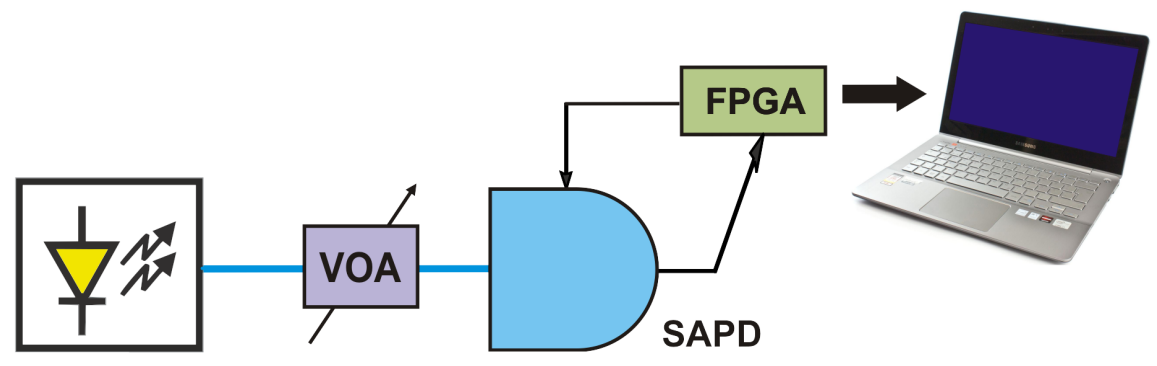

Figura 3.1: Montagem experimental para geração prática de bits aleatórios usando SAPD.

$\eta$ a eficiência do detector. Um trigger efetivo $T_{\text {ef }}$ corresponde a um trigger quando o detector não está no estado ocioso, que ocorre após uma detecção bem sucedida devido ao tempo morto (90). Desta forma, o cálculo de $T_{\text {ef }}$ é direto dado o tempo morto, a taxa de contagem e taxa nominal de trigger $\left(T_{\text {nom }}\right)$, que é gerado pela FPGA e fixada à uma taxa de $1 \mathrm{MHz}$, que se traduz em uma separação de $1 \mu$ s entre os pulsos de trigger. Durante o estado ocioso, o detector ignora 10 pulsos nominais de trigger (tempo morto $=10 \mu \mathrm{s}$ ), então $T_{\text {eff }}$ pode ser calculado como:

$$
T_{\text {eff }}=T_{\text {nom }}-10 \cdot C,
$$

uma vez que o detector só entra no estado ocioso após um evento de detecção bem sucedido. Em última análise, o número médio de fótons por gate foi determinado por $C$, taxa de contagem do detector, dado que todos os outros parâmetros são fixos:

$$
\mu=-\frac{\ln \left(1-\frac{C}{T_{\text {nom }}-10 \cdot C}\right)}{\eta}=f(C) .
$$

Usando $f(C)$, podemos determinar a taxa de contagem no detector que dará o número médio de fótons correspondente a uma probabilidade de detecção de $50 \%$. O produto entre $\mu$ e $\eta$ que cria esta condição de $50 \%$ foi determinado como 0.7. O seguinte problema de minimização simples produz o resultado:

$$
\underset{C}{\arg \min } \| f(C)-\left(\mu_{50 \%} \cdot \eta\right)
$$

O operador argmin procura o argumento que minimiza $\| f(C)-\left(\mu_{50 \%}\right.$.

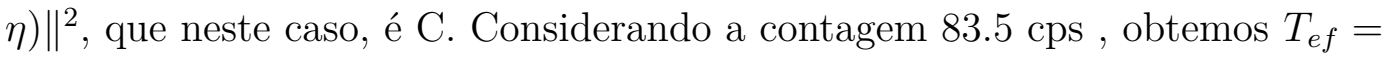
$167 \mathrm{KHz}$, onde a taxa de contagem máxima é limitada pelo tempo morto do detector. A $T_{\text {ef }}$ representa a taxa de geração de bits, pois, para cada trigger efetivo, o sistema emite um bit aleatório. As detecções dentro da janela de gate são tratadas como '1', enquanto '0' são associadas à ausência de detecção. 
O resultado gerado por esses eventos é uma sequência de bits equilibrada composta por $50 \%$ de '1' e $50 \%$ de '0'. O ajuste fino é realizado pelo atenuador óptico variável. De acordo com nossos cálculos, o número médio de fótons que produz uma chance de detecção / não detecção de 50/50 é alcançado para uma determinada taxa de triggers e contagens Eq. 3-7. A taxa de trigger é ajustada para 167000 triggers por segundo com pequenas variações ao longo do tempo; Nós calculamos um desvio padrão de \pm 978 triggers por segundo devido às flutuações de energia. A taxa de contagem de escuro é pequena o suficiente para que, em comparação com a taxa de contagem real ( $83 \mathrm{Kcps})$, possa ser negligenciada. Os bits aleatórios são pós-processados usando um XOR e uma seqüência '1' / '0' balanceada para ajustar o equilíbrio entre uns e zeros do fluxo de bits RNG de saída (99).

Uma longa seqüência de 300Mbits produzida pela configuração experimental mostrada na Fig. 3.1 foi avaliada por testes de aleatoriedade padrão desenvolvidos pelo Instituto Nacional de Padrões e Tecnologia (NIST, do inglês National Institute of Standards and Technology) (100). Esta seqüência foi dividida em 15 blocos de 20 Mbits e os resultados do teste que são relatados na Fig.3.2 mostram uma aleatoriedade acima do nível de confiança NIST de 0.01, isto é, geração de bit aleatória bem sucedida.

Embora o método proposto tenha sido testado com sucesso através do padrão desenvolvido pelo NIST, sua taxa de geração de bits ainda está longe do mínimo aceitável para aplicações práticas, como a criptografia quântica. Portanto, também propomos uma configuração alternativa onde o objetivo é superar o limite de geração de bit imposto pelo tempo morto. A proposta faz uso de um EOAM (JDS Uniphase 10Gb/s Model (101)) e um SSPD (Single Quantum Eos (102))operando em modo de free-running e o fato de que um detector gatilhado tal como um SAPD é equivalente a um modulador de amplitude com sua entrada óptica "cortada" por um EOAM. A Fig.3.3 descreve ambos os métodos de aquisição.

Nesta nova configuração, apresentada na Fig. 3.3, os WCSs são direcionados para o EOAM que "corta" a luz CW. A equivalência entre os métodos está relacionada ao fato de que usamos um EOAM para "cortar" a luz simulando o modo gate do detector SAPD. Note que a equivalência depende da razão de extinção do EOAM e da sua resposta de frequência. Estes parâmetros foram medidos como $\approx 20 \mathrm{~dB}$ e $2 \mathrm{GHz}$, então o EOAM pode reproduzir o modo gate do SAPD no SSPD quando a luz CW é direcionada para os detectores.

Os SSPDs empregados apresentam vantagens quando comparadas com o SAPD, tais como: alta eficiência $(\approx 80 \%)$; baixa DCR $(<10 \mathrm{cps})$; tempo morto curto $(<10 \mathrm{~ns})$; alta taxa de contagem $(>10 \mathrm{Mcps})$. A taxa de geração 


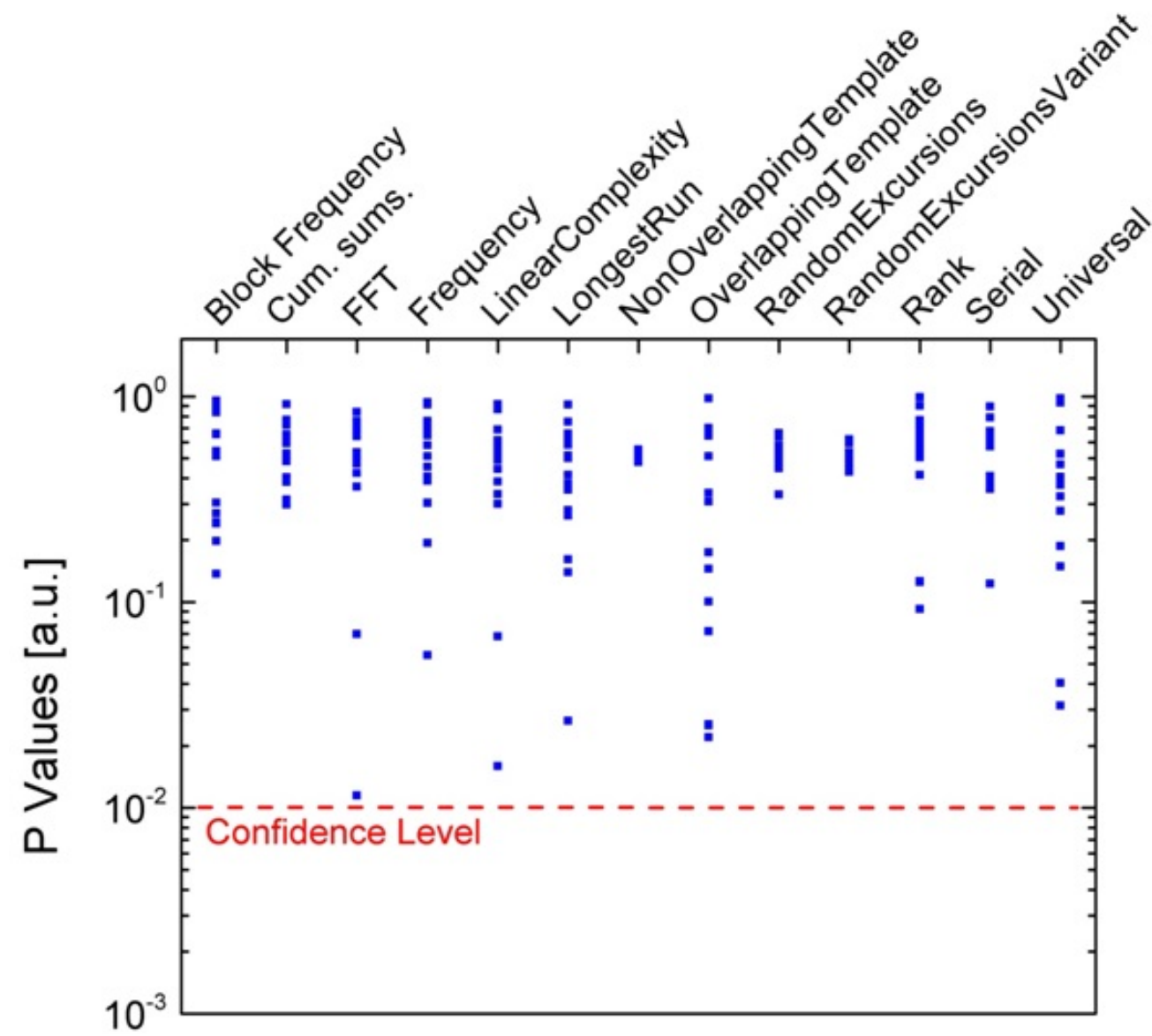

Figura 3.2: Resultados do conjunto de testes de aleatoriedade para a sequência de bits aleatória gerada utilizando SPAD.

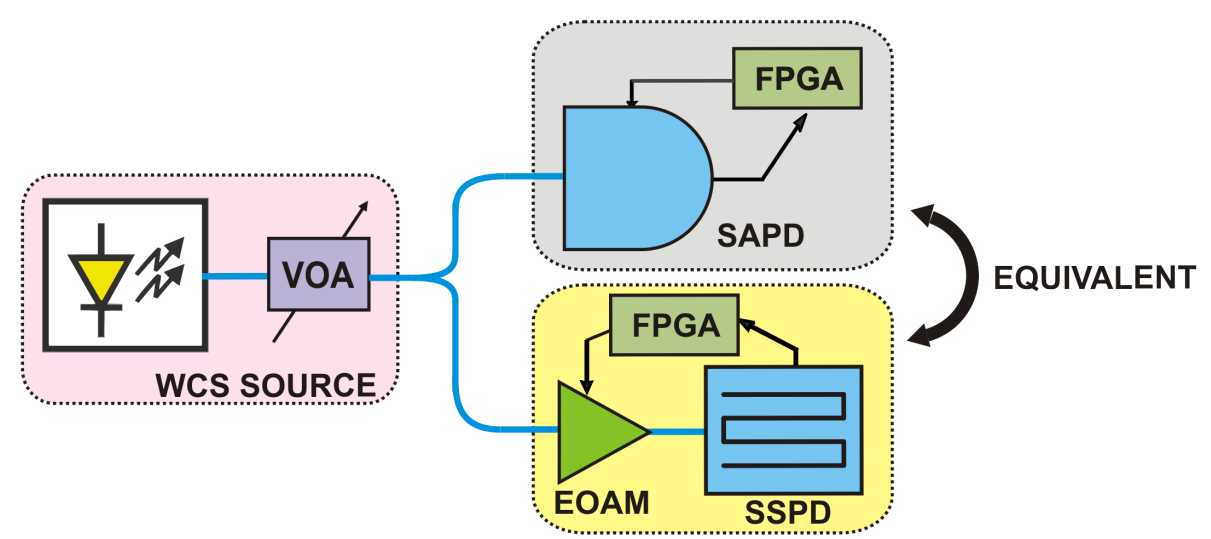

Figura 3.3: Equivalência entre a montagem experimental SAPD e a montagem alternativa usando um EOAM e um SSPD operando no modo free-running.

de bits neste caso será teoricamente limitada pela taxa de contagem máxima do SSPD, uma vez que o tempo morto permitiria uma taxa mais alta $\sim 10$ Mcps), e o EOAM também permitiria uma taxa maior (2 GHz).

Praticamente, no entanto, a limitação é imposta pelo FPGA, que não 
pode transmitir dados para o computador a uma taxa superior a $500 \mathrm{KHz}$. Neste caso, a definição de $T_{\text {nom }}$ no EOAM para $500 \mathrm{KHz}$ rende um $C=250 \mathrm{Kcps}$, uma vez que o tempo morto é muito menor do que a separação entre pulsos de trigger e não afeta a taxa de trigger efetiva.

Nesse caso, também testamos os fluxos de bits com o conjunto de testes de aleatoriedade do NIST para uma sequência de 300 Mbits. A seqüência foi também dividida em 15 blocos de 20Mbits e Fig.3.4 mostra os resultados positivos do teste exibindo uma aleatoriedade acima do nível de confiança de 0.01. Na Tab. 3.1, a entropia calculada de cada fonte é apresentada. As métricas para o valor médio aritmético da sequência e para o coeficiente de correlação serial são $>127.5$ para aleatoriedade e 0.0 para bits totalmente não correlacionados, respectivamente. Os resultados estão dentro da margem das métricas e, como esperado, o cálculo da entropia produziu uma entropia aproximada de 1 bit por detecção.

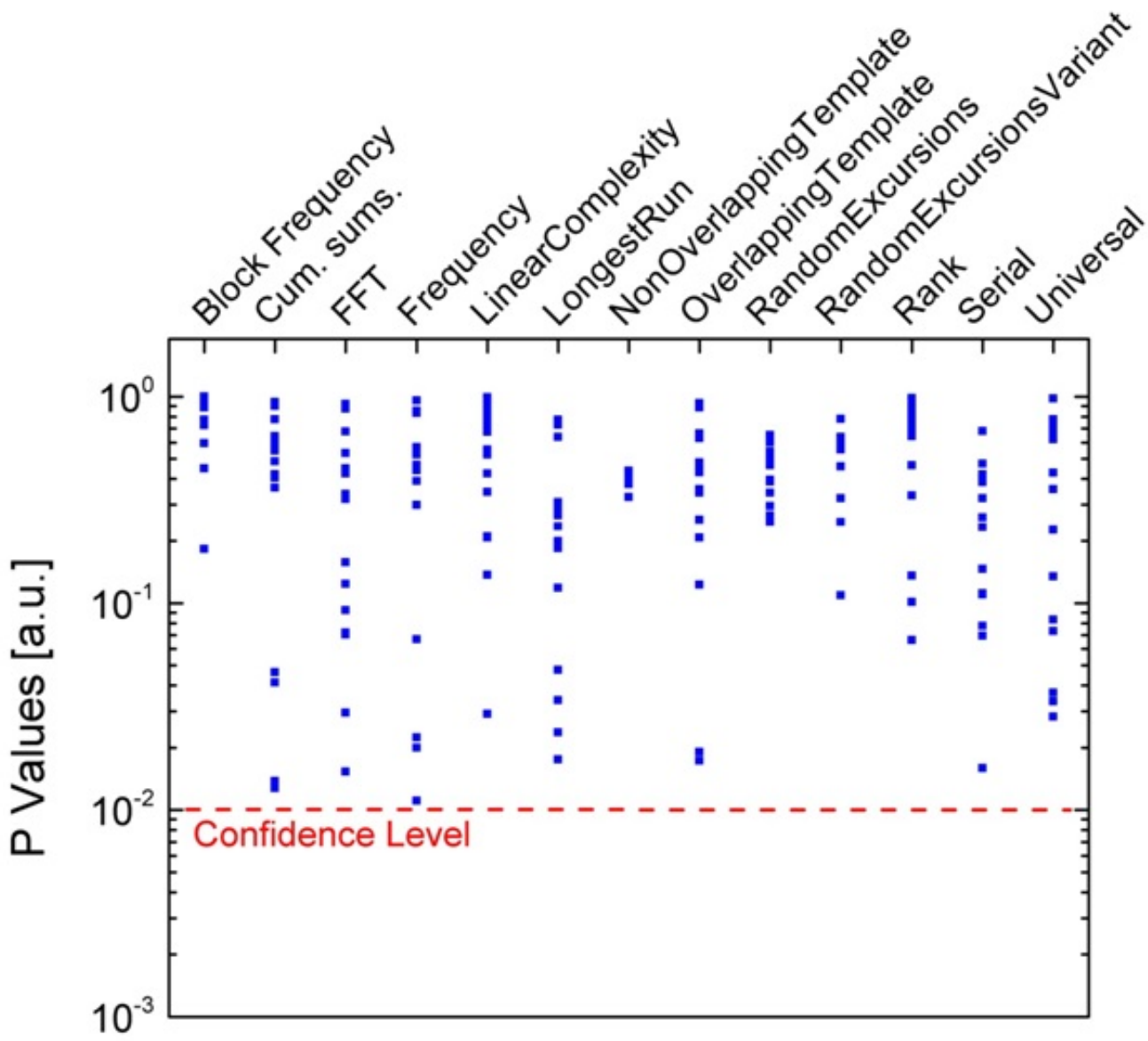

Figura 3.4: Resultados do conjunto de testes de aleatoriedade para a sequência de bits aleatória gerada utilizando a configuração alternativa.

Mesmo que a taxa de geração de bits real seja de grande importância para diferentes aplicações, a diferença importante de uma configuração para a outra é que o primeiro (com o G-APD) tem uma geração de taxa de bits 
Tabela 3.1: Resultado do cálculo de entropia

\begin{tabular}{c|c|c}
\multicolumn{3}{c}{ Tabela 3.1: Resultado do cálculo de entropia } \\
& QRNG G-APD & QRNG SSPD \\
Média aritmética & 127.8406 & 127.3385 \\
Entropia (bits por byte) & 7.999617 & 7.999847 \\
Coef. de Corr. Serial & -0.000222 & -0.000291
\end{tabular}

fixa limitada pelo tempo morto. Essa limitação, no caso do SSPD, é muito menos problemática e permite taxas ainda maiores do que as relatadas. A taxa máxima permitida pela configuração, assumindo que a eletrônica otimizada, que faria com que o detector fosse o único limitador, é $\sim 50 \mathrm{MHz}$, dado o tempo morto da resposta do tempo do SSPD e a taxa de contagem máxima (102).

Nossos resultados experimentais mostram que a seqüência de bits gerada passa pelos testes de aleatoriedade desenvolvidos pelo NIST, o que indica que este método pode ser empregado como um esquema prático de geração de bit aleatórios. Além disso, mostramos que a restrição de taxa é devido ao tempo morto do detector e que um esquema equivalente, usando um EOAM e um detector de funcionamento free-running pode superar essa limitação. Mesmo que a taxa de transferência de dados de FPGA empregado não tenha permitido taxas de geração de bits acima de $500 \mathrm{KHz}$, o fato de que esses resultados também passaram nos testes de aleatoriedade é uma demonstração de prova do princípio.

O experimento também poderia ter sido realizado com fotodiodos de avalanche de silício operando no modo free-running. No entanto, considere um link QKD entre Alice e Bob, onde os fótons de onda de telecomunicações são transmitidos para o processo de geração de chaves secretas. Nesse caso, Alice e Bob podem gerar RNGs usando a configuração proposta dentro de sua configuração QKD simplesmente incluindo um detector extra (que, na maioria das configurações de laboratório, já está disponível). Fazer uso de um Si-APD exigiria a introdução de novos equipamentos e, portanto, maior complexidade. 


\section{4 \\ Descrição Experimental}

O quarto capítulo, intitulado como descrição experimental tem como objetivo apresentar a formulação matématica utilizada para caracterização da complementaridade entre a distinguibilidade espectral e a visisibilidade do padrão de interferencia, a partir da montagem experimental e dos resultados obtidos.

\section{1}

\section{Formulação Matemática}

A configuração empregada para examinar a interferência de HOM de pacotes de onda fotônicos deslocados em frequência é simples e está representada na Fig.4.1: dois feixes ópticos com modos de polarização, modos espaciais e número médio de fótons idênticos, mas centrados em frequências diferentes, são enviados para um interferômetro HOM resolvido no tempo (do inglês TimeResolved HOM interferometer); ajustando o tempo relativo $\tau$ entre detecções, o modo temporal dos pacotes de onda é sincronizado, isto é, a interferência pode ser examinada dentro do tempo de coerência temporal mútua dos pacotes de onda onde as fases são fixas e, assim, o modo temporal é idêntico. Se os pacotes de onda tiverem modos de frequência idênticos, o resultado do interferograma, à medida que $\tau$ é varrido, é o usual dip de HOM (20); entretanto, como vimos, no caso em que as freqüências centrais são diferentes, um padrão de batimento entre elas é observado no interferograma.

Uma observação importante é que, na configuração da Fig.4.1, os modos espaço-temporais e, portanto, os modos de frequência, são definidos pelo caminho óptico, isto é, os pacotes de onda com o modos de frequência centrados em $\omega_{1,2}$ provém dos caminho de entrada 1, 2. Quaisquer dois fótons únicos gerados pelas fontes ópticas que são direcionados para o interferômetro através dos seu braço superior (caminho 1) ou inferior (caminho 2) serão respectivamente descritos como

$$
|1\rangle_{1}=\frac{e^{\frac{-\left(t-\tau_{1}\right)^{2}}{2 \sigma_{1}^{2}}}}{\sigma_{1} \sqrt{2 \pi}} e^{-i\left(\omega_{1}\right) t} \widehat{a}_{1}^{\dagger}|0\rangle=f_{1}(t) \widehat{a}_{1}^{\dagger}|0\rangle
$$




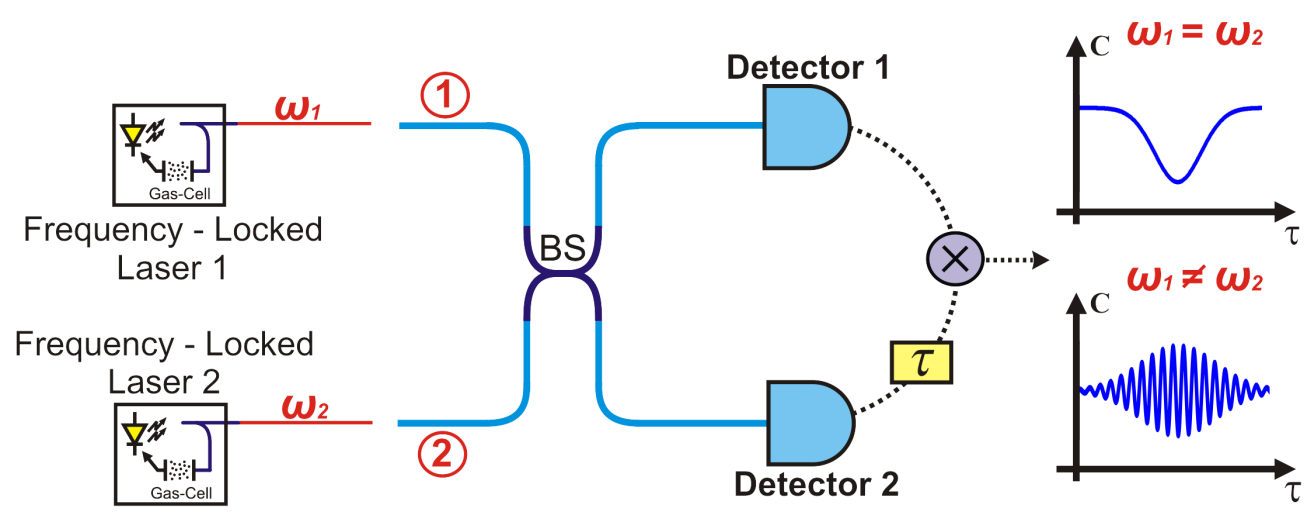

Figura 4.1: Configuração da interferência de HOM resolvida no tempo: quando as frequências centrais ópticas $\omega_{1}$ e $\omega_{1}$ são iguais, o resultado é o dip habitual de HOM; quando $\omega_{1} \neq \omega_{2}$, um padrão de batimento é traduzido no interferograma como franjas de interferência.

$$
|1\rangle_{2}=\frac{e^{\frac{-\left(t-\tau_{2}\right)^{2}}{2 \sigma_{2}^{2}}}}{\sigma_{2} \sqrt{2 \pi}} e^{-i\left(\omega_{2}\right) t} \widehat{a}_{2}^{\dagger}|0\rangle=f_{2}(t) \widehat{a}_{2}^{\dagger}|0\rangle,
$$

onde assumimos que as fontes emitem fótons com pacotes de onda na forma gaussiana em dois modos de frequência bem definidos $\omega_{1}$ e $\omega_{2}$, por simplicidade. $\tau_{1,2}$ representam os atrasos relativos dos pacotes de onda que devem ser compensados no interferômetro HOM resolvido no tempo; $\sigma_{1,2}$ representam a meia largura em $\frac{1}{e}$ dos pacotes de onda; e $\widehat{a}_{1,2}^{\dagger}$ são os operadores de criação para os modos espaciais 1 e 2. A posição do divisor de feixe foi tomada como referência, de modo que toda a dependência espacial de $f_{1,2}(t)$ seja negligenciada (62). É claro que, se pudermos identificar a frequência central de qualquer um dos pacotes de onda interferentes, o trajeto seguido pelo respectivo fóton é automaticamente identificado;

No caso particular em que os pacotes de onda são monocromáticos (isto é, as suas distribuições espectrais são impulsos unitários), e o tempo de integração dos detectores é suficientemente longo, dois pacotes de onda de diferentes frequências serão sempre distinguíveis. Na prática, no entanto, os detectores têm uma resposta de frequência e a largura de linha dos pacotes de onda é diferente de zero, o que deixa margem para erros na distinção da proveniência dos fótons; Dentro da região de indeterminação onde as distribuições se sobrepõem e a proveniência dos fótons não pode ser perfeitamente determinada, os pacotes de onda são indistinguíveis e produzem um padrão de interferência mesmo deslocado pela freqüência. Escrevendo a decomposição espectral dos pacotes de onda interferentes, temos:

$$
|1\rangle_{1}=\int_{-\infty}^{\infty} d \omega X_{1}\left(\omega_{1}\right) \hat{a}_{1}^{\dagger}\left(\omega_{1}\right)|0\rangle
$$




$$
|1\rangle_{2}=\int_{-\infty}^{\infty} d \omega X_{2}\left(\omega_{2}\right) \hat{a}_{2}^{\dagger}\left(\omega_{2}\right)|0\rangle
$$

onde $X_{1}$ e $X_{2}$ são as transformadas de Fourier das funções espaço-temporais $f_{1}(t)$ e $f_{2}(t)$ da Eq.4-1, respectivamente. Com base na Eq.4-1, é interessante desenvolver uma noção física da região de indistinguibilidade entre os pacotes de onda, isto é, a região dentro da qual ocorrerá a interferência de HOM de dois fótons; Um meio natural de fazê-lo é através da fidelidade entre esses estados quânticos.

A fidelidade mede a probabilidade de confundir dois estados quânticos se uma pessoa é autorizada a realizar uma única medição sobre o sistema e, portanto, traduz a distinção entre eles (27). Se dois estados quânticos, digamos $|\rho\rangle$ e $|\sigma\rangle$ são ortogonais (portanto, perfeitamente distinguíveis), a fidelidade desses estados, calculada como $F(|\rho\rangle,|\sigma\rangle)=|\langle\rho \mid \sigma\rangle|^{2}$, é igual a zero; No caso de serem completamente indistinguíveis, $F(|\rho\rangle,|\sigma\rangle)=1$. Conectando as Eq.4-3 e 4-4 à definição de fidelidade, chega-se a:

$$
\begin{aligned}
& \left|\langle 1 \mid 1\rangle_{1,2}\right|^{2}= \\
& \left|\iint d \omega_{1} d \omega_{2} X_{1}\left(\omega_{1}\right) X_{2}^{*}\left(\omega_{2}\right)\left\langle\left. 0\right|_{1} \hat{a}\left(\omega_{1}\right) \hat{a}^{\dagger}\left(\omega_{2}\right) \mid 0\right\rangle_{2}\right|^{2} .
\end{aligned}
$$

Se observarmos cuidadosamente esta expressão, verificamos que o produto interno na parte mais à direita da expressão pode ser simplificado, isto é, $\left\langle\left. 0\right|_{1} \hat{a}\left(\omega_{1}\right) \hat{a}^{\dagger}\left(\omega_{2}\right) \mid 0\right\rangle_{2}=\delta\left(\omega_{1}-\omega_{2}\right)$. Isso permite reescrever a expressão de uma forma mais simples:

$$
F=\left|\int_{-\infty}^{\infty} d \omega X_{1}(\omega) X_{2}^{*}(\omega)\right|^{2}
$$

Nota-se que, uma vez que a fidelidade é igual a 1 sempre que uma medida não pode distinguir entre os estados e zero sempre que os estados são completamente distinguíveis, um parâmetro de distinção entre os estados, digamos $K$, tomaria a forma $K=1-F$, onde $F$ é a fidelidade calculada na Eq.4-6. Além disso, para calcular a fidelidade entre dois estados interferentes em um interferômetro HOM resolvido no tempo, uma simplificação extra pode ser imputada na Eq.4-6: para $\tau$ tal que que os modos temporais estejam perfeitamente sincronizados, isto é, no centro do dip HOM, as fases são fixas e podem ser removidas da integral. De fato, a diferença de fase $\Delta \phi=\phi_{1}-\phi_{2}$ será zero e, a partir da equação de interferência (70), o fator do cosseno que aparece multiplicando o resultado será a unidade. Dessa forma, a multiplicação das duas funções nas formas complexas $X_{1}(\omega)$ e $X_{2}^{*}(\omega)$ são simplificadas pela multiplicação do módulo dessas funções complexas, que é sempre positiva. Em 
outras palavras, o parâmetro $K$ de distinção pode ser reescrito, no centro do dip HOM, como:

$$
K=1-\left|\int_{-\infty}^{\infty} d \omega\right| X_{1}(\omega)|| X_{2}(\omega)||^{2}
$$

Para medir as distribuições espectrais $X_{1}(\omega)$ e $X_{2}^{*}(\omega)$, pode-se recorrer a uma de duas técnicas dependendo da intensidade máxima disponível para as fontes ópticas: se a intensidade está no regime de poucos fótons, a solução é fazer uso da espectroscopia heteródina de poucos fótons (do inglês FewPhoton Heterodyne Spectroscopy) decrita em (24); Se, por outro lado, as fontes forem fontes laser atenuadas, uma amostra não atenuada do sinal óptico pode ser direccionada para um analisador de espectro óptico (OSA, do inglês Optical Spectrum Analyser) clássico de alta resolução. Apesar da praticidade da segunda técnica, deve-se ter cuidado com a natureza da medição em um OSA a intensidade dos campos de luz é medida em vez do campo em si. Felizmente, a intensidade pode estar relacionada ao campo elétrico por $I_{1,2} \propto$ $\left|X_{1,2}\right|^{2}$ onde $\left|X_{1,2}\right|$ que é a distribuição que se deve determinar para a Eq.4-7, e $I_{1,2}$ são estritamente positivos. Portanto, usando a positividade de ambos $\left|X_{1,2}\right|$ e $I_{1,2}$, a expressão de $K$ pode ser escrita como uma função da medida de um OSA como

$$
K=1-\propto\left|\int_{-\infty}^{\infty} d \omega \sqrt{I_{1}(\omega) I_{2}(\omega)}\right|^{2},
$$

onde $\propto$ é um fator de normalização já que a integral na Eq.4-7 não pode ser normalizada. Essa integral, entretanto, representa o segundo momento cruzado das duas distribuições, que tem um modo natural de ser normalizado: $\propto$ corresponde ao inverso da raiz quadrada dos produtos dos segundos momentos individuais de cada distribuição (103). Isso tem o lado positivo de produzir uma figura sem dimensão de mérito, o que concorda com a definição de $K$. Substituindo $\propto$ na Eq.4-8 temos expressão a final de $K$ :

$$
K=1-\left|\frac{\int_{-\infty}^{\infty} d \omega \sqrt{I_{1}(\omega) I_{2}(\omega)}}{\sqrt{\int_{-\infty}^{\infty} d \omega I_{1}(\omega) \int_{-\infty}^{\infty} d \omega I_{2}(\omega)}}\right|^{2} .
$$

Usando a definição espectral apresentada de $K$, nós provamos que a visibilidade $V$ em um interferômetro $\mathrm{HOM}$ esta ligada a $K$ pela relação de complementaridade $K^{2}+V^{2}=1$ (33). Analogamente a $(16,23)$, a visibilidade é definida como $V=\left(R_{\text {dist }}-R_{\text {min }}\right) / R_{\text {dist }}$, onde $R_{\text {dist }}$ é a taxa de contagem fora do intervalo de coerência mútua dos pacotes de onda. Na Fig.4.2, fornecemos uma interpretação gráfica, para maior clareza, da relação de complementaridade proposta entre a medida espectral de $K$ e $V$.

Antes de extrair os valores de $K^{2}+V^{2}$ com base nas aquisições experi- 


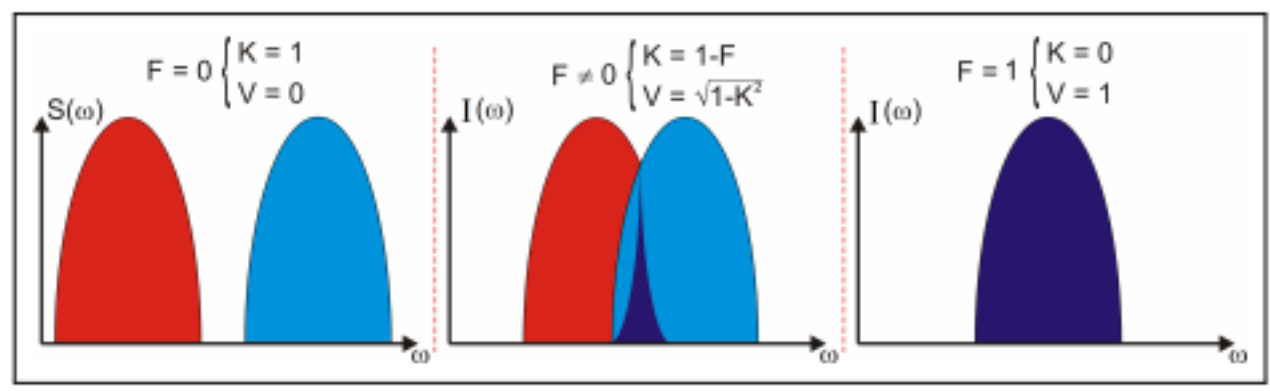

Figura 4.2: Interpretação de $K$ e $V$ em relação à separação espectral dos pacotes de onda fotônicos. A) O recobrimento nulo entre as distribuições espectrais, $K=1$ e $V=0$; B) intersecção não nula, podem ser observadas franjas de interferência; C) espectros indistinguíveis permitem visibilidade máxima, $K=0$ e $V=1$.

mentais, uma questão importante deve ser abordada: a visibilidade atingível é de $50 \%$ devido à contribuição de multi-fótons dos WCSs (22) - uma explicação detalhada é dada na Informação Complementar de (16). As Fig. 4.3 (a) e (b) apresentam a configuração utilizada para destilarmos a contribuição de multi-fótons das taxas de contagem de coincidências. Na Fig. 4.3 (a) podemos observar a visibilidade máxima atíngivél de $50 \%$ para WCSs. O resultado da destilação da contribuição de multi-fótons da taxa de contagem de coincidência é apresentado na Fig. 4.3 (b).

Portanto, levando-se em conta a 4.3 (a) e (b) um novo parâmetro de visibilidade pode ser definido como

$$
\mathcal{V}=\frac{\left(R_{\text {dist }}-0.5 \cdot R_{\text {dist }}\right)-\left(R_{\text {min }}-0.5 \cdot R_{\text {dist }}\right)}{\left(R_{\text {dist }}-0.5 \cdot R_{\text {dist }}\right)},
$$

$\mathcal{V}$ é calculado subtraindo as contagens impostas pelos pulsos com multi-fótons e tenta levar em consideração as contribuições de interferência de dois fótons mesmo quando são empregadas WCSs, no regime de poucos fótons. Em outras palavras, com base no fato de que a indistinguibilidade perfeita entre WCSs é dada por $V=0.5$, o valor da visibilidade tendo em conta o efeito de interferência quântica de dois fótons será definido como $\mathcal{V}=V / 0.5$.

\section{2}

\section{Métodos Experimentais}

A seção intitulada como "Métodos Experimentais" aponta os passos fundamentais para ajuste dos principais parâmetros experimentais com o próposito de destacá-los para uma eventual pesquisa rápida.

\subsection{1}




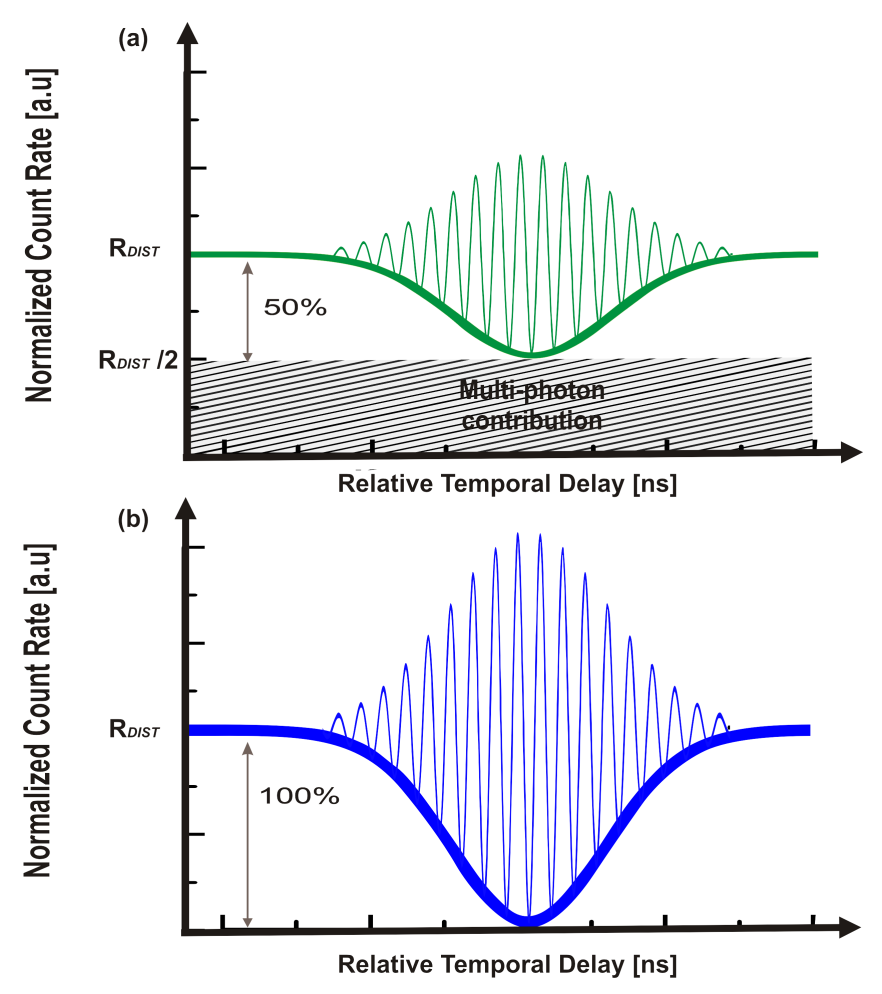

Figura 4.3: Interpretação de $V$ considerando a contribuição de multi-fótons dos WCSs.

\section{Ajuste de Frequência}

Para que possamos visualizar o batimento de frequência entre os WCS e o alargamento dos espectros precisamos que as frequências centrais dos lasers sejam distintas. A Fig.4.4 apresenta o diagrama de blocos da configuração experimental para ajuste do deslocamento de frequência. Através de um sistema PID os lasers foram sintonizados aos espectros de absorção das suas células de gás. A partir dessa sintonia fina da ordem de $\mathrm{MHz}$ permitimos que um dos lasers permanecesse com o comprimento de onda fixo enquanto o outro foi ajustado manualmente para que as fontes de luz estabilizadas em frequência estivessem separadas de $100 \mathrm{MHz}$. Com a finalidade de visualizar e ajustar o deslocamento os espectros clássicos dos lasers foram medidos através do fotodector (p-i-n) e do ESA. Recorremos a utilização do ESA com o objetivo de agilizar o sistema de ajuste já que possui uma resolução menor que o OSA, logo a aquisição dos dados torna-se mais rápida.

Passos para o ajuste de frequência:

$1^{\circ}$ passo: Aplicar o sistema PID para fazer uma sintonia fina da frequência dos lasers.

$2^{o}$ passo: Utilizar o fotodetector e o ESA para visualizar e consequentemente ajustar o deslocamento entre espectros. 


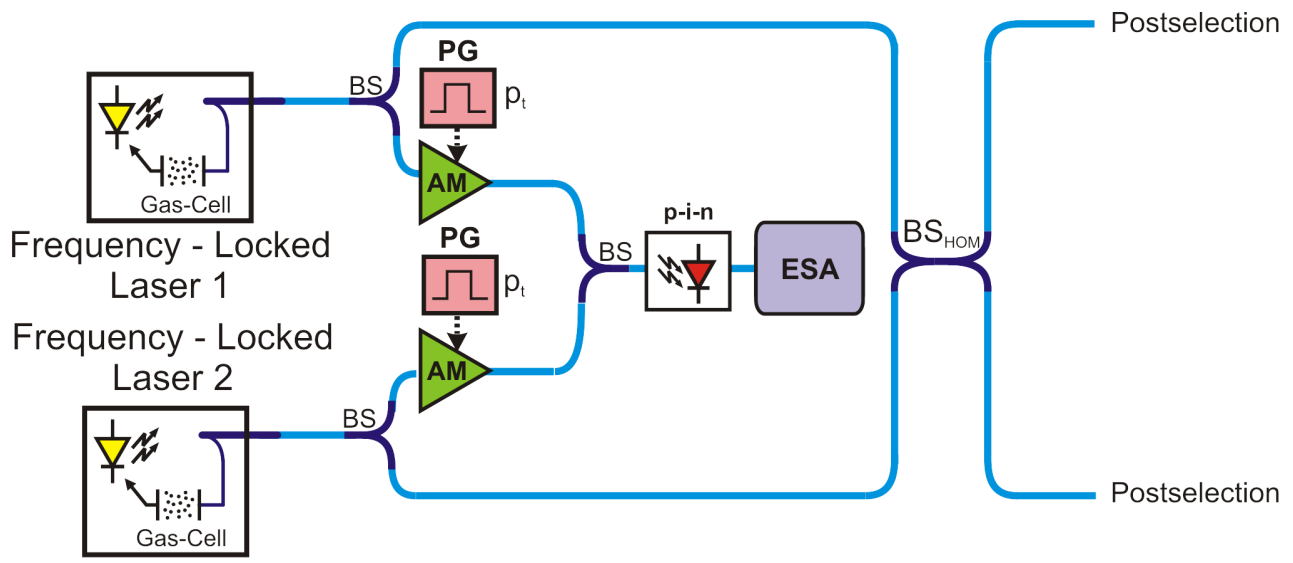

Figura 4.4: Diagrama de blocos da configuração experimental para ajuste do deslocamento de frequência. Espectros Clássicos medidos com o p-i-n e o ESA.

$3^{\circ}$ passo: Ajustar o comprimento de onda do laser sintonizável para que as frequências centrais sejam distintas e estejam separadas de $100 \mathrm{MHz}$.

\subsection{2}

\section{Alinhamento de Polarização}

Pensando na finalidade de garantir à interferência entre os pacotes de onda dos fótons no $\mathrm{BS}_{H O M}$, devemos torná-los indistinguíveis em polarização. O efeito de bunching depende dessa indistinguibilidade e a Fig.4.5 apresentada por (24) exibe a relação entre a visibilidade do padrão de interferência no interferômetro de HOM e a polarização dos estados de entrada no divisor de feixe.

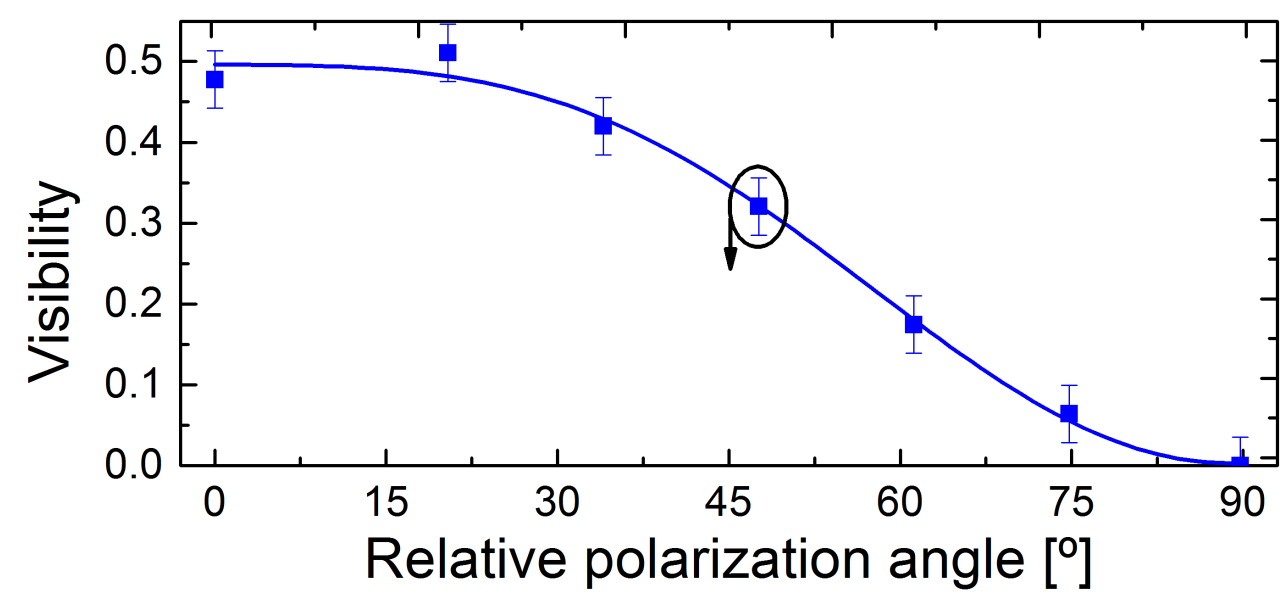

Figura 4.5: Dependência da visibilidade de interferência na relação de polarização dos estados (24).

Pensando nisso, o alinhamento de polarização foi necessário e adquirido através da utilização de estabilizadores de polarização (do inglês polarization 
trackers) que neutralizam as variações do estados de polarização (SOP, do inglês States of Polarization) nos braços de entrada do experimento. Nesse caso, temos um ajuste automático do SOP para um estado de referência que é determinado por um sinal de realimentação. Para o ajuste fino da polarização as contagens no $\mathrm{SSPD}_{a d j}$ ligado a um divisor de feixe de polarização foram minimizadas. Essa minimização foi feita individualmente em cada braço de entrada por meio de controladores de polarização mecânicos. Além disso, a Fig.4.6 apresenta o acoplamento de controladores mecânicos inseridos na montagem experimental antes dos detectores. Esses controladores são usados para combinar a polarização ótima dos fótons com a orientação do dispositivo já que os detectores SSPDs utilizados são dependentes de polarização (81).

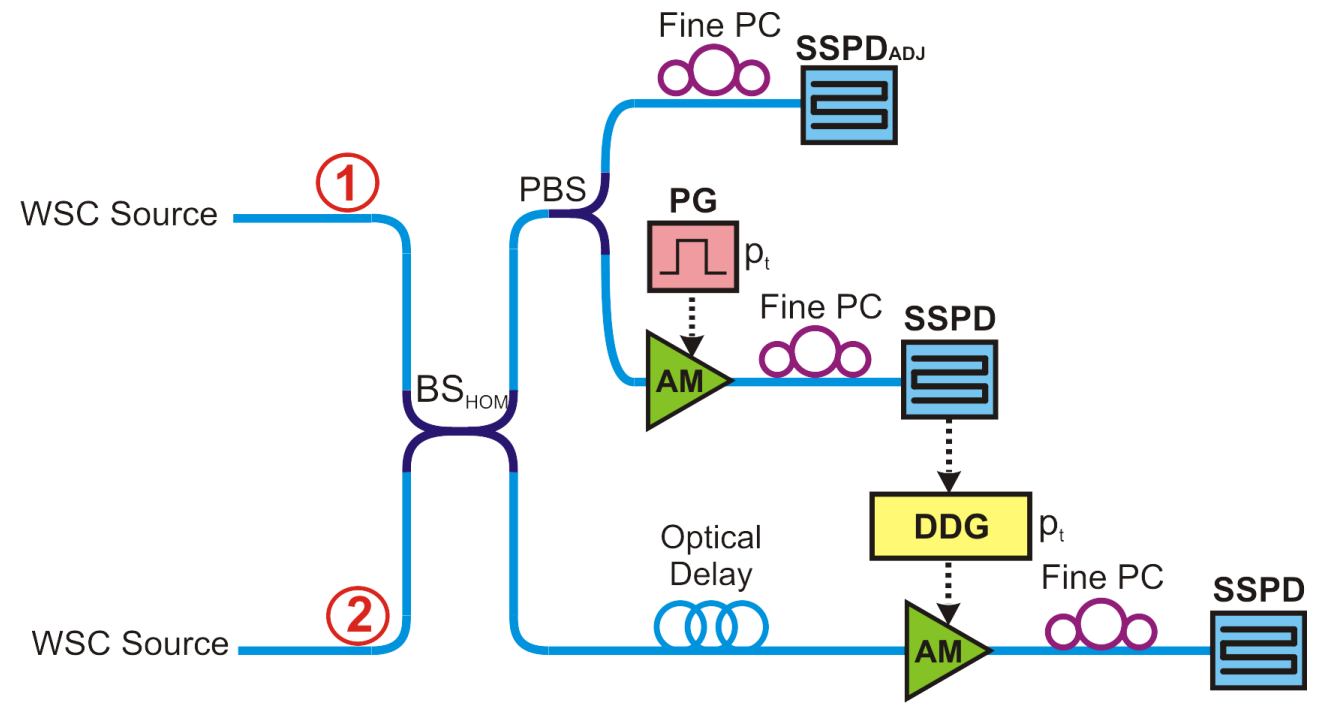

Figura 4.6: Desdobramento da montagem experimental considerando que os detectores SSPDs são dependentes de polarização.

Passos para alinhamento de polarização:

$1^{\circ}$ passo: Determinar o sinal de realimentação para configuração do SOP de referência a fim de ajustar automaticamente os SOPs de entrada alinhando suas polarizações.

$2^{o}$ passo: Desligar o braço 2 da montagem experimental para ajustar individualmente o braço 1 .

$3^{\circ}$ passo: Utilizar o controlador de polarização mecânico na entrada do braço 1 do $\mathrm{BS}_{\text {HOм }}$ Fig. 4.5 para realizar o ajuste fino através da minimização do número de contagens no $\mathrm{SSPD}_{a d j}$.

$4^{o}$ passo: realizar os passos $2^{\circ}$ e $3^{\circ}$ para no outro braço do experimento de modo que os fótons que atingem o interferômetro estejam alinhados por polarização. 
$5^{\circ}$ passo: Utilizar os controladores de polarização mecânicos da entrada dos SSPDs Fig. 4.6 para combinar a polarização ótima dos fótons com a orientação do dispositivo .

\subsection{3}

\section{Intensidade (Número médio de fótons)}

Assim como a polarização, a intensidade (ou número médio de fótons) é um dos graus de liberdade que podem distinguir dois pacotes de onda fotônicos. Na Fig.4.7, G.C.do Amaral e outros mostra a queda na visibilidade do interferograma em função das intensidades relativas dentro do intervalo de tempo no qual os modos temporias são sobrepostos no interferômetro (24).

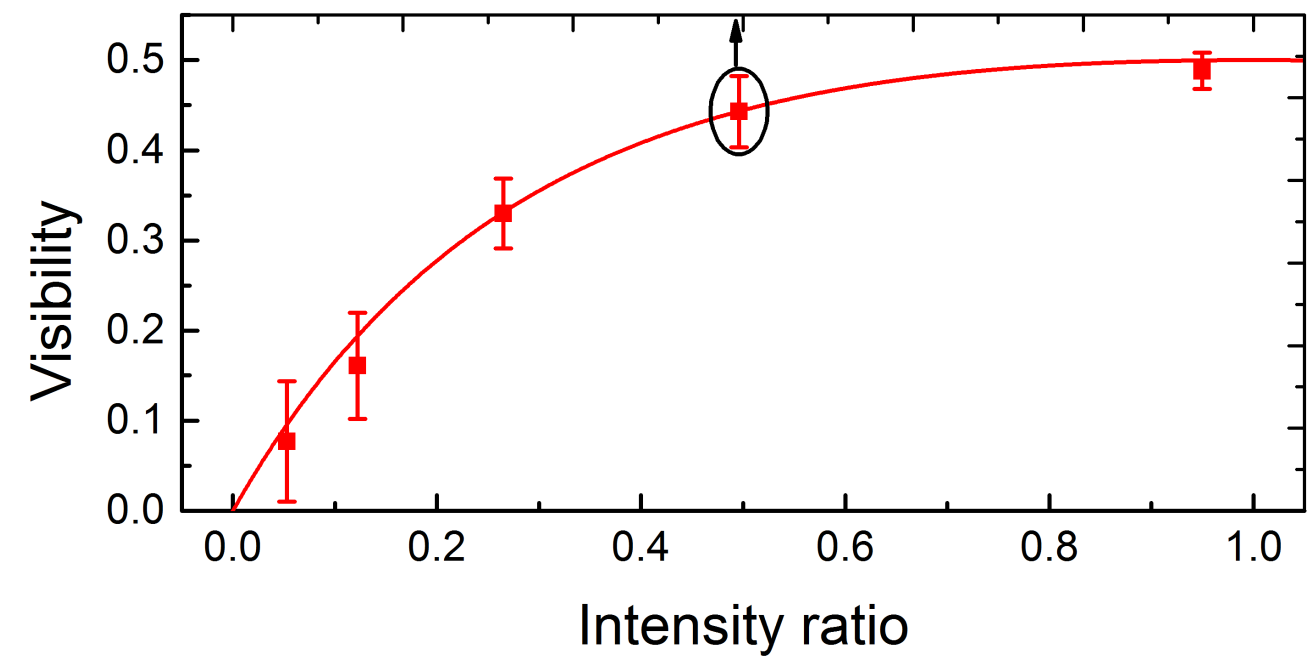

Figura 4.7: Dependência da visibilidade de interferência na relação de intensidade dos estados (24).

Diferente de (24) que utilizou os modos espacias de saída do interferômetro de HOM ligados a dois SPADs operando em modo Geiger, esta proposta tem como objetivo fazer uso de detectores SSPDs operando em modo freerunning. Ainda assim, com este novo esquema foi possível o alinhamento de intensidade na entrada do interferômetro.

Passos para o ajuste da intensidade:

$1^{\circ}$ passo: Desligar o braço 2 da montagem experimental para ajustar individualmente o braço 1.

$2^{o}$ passo: Utilizar o VOA do braço 1 para ajustar a intensidade da fonte correpondente.

$3^{\circ}$ passo: Realizar o passo $1^{\circ}$ para braço 2 do experimento de modo a utilizar o segundo VOA para certificar que a intensidade de ambas as fontes sejam a mesma e também para definir o número médio de fótons próximo ao ideal $(\approx 0.1)$. 


\subsection{4}

\section{Sincronismo e Pós-Seleção}

Para alcançarmos experimentalmente o efeito de interferência quântica no interferômetro de HOM precisamos sincronizar e pós-selecionar as detecções dos dois detectores colocados após o $\mathrm{BS}_{H O M}$. Nesse caso, não estamos interessados na pós-seleção de todos os eventos de detecção e sim nos eventos de coincidência. Como vimos, o dip de HOM ocorre quando varremos o delay temporal entre os dois pacotes de onda fotônicos. Quando esses pacotes de onda não coincidem os eventos pós-selecionados correspondem à condição de distinguibilidade ou seja, nenhuma interferência é observada. Por outro lado, quando as detecções pós selecionadas correspondem à condição de indistinguibilidade, teremos o efeito de interferência e observaremos uma queda nos eventos de coincidência caracterizando o dip. A Fig.4.8 apresenta o meio mais comum de sincronismo e pós-seleção utilizado para análise de eventos de coincidências através de dectores fotodiodo avalanche de InGaas operando no modo Geiger.

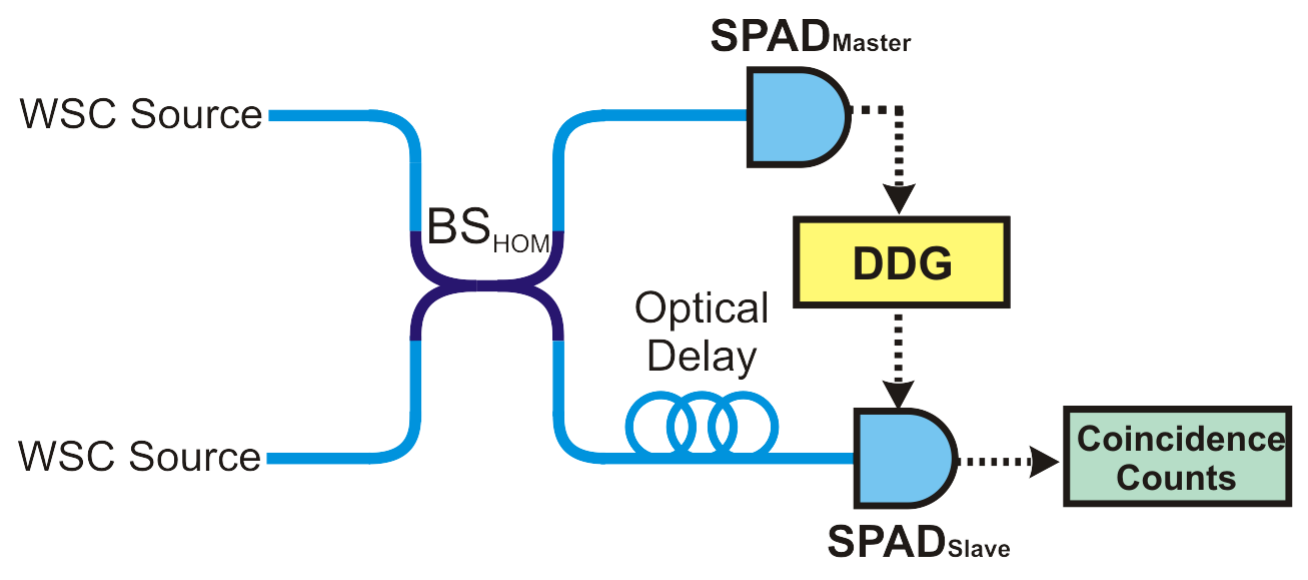

Figura 4.8: Esquema de sincronismo e pós-seleção dos eventos de detecção para SPADs.

O resultado da Fig. 4.10 foi adquirido por meio deste método que inicialmente, para sincronização das detecções, faz uso de um loop de fibra óptica inserida antes do que chamamos de $\mathrm{SPAD}_{\text {Slave }}$ (detector escravo). Esse loop foi utilizado a fim de compensar o atraso elétrico entre o $\mathrm{SPAD}_{\text {Slave }}$ e o que chamamos de $\mathrm{SPAD}_{\text {Master }}$ (detector mestre). Além disso, para pós-seleção de coinciências a técnica consiste em utilizar detecções já disparadas pelo $\mathrm{SPAD}_{\text {Master }}$ para desencadear detecções no $\mathrm{SPAD}_{\text {Slave }}$, ou seja, as contagens coincidentes no $\mathrm{SPAD}_{\text {Slave }}$ estão condicionadas às detecções do $\mathrm{SPAD}_{\text {Master }}$, logo o número de coincidências é exatamente o número de coincidências no 
SPAD $_{\text {Slave }}$ Utilizando um gerador de delay digital (DDG, Digital Generator Delay) somos capazes de impor um delay temporal à um dos pulsos para obtermos o número de contagens através de um contador de fótons e assim traçarmos o interferograma de HOM.

Passos para sincronização e pós-seleção utilizando SPADs:

$1^{o}$ passo: Inserir um loop de fibra óptica antes do SPAD Slave $_{\text {para }}$ compensar opticamente o atraso elétrico em relação ao $\mathrm{SPAD}_{\text {Master }}$.

$2^{\circ}$ passo: Ajustar os parâmetros do $\mathrm{SPAD}_{\text {Slave }}$ e $\mathrm{SPAD}_{\text {Master }}$ a fim de obter o melhor compromisso entre eficiência e contagens escuras (120 Hz): 15\% de eficiência de detecção; 4 ns de largura de gate; e $10 \mu$ s de tempo morto (24).

$3^{\circ}$ passo: Triggar o $\mathrm{SPAD}_{\text {Master }}$ internamente a uma taxa de $1 \mathrm{MHz}$, o que traduz em uma separação de $1 \mu$ s entre pulsos de detecção.

$4^{o}$ passo: Ligar o $\mathrm{SPAD}_{\text {Master }}$ ao trigger externo do DDG.

$5^{\circ}$ passo: Triggar o $\mathrm{SPAD}_{\text {Slave }}$ externamente e sincronizar com a mesma taxa de $1 \mathrm{MHz}$ do $\mathrm{SPAD}_{\text {Master }}$.

$6^{\circ}$ passo:Utilizar as detecções vindas do DDG para acionar as detecções do SPAD $_{\text {Slave }}$.

$7^{\circ}$ passo: Conectar o $\mathrm{SPAD}_{\text {Slave }}$ ao contador de fótons. O número de contagens será extamente o número de coincidências já que o $\mathrm{SPAD}_{\text {Slave }}$ está condicionado as detecções do SPAD Master.

$8^{\circ}$ passo: Varrer o atraso relativo entre os detectores através do DDG.

$9^{\circ}$ passo: Traçar a curva de interferência do HOM em função do número de coincidências e do atraso temporal.

Como vimos, a fim de evitar efeitos indesejados devido à resposta em frequência dos detectores SPADs, substituímos a montagem experimental por uma alternativa com detectores free-running. Nesse caso, os processos de sincronismo e pós-seleção consideram o fato de que o funcionamento do SSPD free-running com uma entrada "cortada" por um AM é equivalente ao funcionameto do SAPD no modo Geiger. A Fig.4.9 apresenta o esquema para o sincronismo e pós-seleção dos eventos de coincidência dos detectores $\mathrm{SSPD}_{\text {Master }}$ e SSPD Slave $_{\text {. }}$

Passos para sincronização e pós-seleção utilizando SSPDs:

$1^{o}$ passo: Inserir um loop de fibra óptica antes do $\mathrm{SSPD}_{\text {Slave }}$ para compensar opticamente o atraso elétrico em relação ao $\mathrm{SSPD}_{\text {Master }}$.

$2^{o}$ passo: Utilizar uma gerador de pulso ( $\mathrm{PG}$, do inglês Pulse Generator) triggado internamente a uma taxa de $1 \mathrm{MHz}$ para disparar o $\mathrm{AM}$ do $\mathrm{SSPD}_{\text {Master. }}$ O AM é responsável por emular o gate no detector $\mathrm{SPPD}_{\text {Master }}$ uma vez que ele opera em modo free-running.

$3^{\circ}$ passo: Ligar o $\mathrm{AM}$ do $\mathrm{SSPD}_{\text {Master }}$ ao trigger externo do DDG. 


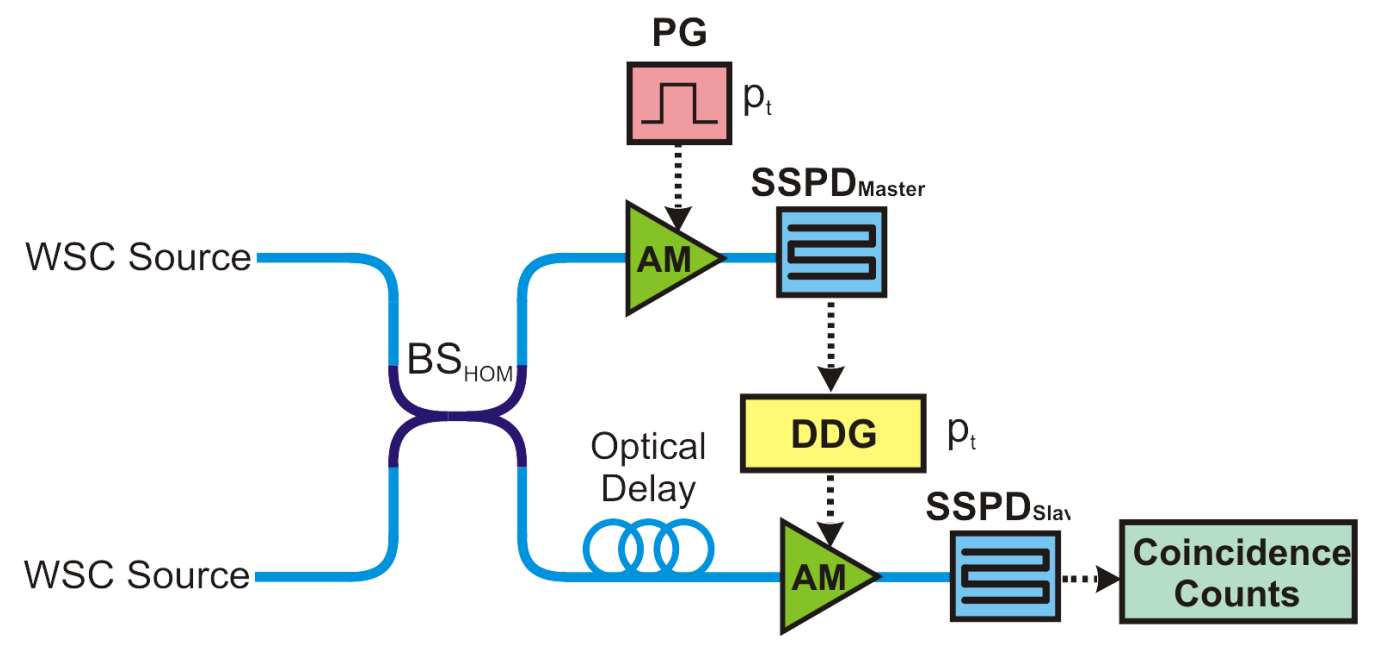

Figura 4.9: Esquema de pós-seleção dos eventos de detecção para SSPDs.

$4^{o}$ passo: Utilizar as detecções vindas do DDG para acionar o AM do $\mathrm{SSPD}_{\text {Slave }}$

$5^{\circ}$ passo: Conectar o $\mathrm{SSPD}_{\text {Slave }}$ ao contador de fótons. O número de contagens será extamente o número de coincidências já que o $\mathrm{AM}$ do $\mathrm{SSPD}_{\text {Slave }}$ está condionado as detecções do $\mathrm{SSPD}_{\text {Master }}$.

$6^{o}$ passo: Através do DDG, varrer o atraso relativo entre os pulsos enviados para $\mathrm{AM}$ do $\mathrm{SSPD}_{\text {Master }}$ e o $\mathrm{AM}$ do $\mathrm{SSPD}_{S}$ lave.

$7^{\circ}$ passo: Variar os pulsos enviados para os AMs na faixa entre 10 a 4 ns.

$8^{\circ}$ passo: Traçar a curva de interferência do HOM em função do número de coincidências e do atraso temporal para cada largura de pulso $\mathrm{p}_{t}$.

\subsection{5}

\section{Caracterização do Alargamento Espectral}

Com o objetivo de caracterizar o alargamento espectral dos pacotes de onda fotônicos, dirigimos os espectros aos AMs. Além disso, variamos a largura dos pulsos $\mathrm{p}_{t}$ enviados à eles e os resultados foram visualizados e medidos através de um monitor óptico de alta resolução (OSA).

Passos para a caracterização do alargamento espectral:

$1^{\circ}$ passo: Ligar os lasers aos AMs.

$2^{o}$ passo: Utilizar os PGs para variar a lagura dos pulsos $\mathrm{p}_{t}$ enviados aos AMs.

$2^{o}$ passo: Vizualizar e medir os espectros com o OSA para cada largura de pulso $\mathrm{p}_{t}$. 


\section{3}

\section{Montagem Experimental e Resultados}

A primeira evidência experimental que despertou nossa proposição para complementaridade espectral foi dada pelos resultados da Fig.4.10. Estas medições foram realizadas com detectores de fótons únicos fotodiodo avalanche de InGaAs operando em modo Geiger e mostram que, para uma largura de gate fixa, a variação da separação espectral dos pacotes de onda fotônicos $(\Delta \omega=60 \mathrm{MHz}$ e $\Delta \omega=240 \mathrm{MHz}$ ) provoca uma variação da visibilidade do interferograma HOM. Inicialmente, especulamos que a visibilidade reduzida era um efeito da largura de linha geral ampliada: a largura de linha medida se aproxima da separação espectral $\Delta \omega$, uma vez que as larguras de linha individuais são muito mais estreitas do que as últimas. Isto pode ser observado na Fig.4.10 como uma redução da coerência temporal dos pacotes de onda - o interferograma de batimento de $240 \mathrm{MHz}$ é muito mais estreito do que o de 60 $\mathrm{MHz}$, o que traduz uma largura de linha mais larga. Isto, no entanto, não é o caso, uma vez que, como demonstrado por Hong, Ou e Mandel, mesmo quando a largura de linha geral é extremamente ampla, a visibilidade do interferograma pode atingir a unidade.

Outro aspecto da experiência que poderia dar falsa impressão de redução da visibilidade é a média das franjas devido à resposta em frequência dos detectores, que é inversamente proporcional à largura do gate. Para evitar este efeito indesejado, substituímos os detectores gatilhados por detectores de funcionamento free-running: os detectores superconductores de fóton único têm uma resposta de frequência idealmente infinita. O papel de "cortar" o pacote de ondas fotônico no tempo e, portanto, ampliar sua respectiva distribuição espectral é delegado aos AMs. Desta forma, não surgem questões metrológicas elétricas e a eventual redução da visibilidade não será mal interpretada.

Nosso aparelho experimental, apresentado na Fig.4.11, descreve a preparação do estado, interferência e medição. Os estados coerentes deslocados em frequência são gerados por dois lasers de comprimento de onda ajustáveis independentes, que operam dentro da banda de telecomunicações, e cujo comprimento de onda pode ser ajustado por um sinal de realimentação. Os espectros de emissão dos lasers foram ajustados aos espectros de absorção das células de gás de factor Q elevado através de um sistema PID, o que permite uma sintonia fina da ordem de $\mathrm{MHz}$ dentro da curva de absorção. As saídas dos lasers sintonizados em frequência também são estabilizadas em polarização por controladores de polarização ativos. Finalmente, atenuadores ópticos variáveis e controladores de polarização mecânica garantem o ajuste preciso necessário para garantir indistinguibilidade em termos de polarização e intensidade. 


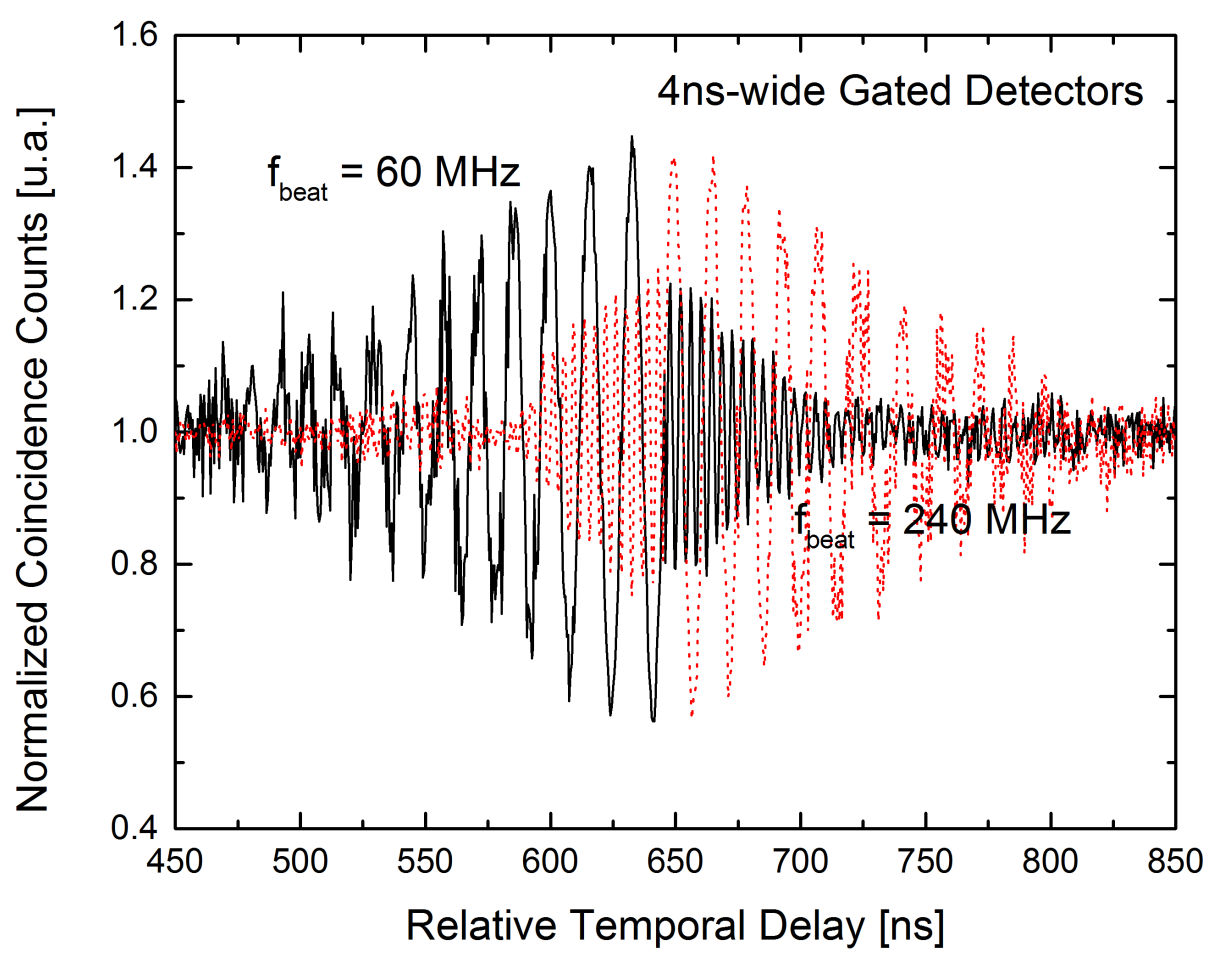

Figura 4.10: Primeira evidência experimental da relação de complementaridade espectral em um interferômetro HOM. A visibilidade do padrão de interferência cai quando a separação entre os pacotes de onda fotônicos é elevada, o que traduz a distinguibilidade espectral. $\mathrm{O}$ uso de detectores gatilhados, no entanto, pode ter um impacto direto sobre os resultados, desse modo utilizamos detectores supercondutores de fótons únicos em modo free-running.

Os WCSs deslocados em frequência são enviadas para o divisor de feixes simétrico $\mathrm{BS}_{H O M}$. Conectado a uma das saídas da $\mathrm{BS}_{H O M}$ está um divisor de feixes de polarização (PBS, do inglês Polarizing Beam Splitter) com uma das portas conectadas ao SSPD, que fornece o feedback para o ajuste fino das polarizações de entrada com os controladores de polarização mecânicos; Minimizando as contagens neste SSPD para ambos os estados de entrada, garante-se que os estados de polarização estão alinhados. O interferograma de HOM é determinado colocando dois SSPDs nas saídas restantes do PBS e do $\mathrm{BS}_{\text {HOM }}$. Antes de ambas os SSPDs, no entanto, é introduzido um AM, o qual é responsável por "cortar" o pulso óptico que chega ao detector. O efeito dos AMs é, assim, emular a porta do detector uma vez que os SSPDs estão em funcionamento free-running e têm, idealmente, tempo de integração infinito, isto é, os AMs impõem uma resposta de frequência imperfeita aos detectores. Os dois SSPDs são ligados de modo que as detecções do primeiro detector acionem o AM conectado diretamente ao segundo e sempre que as detecções dos SSPDs chegam ao mesmo tempo em uma unidade de coincidência, uma contagem é registrada. O sistemas de pós-selecão do interferograma de HOM 
será apresentado mais detelhadamente na próxima seção.

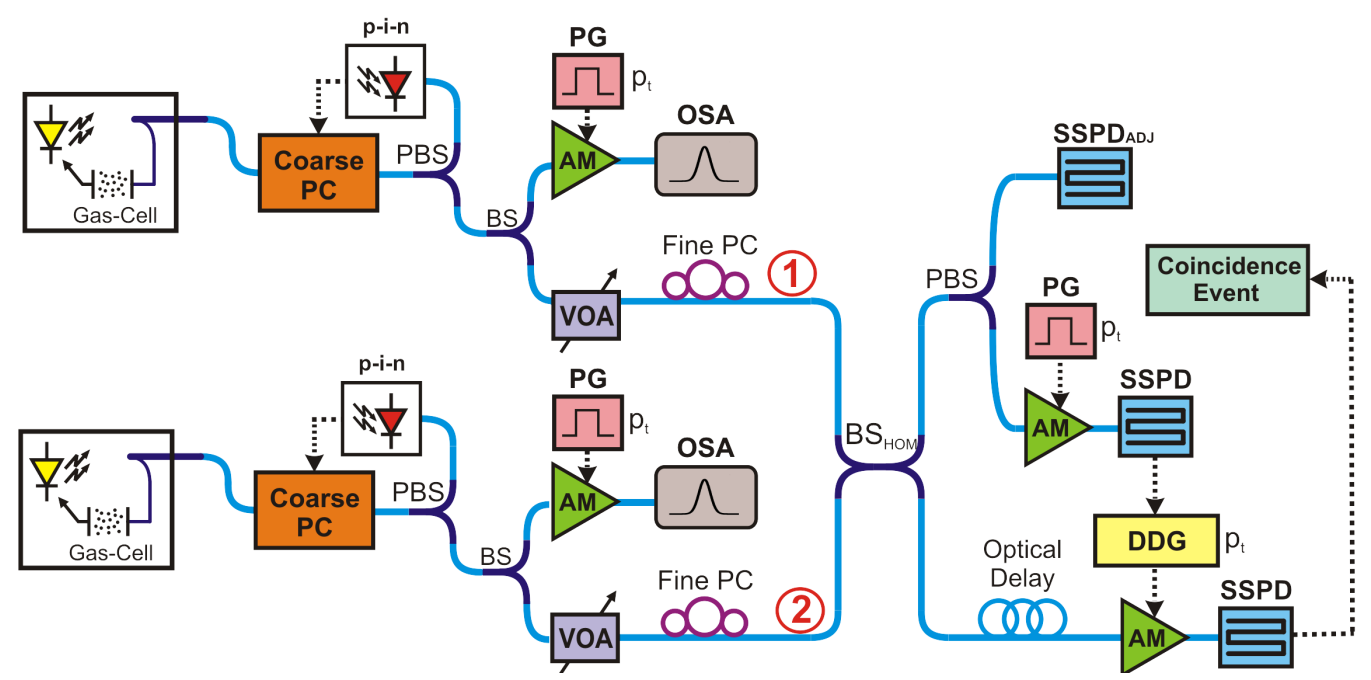

Figura 4.11: Diagrama de blocos da configuração experimental. As fontes de luz estabilizadas em frequência e polarização são definidas com estados de polarização idênticos e com frequências de centro óptico separadas de $100 \mathrm{MHz}$. Os VOAs (atenuadores ópticos variáveis) são responsáveis por certificar que a intensidade de ambas as fontes é a mesma e também para definir o número médio de fótons para que os detectores operem linearmente. O alinhamento do estado de polarização fina é realizado por controladores de polarização mecânica (PC fino). As detecções da SSPD inferior são interpretadas como os eventos de coincidência e formam o interferograma.

Para a determinação experimental da relação de complementaridade espectral entre $K$ e $V$, as freqüências centrais das fontes de laser são ajustadas para um valor fixo, de modo que sua separação corresponda a $100 \mathrm{MHz}$. Uma vez que a largura de linha espectral de cada laser é da ordem de $10 \mathrm{MHz}\left(\omega_{1,2}\right.$ $\pm 5 \mathrm{MHz}$ no espectro óptico) e assumindo que o pulso de disparo enviado para os AMs seja maior do que o tempo de coerência correspondente de 100 ns, nenhum padrão de interferência será observado para estes lasers, isto é, os fótons serão absolutamente distinguíveis da perspectiva do detector. Em outras palavras, ao medir os pacotes de onda, os detectores conseguem identificar com êxito a sua frequência central e, assim, determinar a sua proveniência, o que não provoca qualquer interferência - lembre-se de que os pacotes de onda devem ser indistinguíveis para a interferência de HOM. Ao estreitar as larguras de pulso de disparo dos AMs $\left(p_{t}\right)$ de 100 ns para 4 ns (que é o máximo alcançado pelo gerador de pulsos empregado), pode-se observar um padrão de interferência quando $p_{t} \leq 10 \mathrm{~ns}$. Focalizando, portanto, na faixa entre 10 a 4 ns, os efeitos de $p_{t}$ decrescente são duplos e complementares: as distribuições espectrais são ampliadas, uma vez que o pulso de corte é mais estreito do que a 
coerência temporal da fonte óptica e termina em uma sobreposição, causando a diminuição de $K$ - consulte as Figs. 4.2 e 4.12; Entretanto, a visibilidade do interferograma HOM aumenta ( $V$ aumenta) apresentando um padrão fixo de franja de interferência de $100 \mathrm{MHz}$ - consulte a Fig. 4.13.
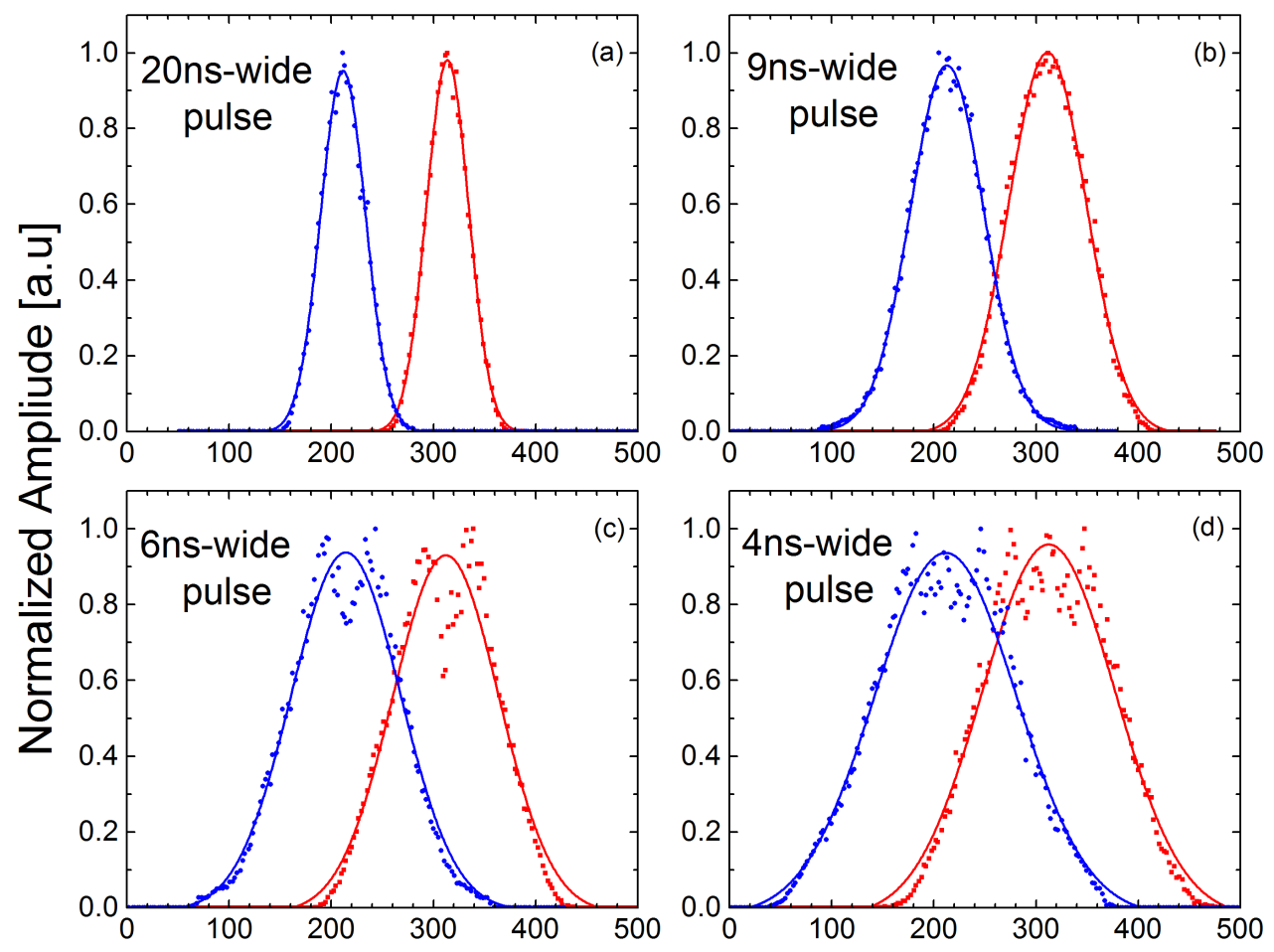

Frequency $[\mathrm{MHz}]$

Figura 4.12: A distribuição de intensidade espectral dos pacotes de onda para diferentes valores da largura de pulso. Quando $p_{t}$ é maior que $10 \mathrm{~ns}$ (a), a sobreposição espectral é mínima. Quando $p_{t}$ é mais estreito do que $10 \mathrm{~ns}$ (bc-d), no entanto, a sobreposição cresce significativamente. As linhas contínuas representam o ajuste gaussiano.

Mesmo que os espectros sejam também ampliados quando $\mathrm{p}_{t}$ se encontra dentro da região de 100 a 10 ns, esse alargamento não é suficiente para criar uma sobreposição espectral não nula, isto é, o produto entre $I_{1}(\omega)$ e $I_{2}(\omega)$ é sempre zero. Com o lado direito da Eq. 4-9 zero, $K$ é a unidade e, como esperado da proposta, $V$ é nulo, isto é, a visibilidade do interferograma é zero. Em $\mathrm{p}_{t} \leqslant 10 \mathrm{~ns}$, no entanto, as larguras de linha são ampliadas até um ponto onde uma sobreposição espectral não nula é observada. Usando a relação inversa entre a largura de linha e o tempo de coerência $\tau_{c}=0.66 / \Delta \omega(70)$ para pacotes de onda gaussianos, calculamos que o FWHM em $\mathrm{p}_{t}=100 \mathrm{~ns}$ é $\Delta \omega \approx$ $70 \mathrm{MHz}\left(\omega_{1,2} \pm 35 \mathrm{MHz}\right)$, o que não é suficiente para que as distribuições se sobreponham a meia altura máxima $\left(\Delta \omega=\omega_{1}-\omega_{2}=100 \mathrm{MHz}\right)$, mas suficiente para que as saias gaussianas se sobreponham - consulte a Fig.4.12(b). 


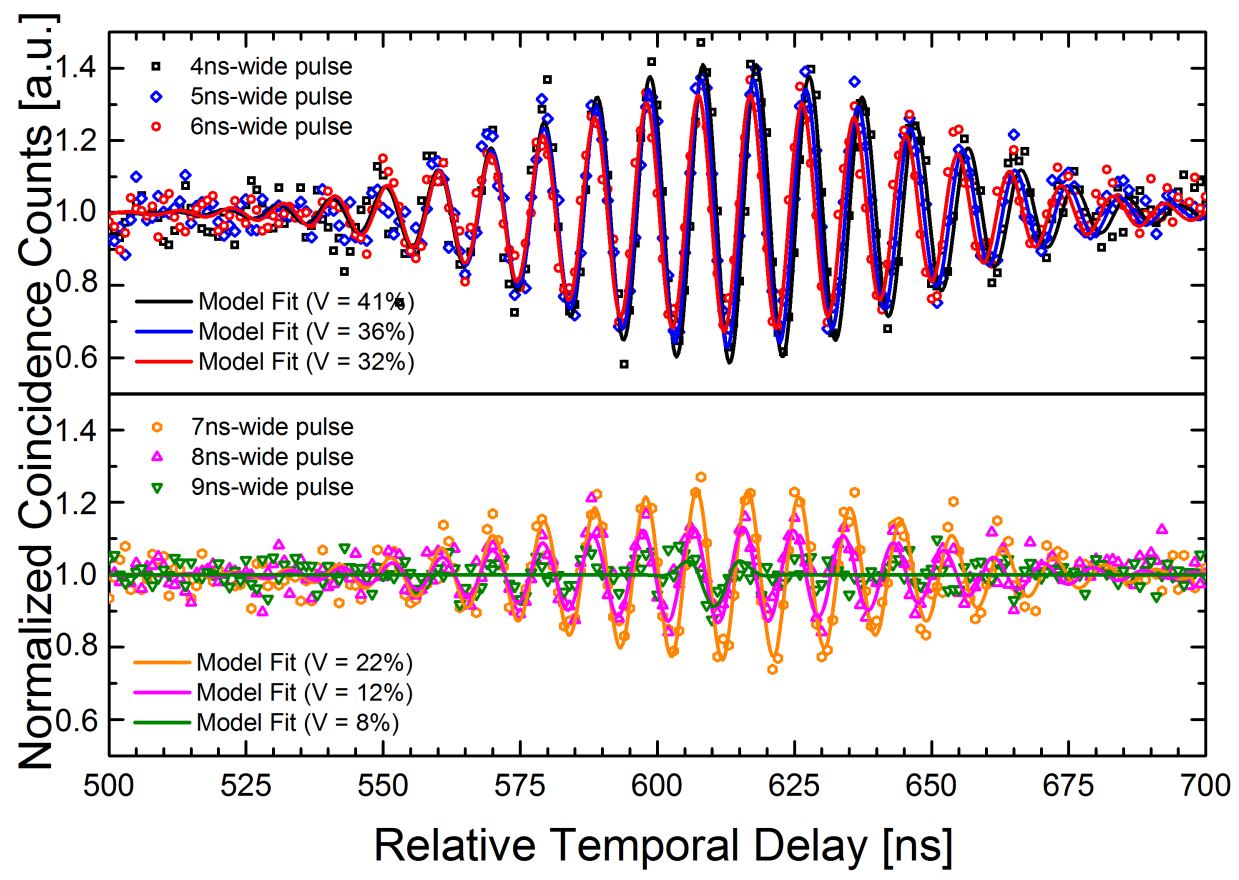

Figura 4.13: Padrões de interferência adquiridos com diferentes larguras de pulso. É evidente a redução de visibilidade à medida que $p_{t}$ cresce. As linhas contínuas representam o ajuste do modelo quando pulsos de forma gaussiana são considerados.

Na Tab. 4.14, os valores experimentais de $\mathrm{K}^{2}+\mathcal{V}^{2}$ são apresentados como uma função da largura do pulso $p_{t}$ enviado para as AMs. A Fig.4.14 representa esses resultados; as barras de erro correspondem a erros de adaptação das formas de onda apresentadas nas Figs. 4.12 e 4.13 a partir dos quais foram determinados os valores de $K$ e $\mathcal{V}$; Foram utilizadas aproximações de primeira ordem, por simplicidade, a fim de explicar a associação não linear entre $K \mathrm{e}$ $\mathcal{V}$. 
Tabela 4.1: Valores experimentais de $K^{2}$ e $\mathcal{V}^{2}$ medidos em relação à largura de pulso $\mathrm{p}_{t}$.

\begin{tabular}{c||c|c|c} 
Lagura do pulso $\left(\mathrm{p}_{t}\right)$ & $K^{2}$ & $\mathcal{V}^{2}$ & $K^{2}+\mathcal{V}^{2}$ \\
\hline \hline $4 \mathrm{~ns}$ & 0.3300 & 0.7056 & $(1.0356 \pm 0.0828)$ \\
\hline $5 \mathrm{~ns}$ & 0.4121 & 0.5715 & $(0.9836 \pm 0.0786)$ \\
\hline $6 \mathrm{~ns}$ & 0.5125 & 0.4516 & $(0.9641 \pm 0.0771)$ \\
\hline $7 \mathrm{~ns}$ & 0.8556 & 0.2134 & $(1.0690 \pm 0.0855)$ \\
\hline $8 \mathrm{~ns}$ & 0.9387 & 0.0635 & $(1.0022 \pm 0.0801)$ \\
\hline $9 \mathrm{~ns}$ & 0.9774 & 0.0282 & $(1.0056 \pm 0.0804)$
\end{tabular}

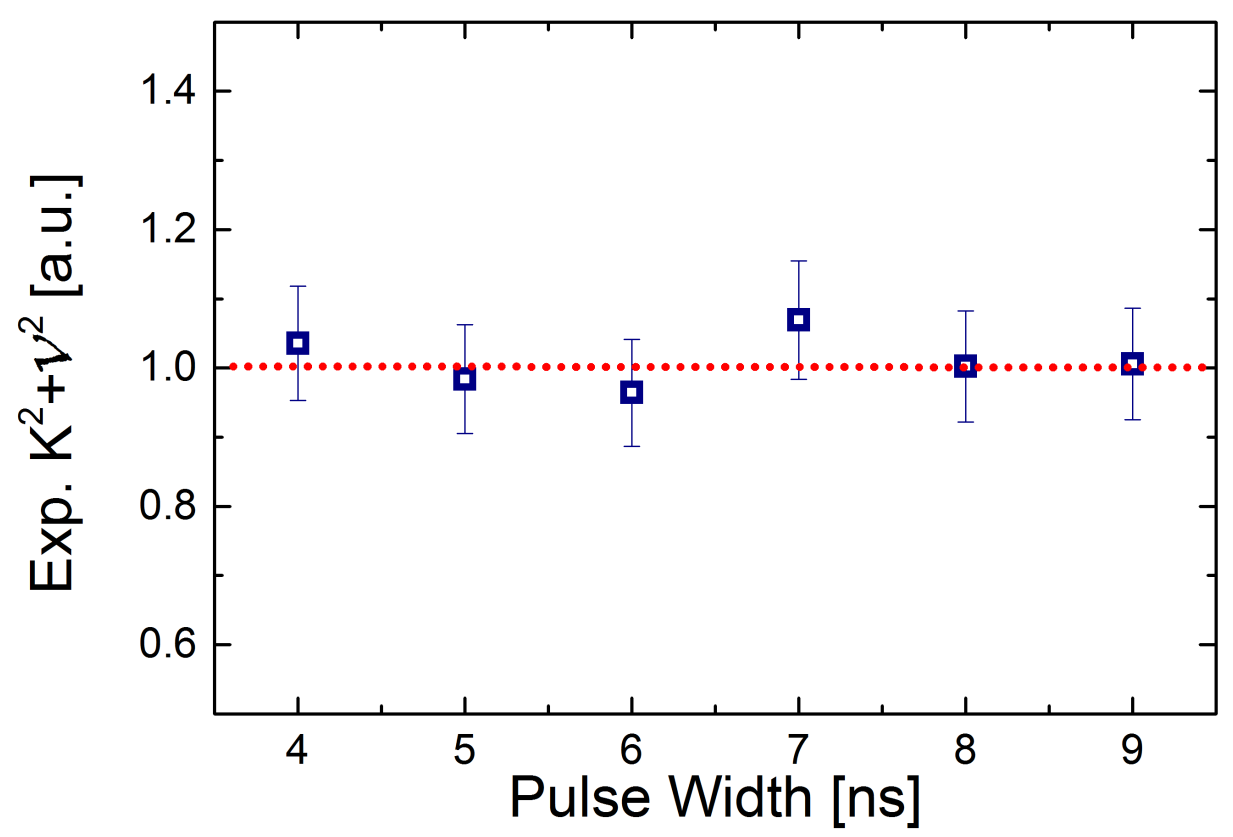

Figura 4.14: Valores experimentais de $K^{2}+\mathcal{V}^{2}$ rastreados em relação à largura de pulso $p_{t}$. Os resultados seguem a previsão teórica - representada pela linha vermelha pontilhada - dentro da margem de erro experimental. 


\section{Conclusão}

Neste trabalho, foi apresentada uma discussão sobre a distinguibilidade entre os pacotes de onda no contexto espectral, com foco no fenômeno de interferência de dois fótons em um interferômetro de Hong-Ou-Mandel alimentado com estados coerentes atenuados.

Uma definição experimental e teórica do parâmetro de distinguibilidade espectral $K$ foi estabelecida com base na fidelidade entre os estados quânticos. Como vimos, à medida que as distribuições espectrais dos pacotes de onda interferentes são ampliadas aumentando à largura dos pulsos que modulam o sinal óptico através do modulador de amplitude eletro-óptico, o parâmetro $K$ cai. A visibilidade, por outro lado, sobe seguindo à relação $K^{2}+V^{2} \leq$ 1. Ou seja, os resultados atestam que $K$ e $V$ possuem uma relação de complementaridade, isto é, mesmo que uma medição espectral não seja realizada pelos detectores de um único fóton, a mera possibilidade de avaliar a informação de distinguibilidade espectral é suficiente para impactar a visibilidade do interferograma resultante. Além disso, provou-se que o aspecto quântico da interferência de dois fótons em um interferômetro de Hong-Ou-Mandel poderia ser examinado com estados coerentes atenuados. Esta pesquisa teórica fundamentada através de uma experiência prática pode contribuir com as diversas discussões em torno na mecânica quântica sobre o comportamento da luz e seu aspecto dualístico.

Como extensão desse trabalho, pode-se investigar a aplicação do experimento para investigar a relação de complementaridade levando em conta outros graus de liberdade para distinção dos pacotes de onda fotônicos como: modo de polarização e intensidade. Além disso, a configuração experimental para o cálculo de $K$ pode ser substituída utilizando um FM para comprovar os dados obtidos. A partir dessa comprovação, os resultados poderiam ser utilizados para um estudo teórico e prático no contexto mais aprofundado de apagamento quântico.

\section{1}




\section{Submissões}

Ambos os trabalhos apresentados nesta tese sobre a geração de bits aleatórios usando estados coerentes e o threshold dos detectores e sobre a complementaridade entre distinguibilidade espectral e visibilidade das franjas de interferência foram submetidos respectivamente nas revistas Applied Optics e Physical Review A. 


\section{Referências bibliográficas}

[1] A.Einsten "On a heuristic point of view concerning the production and transformation of light" Annalen der Physik: 1-18, 1905.

[2] A.Einsten (1909). " $L$ ' évolution de nos conceptions sur la nature et la constitution du rayonnement". Em Einstein, 1989, cap 5, p. 86-100. Oeuvres Choisies, vol 1: Mecanique Statistique et Physique Quantique.

[3] L. de Broglie, "Recherches sur la théorie des quanta", Thesis (Paris), 1924; L. de Broglie, Ann. Phys. (Paris) 3, 22 (1925). Reimpresso em Ann. Found. Louis de Broglie 17 (1992) p. 22.

[4] H. A. Medicus, "Fifty years of matter waves", Physics Today, vol. 27, no. 2, pp. 38-45, 1974.

[5] E. Segrè, "Dos raios $X$ aos quarks: físicos modernos e suas descobertas". Ed. UnB, 1987.

[6] T. Young, "Outlines of Experiments and Inquiries Respecting Sound and Light", Philosophical Transactions of the Royal Society of London, pp. 106$150,1800$.

[7] C. Jönsson, "Electron diffraction at multiple slits", American Journal of Physics, vol. 42, no. 1, pp. 4-11, 1974.

[8] A. Tonomura, J.Endo, T.Matsuda, T.Kawasaki, H. Ezawa, "Demonstration of single-electron buildup of an interference pattern", American Journal of Physics 57.2, 117-120, 1989.

[9] S. Frabboni, G. C. Gazzadi, and G. Pozzi, "Nanofabrication and the realization of Feynman's two-slit experiment", Applied Physics Letters, vol. 93, no. 7, p. $073108,2008$.

[10] P. A. Dirac, "The quantum theory of the emission and absorption of radiation" in Proceedings of the Royal Society of London A: Mathematical, Physical and Engineering Sciences, vol. 114, pp. 243-265, The Royal Society, 1927.

[11] R. J. Glauber, "The quantum theory of optical coherence", Physical Review, vol. 130, no. 6 , p. 2529, 1963. 
[12] R. L. Pfleegor and L. Mandel, "Interference of independent photon beams", Physical Review, vol. 159, no. 5, p. 1084, 1967.

[13] C. Hong, Z.-Y. Ou, and L. Mandel, "Measurement of subpicosecond time intervals between two photons by interference", Physical Review Letters, vol. 59, no. 18 , p. 2044, 1987.

[14] R. H. Brown and R. Twiss, "A test of a new type of stellar interferometer on Sirius", Nature, vol. 178, no. 4541, pp. 1046-1048, 1956.

[15] U. Fano, "Quantum theory of interference effects in the mixing of light from phase-independent sources", American Journal of Physics, vol. 29, no. 8, pp. 539-545, 1961.

[16] J. Jin, J. A. Slater, E. Saglamyurek, N. Sinclair, M. George, R. Ricken, D. Oblak, W. Sohler, and W. Tittel, "Two-photon interference of weak coherent laser pulses recalled from separate solid-state quantum memories", Nature communications, vol. 4, 2013.

[17] H. Weinfurter, “Experimental Bell-state analysis”, EPL (Europhysics Letters), vol. 25, no. 8, p. 559, 1994.

[18] P.Meystre, M. Sargent, "Elements of quantum optics". Springer Science and Business Media, p.480, 2007.

[19] H.-K. Lo, M. Curty, and B. Qi, “Measurement-device-independent quantum key distribution", Physical review letters, vol. 108, no. 13, p. 130503, 2012.

[20] T. F. da Silva, D. Vitoreti, G. Xavier, G. do Amaral, G. Temporao, and J. von der Weid, "Proof-of-principle demonstration of measurement-deviceindependent quantum key distribution using polarization qubits", Physical Review A, vol. 88, no. 5, p. 052303, 2013.

[21] N. Gisin, G. Ribordy, W. Tittel, and H. Zbinden, "Quantum cryptography", Reviews of modern physics, vol. 74, no. 1, p. 145, 2002.

[22] L. Mandel, "Photon interference and correlation effects produced by independent quantum sources", Physical Review A, vol. 28, no. 2, p. 929, 1983.

[23] T. F. da Silva, G. C. Amaral, G. P. Temporão, and J. P. von der Weid, “Linearoptic heralded photon source", Physical Review A, vol. 92, no. 3, p. 033855 , 2015. 
[24] G. C. Amaral, T. F. da Silva, G. P. Temporão, and J. P. von der Weid, "Fewphoton heterodyne spectroscopy", Optics letters, vol. 41, no. 7, pp. 15021505, 2016.

[25] M. Bula, K. Bartkiewicz, A. Cernoch, D. Javurek, K. Lemr, V. Michalek, and J. Soubusta, "Measuring evolution of a photon in an interferometer with spectrally resolved modes", Physical Review A, vol. 94, no. 5, p. 052106, 2016.

[26] B.-G. Englert, "Fringe visibility and which-way information: An inequality", Physical review letters, vol. 77, no. 11, p. 2154, 1996.

[27] V. Vedral, "Introduction to quantum information science". Oxford University Press on Demand, 2006.

[28] I. Newton, "Opticks: or, a treatise of the reflexions, refractions, inflexions and colours of light", Royal Society of London, 1704.

[29] S. P. Walborn, M. O. T. Cunha, S. Pádua, and C. H. Monken, "Quantum Erasure", American Scientist, vol. 91, no. 4, pp. 336-343, 2003.

[30] Gerry, C and Knight, P, , "Introductory Quantum Optics" Cambridge University Press, 2005.

[31] J. A. O. Huguenin, "Correlações espaciais e temporais na amplificação e oscilação paramétrica". PhD thesis, Universidade Federal Fluminense, 2006.

[32] Loudon, R. “The quantum theory of light". OUP Oxford, 2000.

[33] N. Bohr et al., "The quantum postulate and the recent development of atomic theory", vol. 3. Printed in Great Britain by R. \& R. Clarke, Limited, 1928.

[34] M. Jakob and J. A. Bergou, "Quantitative complementarity relations in bipartite systems: Entanglement as a physical reality", Optics Communications, vol. 283, no. 5, pp. 827-830, 2010.

[35] J.-S. Tang, Y.-L. Li, C.-F. Li, and G.-C. Guo, "Revisiting Bohr's principle of complementarity with a quantum device", Physical Review A, vol. 88, no. 1, p. $014103,2013$.

[36] Wheeler, JA and Zurek, W, , "Quantum Theory of Measurement", Princeton University Press, Princeton, 1983.

[37] S. Dürr, T. Nonn, and G. Rempe, "Origin of quantum-mechanical complementarity probed by a 'which-way'experiment in an atom interferometer", Nature, vol. 395, no. 6697, pp. 33-37, 1998. 
[38] P. Storey, S. Tan, and M. Collett, “Uncertalnty principle”, Nature, vol. 367, p. 17, 1994.

[39] G. Björk, J. Söderholm, A. Trifonov, T. Tsegaye, and A. Karlsson, “Complementarity and the uncertainty relations", Physical Review A, vol. 60, no. 3, p. $1874,1999$.

[40] O. Steuernagel, "Uncertainty is complementary to Complementarity", arXiv preprint quant-ph/9908011, 1999.

[41] M. T. Cunha, "Emaranhamento: caracterizaçao, manipulaçao e consequências". PhD thesis, UFMG, 2005.

[42] R. P. Feynman, R. B. Leighton, and M. Sands, "The feynman lectures on physics", Desktop Edition, vol. 1, 2013.

[43] S. Dürr, T. Nonn, and G. Rempe, "Fringe visibility and which-way information in an atom interferometer", Physical review letters, vol. 81, no. 26, p. 5705, 1998.

[44] O. Steuernagel, "Afshar's experiment does not show a violation of complementarity", Foundations of Physics, vol. 37, no. 9, pp. 1370-1385, 2007.

[45] S. K. Berberian, "Introduction to Hilbert space", vol. 287. American Mathematical Soc., 1999.

[46] P. A. Dirac. "A new notation for quantum mechanics". Mathematical Proceedings of the Cambridge Philosophical Society. Vol. 35. No. 3. Cambridge University Press, 1939.

[47] F. Neukart, "Reverse engineering the mind" in Reverse Engineering the Mind, pp. 237-354, Springer, 2017.

[48] G.Cariolaro, “Quantum communications”, Springer, 2015.

[49] D. W. Cohen, "An introduction to Hilbert space and quantum logic", p.20 Springer, 1989.

[50] V.K.Tankappan, “Quantum Mechanics”, Wiley Eastern, New Delher, 2nd ed., pp. 19-63, 1993.

[51] W. Greiner, "Quantum Mechanics - An Introduction", Springer, Berlin, 4th ed., pp. 447-512, 2001.

[52] G. C. Amaral, "Linear-Optic Two-Photon Interference". PhD thesis, PUC-Rio, 2016. 
[53] L., Marchildon. "Quantum mechanics: from basic principles to numerical methods and applications", Springer Science and Business Media, p.21-38 2013.

[54] M., Saleem. "Quantum mechanics", Institute of Physics Publishing, p.51 2015.

[55] R.Shankar. "Principles of quantum mechanics", Springer Science and Business Media, pp.224-579, 2012.

[56] U. Titulaer and R. Glauber, "Correlation functions for coherent fields", Physical Review, vol. 140, no. 3B, p. B676, 1965.

[57] L. Davidovich, "The quantum of light and quantum optics", Revista Brasileira de Ensino de Física, vol. 37, no. 4, pp. 4205-1, 2015.

[58] I. K. Eaves, "Hong-Ou-Mandel Interferometer", Drexel University, 2012.

[59] R. Lopes et al., "Quantum intereference links the fate of two atoms", Phys Org, 2015.

[60] Z. Ou, "Multi-photon interference and temporal distinguishability of photons", International Journal of Modern Physics B, vol. 21, no. 30, pp. 5033-5058, 2007.

[61] N. Borjemscaia, "Hong Ou Mandel interferometer: A quantum measurement tool". Georgetown University, 2012.

[62] T. Legero, T. Wilk, A. Kuhn, and G. Rempe, "Time-resolved two-photon quantum interference", Applied Physics B: Lasers and Optics, vol. 77, no. 8, pp. 797-802, 2003.

[63] Z.-Y. J. Ou, “Multi-photon quantum interference”, Springer, 2007.

[64] B. A, "Theoretical Physics T2 Quantum Mechanics", University of Vienna, 2008.

[65] T. F. da Silva, T. Pinheiro, G. Xavier, and J. von der Weid, "A heralded singlephoton source for quantum communications compatible with long-distance optical fibers" in Microwave and Optoelectronics Conference (IMOC), 2009 SBMO/IEEE MTT-S International, pp. 718-720, IEEE, 2009.

[66] Nielsen, Michael A and Chuang, Isaac, , "Quantum computation and quantum", information, American Journal of Physics, 2002. 
[67] G. C. do Amaral, "FPGA Applications on Single-Photon Detection Systems". PhD thesis, Programa de Pós-Graduaçao em Engenharia Elétrica of the Departamento de Engenharia Elétrica, PUC-Rio, 2014.

[68] T. Legero, T. Wilk, M. Hennrich, G. Rempe, and A. Kuhn, "Quantum beat of two single photons", Physical review letters, vol. 93, no. 7, p. 070503, 2004.

[69] T. F. da Silva, G. C. do Amaral, D. Vitoreti, G. P. Temporão, and J. P. von der Weid, "Spectral characterization of weak coherent state sources based on twophoton interference", JOSA B, vol. 32, no. 4, pp. 545-549, 2015.

[70] B. E. Saleh, M. C. Teich, and B. E. Saleh, "Fundamentals of photonics", vol. 22. Wiley New York, 1991.

[71] S. A. Observatory, S. P. Langley, C. G. Abbot, and F. E. Fowle, "Annals of the Astrophysical Observatory of the Smithsonian Institution". 1900.

[72] R. A. Smith, F. E. Jones, and R. P. Chasmar, "The detection and measurement of infrared radiation", Clarendon Press, 1968.

[73] C. Bertin and K. Rose, "Radiant-Energy Detection by Superconducting Films", Journal of Applied Physics, vol. 39, no. 6, pp. 2561-2568, 1968.

[74] J. Andrews and M. Strandberg, "Thermal microwave phonons", Proceedings of the IEEE, vol. 54, no. 4, pp. 523-528, 1966.

[75] R. Von Gutfeld, A. Nethercot Jr, and J. Armstrong, "Transport of heat from metals to insulators at low temperatures", Physical Review, vol. 142, no. 2, p. $436,1966$.

[76] G. Gol'Tsman, A. Semenov, Y. P. Gousev, M. Zorin, I. Godidze, E. Gershenzon, P. Lang, W. Knott, and K. Renk, "Sensitive picosecond NbN detector for radiation from millimetre wavelengths to visible light", Superconductor Science and Technology, vol. 4, no. 9, p. 453, 1991.

[77] R. H. Hadfield, "Single-photon detectors for optical quantum information applications", Nature photonics, vol. 3, no. 12, pp. 696-705, 2009.

[78] G. Gol'Tsman, O. Okunev, G. Chulkova, A. Lipatov, A. Semenov, K. Smirnov, B. Voronov, A. Dzardanov, C. Williams, and R. Sobolewski, "Picosecond superconducting single-photon optical detector", Applied Physics Letters, vol. 79 , no. 6, pp. 705-707, 2001. 
[79] C. M. Natarajan, M. G. Tanner, and R. H. Hadfield, "Superconducting nanowire single-photon detectors: physics and applications", Superconductor science and technology, vol. 25, no. 6, p. 063001, 2012.

[80] D. Henrich, "Influence of material and geometry on the performance of superconducting nanowire single-photon detectors", vol. 10. KIT Scientific Publishing, 2013.

[81] N. Dorenbos, "Superconducting single phton detectors". PhD thesis, Uiversiteit Delft, 2011.

[82] G. Buller and R. Collins, "Single-photon generation and detection", Measurement Science and Technology, vol. 21, no. 1, p. 012002, 2009.

[83] D. Renker, "Geiger-mode avalanche photodiodes, history, properties and problems", Nuclear Instruments and Methods in Physics Research Section A: Accelerators, Spectrometers, Detectors and Associated Equipment, vol. 567, no. 1 , pp. 48-56, 2006.

[84] A. Migdall, S. V. Polyakov, J. Fan, and J. C. Bienfang, "Single-Photon Generation and Detection: Physics and Applications", vol. 45. Academic Press, 2013.

[85] H. Kume, K. Koyama, K. Nakatsugawa, S. Suzuki, and D. Fatlowitz, "UItrafast microchannel plate photomultipliers", Applied optics, vol. 27, no. 6, pp. 1170-1178, 1988.

[86] T. F. da Silva, "Elementos para comunicação quântica experimental utilizando fotodiodos avalanche", PhD thesis, PUC-Rio, 2011.

[87] A. Gallivanoni, I. Rech, and M. Ghioni, "Progress in quenching circuits for single photon avalanche diodes", IEEE Transactions on nuclear science 57, 3815-3826, 2010.

[88] G. P. Temporão, "Contagem de fótons no infravermelho próximo e médio via conversão de freqüências aplicada a comunicações quânticas ". PhD thesis, PUC-Rio, 2007.

[89] M. Hijlkema, B. Weber, H. P. Specht, S. C. Webster, A. Kuhn, and G. Rempe, "A single-photon server with just one atom", Nature Physics, vol. 3, no. 4, pp. 253-255, 2007.

[90] S. Cova, M. Ghioni, A. Lacaita, C. Samori, and F. Zappa, "Avalanche photodiodes and quenching circuits for single-photon detection", Applied optics, vol. 35, no. 12, pp. 1956-1976, 1996. 
[91] P. G. Neudeck, "Progress in silicon carbide semiconductor electronics technology", Journal of Electronic Materials, vol. 24, no. 4, pp. 283-288, 1995.

[92] Fitch, M. J. et al. "Photon-number resolution using time-multiplexed singlephoton detectors". Physical Review A, v. 68, n. 4, p. 043814, 2003.

[93] B. Hensen, H. Bernien, A. E. Dréau, A. Reiserer, N. Kalb, M. S. Blok, J. Ruitenberg, R. F. Vermeulen, R. N. Schouten, C. Abellán, et al., “Loopholefree Bell inequality violation using electron spins separated by 1.3 kilometres", Nature, vol. 526, no. 7575, pp. 682-686, 2015.

[94] M. Giustina, M. A. Versteegh, S. Wengerowsky, J. Handsteiner, A. Hochrainer, K. Phelan, F. Steinlechner, J. Kofler, J.-Å. Larsson, C. Abellán, et al., "Significant-loophole-free test of Bell's theorem with entangled photons", Physical review letters, vol. 115, no. 25, p. 250401, 2015.

[95] Mitsubishi, “Mitsubishi fu-68pdf-5”, http://www.glztech.com/product_ datasheet/OSC-LDPM-C-009C_pdf1.pdf, 2008.

[96] id Quantique, "201 single-photon detection module", http: //www. idquantique.com/wordpress/wp-content/uploads/ id201-operating-guide.pdf, 2008.

[97] XilinX, "Spartan-3efpga family data sheet", https://www.xilinx.com/ support/documentation/data_sheets/ds312.pdf, 2013.

[98] D. J. Kissick, R. D. Muir, and G. J. Simpson, "Statistical treatment of photon/electron counting: extending the linear dynamic range from the dark count rate to saturation", Analytical chemistry, vol. 82, no. 24, pp. 1012910134, 2010.

[99] T. F. da Silva, G. Xavier, G. Amaral, G. Temporão, and J. von der Weid, "Quantum random number generation enhanced by weak-coherent states interference", Optics Express 24, 19574-19580, 2016.

[100] A. Rukhin, J. Soto, J. Nechvatal, M. Smid, and E. Barker, “A statistical test suite for random and pseudorandom number generators for cryptographic applications", Technical Report, 2001.

[101] J. Uniphase, "10 $\mathrm{gb} / \mathrm{s}$ amplitude modulator", http://www . lightwavestore.com/product_datasheet/OSC-MOD-10Gb-010C_ pdf1.pdf, 2010.

[102] S. Quantum, "Single quantum eos", http://www.singlequantum.com/ wp-content/uploads/2017/06/Single-Quantum-Eos.pdf, 2017. 
[103] J. P. Lewis, "Fast normalized cross-correlation in Vision interface" vol. 10, pp. 120-123, 1995. 